PREDICTION OF HEAT TRANSFER AND PROBABILITY OF INSULATION

FAILURE IN WOOD-FRAMED WALLS

\author{
BY \\ NING WANG \\ B.ENG., HARBIN INSTITUTE OF TECHNOLOGY, 1993 \\ B.SC., NANJING UNIVERSITY, 2001
}

\begin{abstract}
A thesis submitted to
The Faculty of Graduate Studies and Research

in partial fulfilment of

the degree requirements of

Master of Applied Science
\end{abstract}

Department of Civil and Environmental Engineering

Carleton University

Ottawa, Ontario, Canada

Jan 2009

Copyright (C)

2009 - Ning Wang 


$\begin{array}{ll}\begin{array}{l}\text { Library and } \\ \text { Archives Canada }\end{array} & \begin{array}{l}\text { Bibliothèque et } \\ \text { Archives Canada }\end{array} \\ \begin{array}{l}\text { Published Heritage } \\ \text { Branch }\end{array} & \begin{array}{l}\text { Direction du } \\ \text { Patrimoine de l'édition }\end{array} \\ \begin{array}{l}\text { 395 Wellington Street } \\ \text { Ottawa ON K1A 0N4 } \\ \text { Canada }\end{array} & \begin{array}{l}\text { 395, rue Wellington } \\ \text { Ottawa ON K1A 0N4 } \\ \text { Canada }\end{array}\end{array}$

Your file Votre référence

ISBN: 978-0-494-47523-2

Ourfile Notre référence

ISBN: 978-0-494-47523-2

NOTICE:

The author has granted a nonexclusive license allowing Library and Archives Canada to reproduce, publish, archive, preserve, conserve, communicate to the public by telecommunication or on the Internet, loan, distribute and sell theses worldwide, for commercial or noncommercial purposes, in microform, paper, electronic and/or any other formats.

The author retains copyright ownership and moral rights in this thesis. Neither the thesis nor substantial extracts from it may be printed or otherwise reproduced without the author's permission.
AVIS:

L'auteur a accordé une licence non exclusive permettant à la Bibliothèque et Archives Canada de reproduire, publier, archiver, sauvegarder, conserver, transmettre au public par télécommunication ou par l'Internet, prêter, distribuer et vendre des thèses partout dans le monde, à des fins commerciales ou autres, sur support microforme, papier, électronique et/ou autres formats.

L'auteur conserve la propriété du droit d'auteur et des droits moraux qui protège cette thèse. $\mathrm{Ni}$ la thèse ni des extraits substantiels de celle-ci ne doivent être imprimés ou autrement reproduits sans son autorisation.
In compliance with the Canadian Privacy Act some supporting forms may have been removed from this thesis.

While these forms may be included in the document page count, their removal does not represent any loss of content from the thesis.
Conformément à la loi canadienne sur la protection de la vie privée, quelques formulaires secondaires ont été enlevés de cette thèse.

Bien que ces formulaires aient inclus dans la pagination, il n'y aura aucun contenu manquant.

\section{Canada}


The undersigned recommend to

the Faculty of Graduate Studies and Research

acceptance of the thesis

\title{
PREDICTION OF HEAT TRANSFER AND PROBABILITY OF INSULATION FAILURE IN WOOD-FRAMED WALLS
}

\author{
Submitted by Ning Wang, B. Eng., B. Sc. \\ in partial fulfilment of the requirements for the degree of \\ Master of Applied Science
}

Professor G.V. Hadjisophocleous, Thesis Supervisor

Professor A. Sarkar, Thesis Co-Supervisor

Professor A.O; Halim, Chair, Department of Civil and Environmental Engineering

Carleton University

2009 


\begin{abstract}
A model, WALL2DN, was developed by FPInnovation - Forintek Division. for predicting the fire resistance of gypsum-board protected wood-stud walls with glass-fibre or mineral-wool insulation filling the stud cavities, or without insulation in the cavities. This model, based on two-dimensional heat-conduction equations and approximated thermophysical property functions, can facilitate cost-effective and flexible design options for gypsum-board-protected wood-stud walls.
\end{abstract}

In this study, a statistical method, Monte Carlo Simulation, was applied to the existing WALL2DN model to address the uncertainties in the thermo-physical properties of materials used to construct wood-stud wall assemblies. The results of the Monte Carlo simulation are used to calculate the time dependent probability of failure of the assemblies when subjected to the standard time-temperature curve. 


\section{ACKNOWLEDGEMENTS}

I hereby express my sincere thanks to my supervisor, Dr. George. V. Hadjisophocleous, to my co-supervisor Dr. Abhijit Sarkar, and to Dr. Jim Mehaffey, for their guidance and help during the course of this work. Thanks are also given to Mr. Steven Craft for giving me the helpful information related to wall assembly properties used in the WALL2D series software in this thesis. 


\section{TABLE OF CONTENTS}

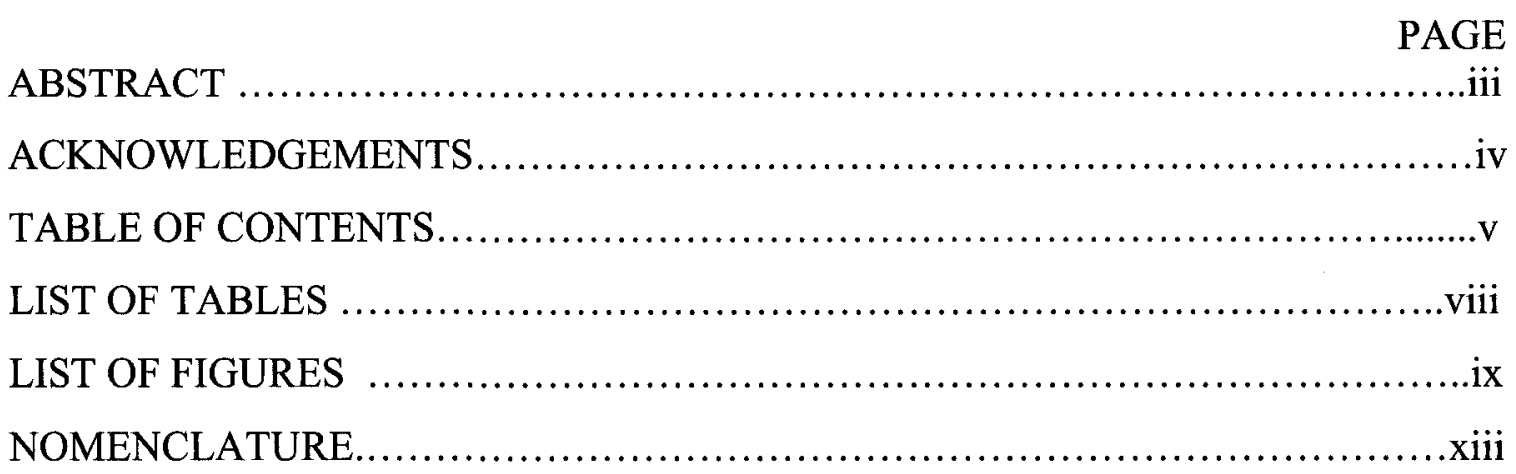

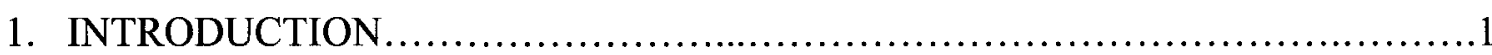

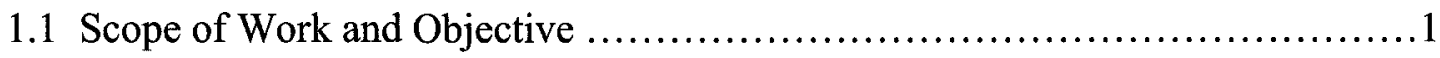

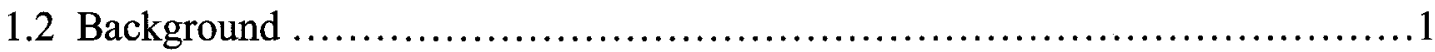

1.3 Motivation for Work......................................................

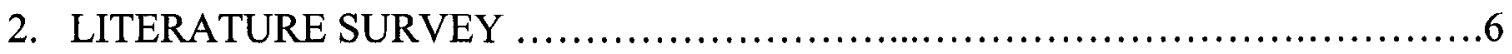

2.1 WALL2DN Model ..................................................... 6

2.1.1 Temperature Dependent Properties of Gypsum Board .................8

2.1.2 Temperature Dependent Properties of Wood Stud ......................14

2.1.3 Temperature Dependent Properties of Insulations .....................17

2.2 Monte Carlo Method ...................................................... 19

2.2.1 Major Components of a Monte Carlo Algorithm .....................21

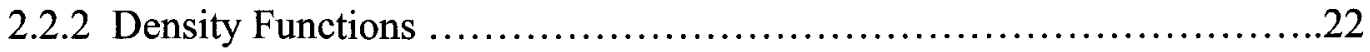

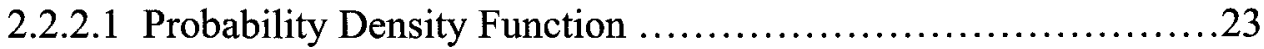

2.2.2.2 Cumulative Density Function .............................24

2.2.3 Stratified Sampling ...........................................25

2.2.4 Variance Reduction Techniques ..................................26

2.2.5 Multivariate Probability Density Functions .........................27

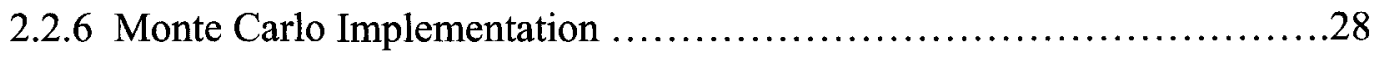

2.3 Significance of Applying Monte Carlo Method in WALL2DN ...............29

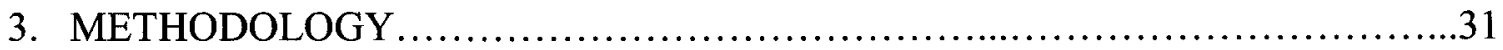


3.1 Normal Probability Distribution Function .....................................

3.1.1 Parameter Estimation .................................................

3.1.2 Random Number Generation .......................................... 34

3.2 Triangular Probability Distribution Function ................................. 35

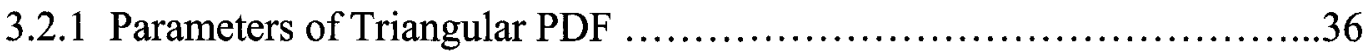

3.2.2 Probability Distribution Function of Triangle ............................36

3.2.3 Parameter Estimation .............................................

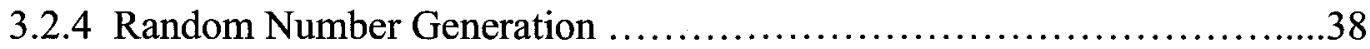

3.3 Lognormal Probability Distribution Function ...................................39

3.3.1 Parameters to Describe Lognormal PDF ...............................39

3.3.2 Parameter Estimation .................................................... 41

3.3.3 Random Number Generation ...................................... 41

3.4 Relationships Between Monte Carlo Methods and the Wood-Framed

Wall-Assembly Properties of WALL2DN Model .............................42

3.4.1 General Approach ................................................... 43

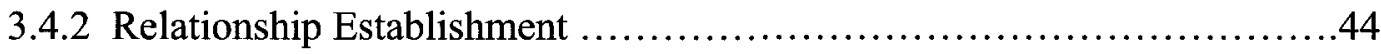

3.4.2.1 Density ....................................................44

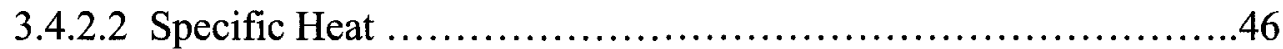

3.4.2.3 Thermal Conductivity .....................................64

3.4.2.4 Gypsum Board Shrinkage ....................................... 83

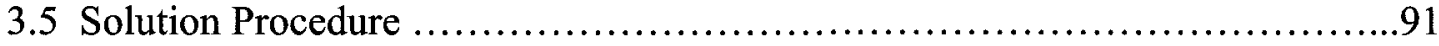

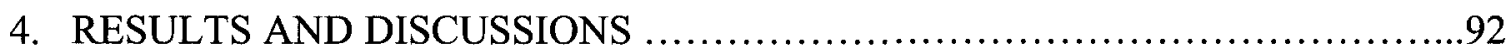

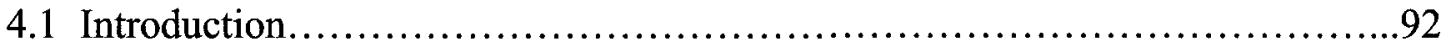

4.2 Typical Results of WALL2DN-MC ....................................... 94

4.2.1 Features of New Interface .........................................94

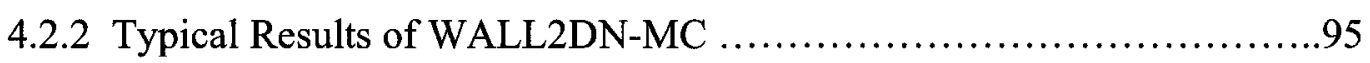

4.3 Exploratory Runs ..................................................... 100

4.3.1 Required Number of Monte Carlo Runs ..........................100

4.3.2 Impact of pdf Types .............................................. 105

4.3.3 Influence of Wall Assembly Properties ................................107 
4.4 Time Predictions .......................................................... 110

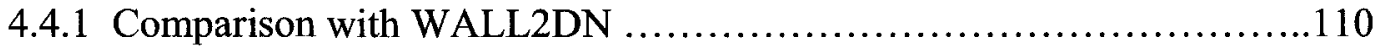

4.4.2 Comparison with Experiments ......................................111

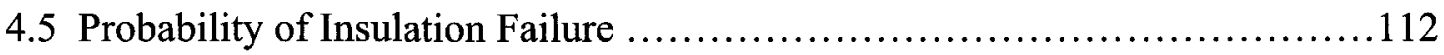

4.5.1 Insulated Walls - 60 Minute Rating ...............................113

4.5.2 Non-Insulated Walls - 45 Minute Rating .......................... 114

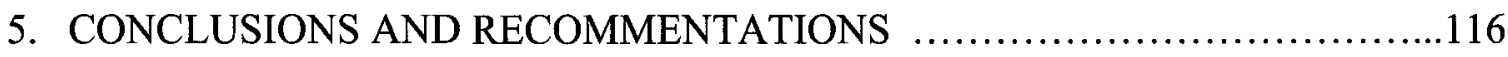

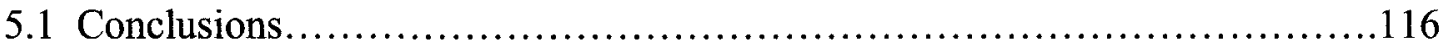

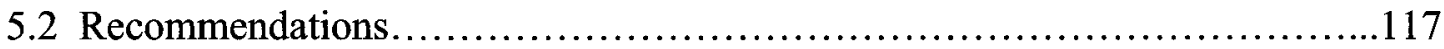

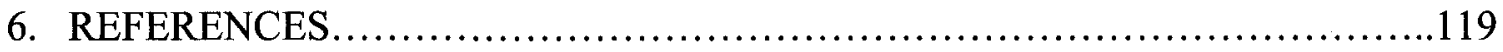

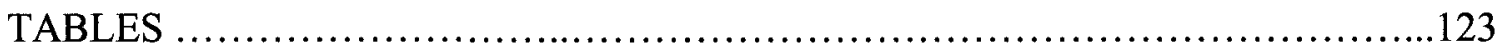

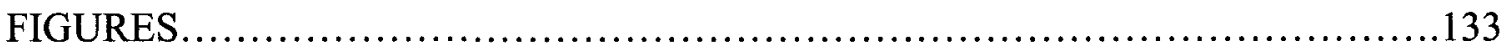

APPENDIX A: Program Documentation.......................................190 


\section{LIST OF TABLES}

PAGE

1. Fire Resistance Tests for Probability of Insulation Failure

2. Standard Deviation, Mean and Percentage Difference with Different Runs for Normal PDF

3. Standard Deviation, Mean and Percentage Difference with Different Runs for Logormal PDF

4. Variance, Mode and Percentage Difference with Different Runs for Triangular PDF

5. Full-Scale Fire Resistance Test Wall Assemblies. 128

6. Descriptions of Different Wall Assemblies 129

7. Comparison of WALL2DN and the WALL2DN-MC Model Predictions 130

8. Fire Resistance Tests

9. Comparison of Model Predictions and Test Results 132 


\section{LIST OF FIGURES}

PAGE

1 The Structure of a Typical Wood-Framed Wall..........................134

2 ASTM E119 and CAN/ULC-S101 Standard Time-Temperature Curve....135

3 A Cross-Sectional View of a Wall with Points at Which Comparison Between Statistical Method and Experiment is Undertaken (points A - D)

$4 \quad$ Mass (density) as a Function of Temperature for gGypsum Board (Type X - solid line; Type $\mathrm{C}$ - dashed line) and for Wood (dotted line)

$5 \quad$ Specific Heat as a Function of Temperature for Gypsum Board (Type $\mathrm{X}$ - solid line; Type $\mathrm{C}$-dashed line).

6 Thermal Conductivity as a Function of Temperature for Gypsum Board (solid line) and for Wood (dashed line).

$7 \quad$ Expansion (contraction) as a Function of Temperature for Gypsum Board (Type X - solid line; Type C - dashed line)

8 Enthalpy as a Function of Temperature for Gypsum Board (solid line) and for Wood (dashed line)

9 Linear Shrinkage of Polystyrene Foam, Polyurethane Foam, Glass-Fibre Insulation and Rock-Fibre Insulation as a Function of Temperature.

10 Insulation Shrinking and Melting: (a) Fully Filled Cavity with Insulation, (b) Empty Space Appear, (c) Insulation Deform by Gravitational Effect...143

11 Monte Carlo Simulation in Physical System

12 Typical Probability Distribution Function.............................. 145

13 Typical Cumulative Distribution Function.............................146

14 Schematic Principle of Monte Carlo Simulation for Uncertainty Propagation

15 Normal Probability Distribution Function Pattern 148 
16 Symmetric Characteristic of Mean in Normal PDF

17 Characteristics of Standard Deviation in Normal PDF

18 Calculation Principle of Probability for Normal PDF

19 Rules for Thumb in Normal PDF

20 Triangular Probability Distribution Function Pattern 153

21 Lognormal Probability Distribution Function Pattern

Thermo-gravimetric Curve for a Pine of $400 \mathrm{~kg} / \mathrm{m}^{3}$ Density 155

23 Specific Heat Curves for Wood with $12 \%$ Moisture Content 156

24 Thermal Conductivity as a Function of Temperature

for Gypsum board (solid line) and for Wood (dashed line)

25 Thermal Conductivity Curves for Wood with

a Density of $460 \mathrm{~kg} / \mathrm{m}^{3}$ and Moisture Content of $12 \%$

26 Shrinkage of Gypsum Board as a Function of Temperature

Flow Chart of the WALL2DN-MC Model

Flow Chart of Subroutine - Monte Carlo Simulation (MCS)....

29 All Five Properties of Wood-Framed Wall simulated on Basis of Normal pdf and Test 5 .

Number of Simulation Runs as a Function of Insulation Failure Time with all Five Properties Selected on Basis of Normal PDF and Test 5

31 Number of Simulation Runs as a Function of Insulation Failure Time with Each Individual Property on Basis of Normal PDF and Test 5

32 Cumulative Probability as a Function of Insulation Failure Time with all Five Properties Selected on Basis of Normal PDF and Test 5

33 All Five Properties of Wood-Framed Wall Simulated on Basis of Lognormal PDF and Test 5

34 Number of Simulation Runs as a Function of Insulation Failure Time with all Five Properties Selected on Basis of Lognormal PDF and Test 5 
35 Number of Simulation Runs as a Function of Insulation Failure Time with Each Individual Property on Basis of Lognormal PDF and Test 5

36 Cumulative Probability as a Function of Insulation Failure Time with all Five Properties Selected on Basis of Lognormal PDF and Test 5

37 All Five Properties of Wood-Framed Wall Simulated on Basis of Triangular

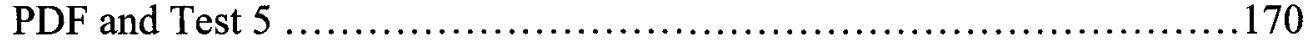

38 Number of Simulation Runs as a Function of Insulation Failure Time with all Five Properties Selected on Basis of Triangular PDF and Test 5 ..........171

39 Number of Simulation Runs as a Function of Insulation Failure Time with Each Individual Property on Basis of Triangular PDF and Test 5

40 Cumulative Probability as a Function of Insulation Failure Time with all Five Properties Selected on Basis of Triangular PDF and Test 5 173

41 Histogram Curves of 100, 500 and 1,000 Runs as a Function of Insulation Failure Time with all Five Properties Selected on Basis of Normal PDF and

Test 5

42 Histogram Curves of 100, 500 and 1,000 Runs as a Function of Insulation Failure Time with all Five Properties Selected on Basis of Lognormal PDF and Test 5

43 Histogram Curves of 100, 500 and 1,000 Runs as a Function of Insulation Failure Time with all Five Properties Selected on Basis of Triangular PDF and Test 5 ......................................................... 176

44 Number of Simulation Runs as a Function of Insulation Failure Time Showing Probability of Insulation Failure for Test G1

45 Number of Simulation Runs as a Function of Insulation Failure Time Showing Probability of Insulation Failure for Test 5

46 Number of Simulation Runs as a Function of Insulation Failure Time Showing Probability of Insulation Failure for Test 6

$47 \quad$ Number of Simulation Runs as a Function of Insulation Failure Time on Basis of Normal PDF and Test 5

48 Number of Simulation Runs as a Function of Insulation Failure Time on Basis of Lognormal PDF and Test 5 
49 Number of Simulation Runs as a Function of Insulation Failure Time on Basis of Triangular PDF and Test 5

50 Number of Simulation Runs as a Function of Insulation Failure Time with Each Individual Property on Basis of Normal PDF and Test 5

$51 \quad$ Number of Simulation Runs as a Function of Insulation Failure Time with Each Individual Property on Basis of Lognormal PDF and Test 5 .........184

52 Number of Simulation Runs as a Function of Insulation Failure Time with Each Individual Property on Basis of Triangular PDF and Test 5 ........185

53 Number of Simulation Runs as Function of Insulation Failure Time Showing Probability of Insulation Failure for an Insulated 60-Minute Rating Wall

54 Cumulative Probability as Function of Insulation Failure Time Showing Probability of Insulation Failure for an Insulated 60-Minute Rating Wall

$55 \quad$ Number of Simulation Runs as Function of Insulation Failure Time Showing Probability of Insulation Failure for a Non-Insulated 45-Minute Rating Wall

56 Cumulative Probability as Function of Insulation Failure Time Showing Probability of Insulation Failure for a Non-Insulated 45-Minute Rating Wall 


\section{NOMENCLATURE}

$B_{p h} \quad$ Intercept of specific heat curve of wood stud $\left(\mathrm{kJ} / \mathrm{kg} .{ }^{\circ} \mathrm{C}\right)$

Cp Specific heat $\left(\mathrm{J} / \mathrm{kg} .{ }^{\circ} \mathrm{C}\right)$

Cw Specific heat of oven-dried wood $\left(\mathrm{J} / \mathrm{kg} .{ }^{\circ} \mathrm{C}\right)$

$C p_{g} \quad$ Specific heat of gypsum board $\left(\mathrm{J} / \mathrm{kg} .{ }^{\circ} \mathrm{C}\right)$

$C p_{g, a} \quad$ Specific heat of gypsum board at ambient temperature $\left(\mathrm{J} / \mathrm{kg} .{ }^{\circ} \mathrm{C}\right)$

$C p_{w} \quad$ Specific heat of wood stud $\left(\mathrm{J} / \mathrm{kg} .{ }^{\circ} \mathrm{C}\right)$

$C p_{S} \quad$ Specific heat of steam $\left(\mathrm{J} / \mathrm{kg} .{ }^{\circ} \mathrm{C}\right)$

$\varepsilon_{\text {eff }} \quad$ Effective emissivity

$\varepsilon_{f} \quad$ Furnace gas emissivity

$\varepsilon_{g} \quad$ Gypsum board surface emissivity

$h_{f} \quad$ Heat transfer coefficient on fire-exposed side $\left(\mathrm{W} / \mathrm{m}^{2} . \mathrm{K}\right)$

$h_{a} \quad$ Heat transfer coefficient on ambient side $\left(\mathrm{W} / \mathrm{m}^{2} . \mathrm{K}\right)$

$H(T) \quad$ Enthalpy $(\mathrm{J} / \mathrm{kg})$

$K \quad$ Thermal conductivity (W/ $\left./ \mathrm{m}^{2} \cdot \mathrm{K}\right)$

$K_{g} \quad$ Thermal conductivity of gypsum board $\left(\mathrm{W} / \mathrm{m}^{2} . \mathrm{K}\right)$

$K_{g, 0} \quad$ Thermal conductivity of gypsum board at ambient temperature $\left(\mathrm{W} / \mathrm{m}^{2} . \mathrm{K}\right)$

$K_{g, 200}$ Thermal conductivity of gypsum board at temperature of $200^{\circ} \mathrm{C}\left(\mathrm{W} / \mathrm{m}^{2} . \mathrm{K}\right)$

$K_{g, 1000}$ Thermal conductivity of gypsum board at temperature of $1000^{\circ} \mathrm{C}\left(\mathrm{W} / \mathrm{m}^{2} . \mathrm{K}\right)$

$K_{w} \quad$ Thermal conductivity of wood stud (W/ $\left./ \mathrm{m}^{2} . \mathrm{K}\right)$

$K_{w, 0} \quad$ Thermal conductivity of wood stud at ambient temperature $\left(\mathrm{W} / \mathrm{m}^{2} . \mathrm{K}\right)$

$K_{w, 200} \quad$ Thermal conductivity of wood stud at temperature of $200^{\circ} \mathrm{C}\left(\mathrm{W} / \mathrm{m}^{2} \cdot \mathrm{K}\right)$

$K_{w, 350}$ Thermal conductivity of wood stud at temperature of $350^{\circ} \mathrm{C}\left(\mathrm{W} / \mathrm{m}^{2} . \mathrm{K}\right)$

$K_{w, 800} \quad$ Thermal conductivity of wood stud at temperature of $800^{\circ} \mathrm{C}\left(\mathrm{W} / \mathrm{m}^{2} . \mathrm{K}\right)$

$K_{\text {glass }} \quad$ Thermal conductivity of glass-fibre $\left(\mathrm{W} / \mathrm{m}^{2} . \mathrm{K}\right)$ 
$K_{\text {rock }} \quad$ Thermal conductivity of rock-fibre $\left(\mathrm{W} / \mathrm{m}^{2} . \mathrm{K}\right)$

$m_{w} \quad$ Mass fraction of free water within gypsum board (\%)

$m_{g} \quad$ Mass fraction of gypsum board without free water (\%)

$m_{F W} \quad$ Mass fraction of water within wood stud (\%)

$m_{F D} \quad$ Mass fraction of dry wood within wood stud (\%)

$M \quad$ Moisture content of wood studs (\%)

$P_{W} \quad$ Fraction of water within gypsum board (\%)

$Q \quad$ Enthalpy (J)

$S \quad$ Specific gravity of wood studs

$S_{p h} \quad$ Slope of specific heat curve of wood stud

$S_{G B} \quad$ Slope of thermal conductivity curve of gypsum board

$S_{W S-1} \quad$ Slope of thermal conductivity curve of wood stud at temperature $<200^{\circ} \mathrm{C}$

$S_{W S-2} \quad$ Slope of thermal conductivity curve of wood stud at temperature $200-350{ }^{\circ} \mathrm{C}$

$S_{W S-3} \quad$ Slope of thermal conductivity curve of wood stud at temperature $350-800{ }^{\circ} \mathrm{C}$

$S P_{G B} \quad$ Shrinkage percentage of gypsum board (\%)

$t \quad$ Time (second)

$T \quad$ Temperature $\left(\mathrm{K}\right.$ or $\left.{ }^{\circ} \mathrm{C}\right)$

$T_{a} \quad$ Ambient temperature $\left(\mathrm{K}\right.$ or $\left.{ }^{\circ} \mathrm{C}\right)$

$T_{f} \quad$ Furnace temperature $\left(\mathrm{K}\right.$ or $\left.{ }^{\mathrm{O}} \mathrm{C}\right)$

$T_{\text {gaa }} \quad$ Surface temperature of gypsum board on ambient side $\left(\mathrm{K}^{\circ}{ }^{\circ} \mathrm{C}\right)$

$T_{g f f} \quad$ Surface temperature of gypsum board on fire-exposed side $\left(\mathrm{K}\right.$ or $\left.{ }^{\circ} \mathrm{C}\right)$

$\rho \quad$ Density $\left(\mathrm{kg} / \mathrm{m}^{3}\right)$

$\rho_{0} \quad$ Density at ambient temperature $\left(\mathrm{kg} / \mathrm{m}^{3}\right)$

$\mu \quad$ Mean of normal pdf

$\sigma \quad$ Standard deviation of normal pdf, or Stephan-Boltzmann constant

$\mu_{\log } \quad$ Mean of lognormal pdf

$\sigma_{\log } \quad$ Standard deviation of lognormal pdf 
This work is dedicated to my wife, Lily, and my children, Yanbo and Christopher. 


\section{INTRODUCTION}

\subsection{Scope of Work and Objective}

The goal of this study is to develop a computer model, based on a heat transfer model, WALL2DN, and Monte Carlo Methods, to account for the uncertainties in the temperature-dependent material properties of wood-framed wall assemblies, and to extend the model to predict the heat transfer, fire resistance rating and probability of insulation failure for fire-exposed non-bearing wood-framed walls.

\subsection{Background}

Wood frame construction is becoming the predominant method of building homes and low-rise apartments in North America. Increasingly, wood framing is being used in commercial and industrial buildings. Specially, wood-framed walls are also being widely used in high-rise buildings as partitions.

Wood-framed walls as the widely used wood frame assembly commonly consist of two key elements: gypsum boards and wood studs. Generally, wood studs are protected by gypsum boards. Usually, wood studs in bearing and non-bearing walls are nominal $2 \times 4$ inches or $2 \times 6$ inches and are installed with the wide face perpendicular to the wall surface. Stud spacing is 16- or 24-inches on center. The cavity of wood-framed walls may 
or may not be filled with insulation. Commonly, wood studs protected by insulation could be provided with good protection when exposed to fire as well as be provided with good acoustical performance. Figure 1 shows the structure of a typical wood-framed wall.

FPInnovation - Forintek Division developed the WALL2D series of models for predicting the fire resistance of non-bearing wood-framed walls $[1,2,3]$. Two-dimensional heat-conduction equations and thermo-physical property data for the wood studs, gypsum boards and insulations were utilized to calculate heat transfer through assemblies exposed to the standard time-temperature curve.

In studies of fire resistance of the WALL2D series of models, it is common to expose building elements to heating in accordance with a standard temperature-time relation. In North America, the determination of fire resistance ratings is based on the fire exposure and acceptance criteria of ASTM E119 [4] and CAN/ULC-S101 [5] as required by most building codes. The ASTM E119 and CAN/ULC-S101 standard temperature-time curve is shown in Figure 2.

The conditions of acceptance imposed on non-bearing wood-framed walls by ASTM E119 and CAN/ULC-S101 stipulate that during the rating classification time period the assembly should limit the transmission of heat through the assembly such that the average temperature rise on the unexposed surface does not exceed $139^{\circ} \mathrm{C}$ or the temperature rise at a single point does not exceed $181^{\circ} \mathrm{C}[6]$. 
Since two-dimensional heat-conduction equations have been applied to the WALL2D series of models, the criterion used within the WALL2D model to assess an assembly's ability to contain a fire is the limitation of temperature rise above ambient conditions on the unexposed surface to an average of $139^{\circ} \mathrm{C}$.

The basic version of WALL2D mainly focused on predicting heat transfer through uninsulated wood-stud walls protected by gypsum board. However, in North America, in many cases, the cavity of wood-framed walls is filled with insulation so that wood studs could be provided with good protection when exposed to fire and also be provided with good acoustical performance. Shrinkage of gypsum boards occurs at high temperatures so that the joints between adjacent gypsum board sheets open, and then the edge of gypsum board and wood studs are exposed directly to fire, which greatly affects the fire resistance of the wall assembly. To accommodate this, further refinement of the model WALL2D was made at Forintek. The model WALL2DN undertakes an analysis of heat transfer through insulated walls and walls which experience openings at the joints between adjacent sheets of gypsum boards [3].

The validation of the WALL2DN model was conducted by comparing the simulation results to those from full-scale standard fire-endurance tests. These comparisons showed that model predictions were in good agreement with the test results $[1,2,3]$. 


\subsection{Motivation for Work}

To get more reliable simulation results in comparison with full-scale test data, one of the most important factors that should be seriously considered in developing the WALL2D series is how to accommodate discrete temperature-dependent assembly properties into the model. Properties of most interest are the thermo-physical properties of gypsum boards, wood studs and insulations.

In WALL2DN, thermo-physical properties, such as density, thermal conductivity, and specific heat of materials are based on reported values in the literature and from small and full-scale test results. Forintek and the National Research Council of Canada (NRCC) collected those values, summarized the relationships of these temperature-dependent properties, and imported them into the model.

As most of those reported thermo-physical-property values, derived from many small and full-scale experimental tests, exhibit scatter in the temperature-related figures, Forintek's representation of those properties as functions of temperature does not reflect the range of temperature-dependent characteristics of those material properties.

This study applies the Monte Carlo Method to WALL2DN to generate a variety of temperature-dependent assembly property values that derived from discrete data (i.e., reported curves and experimental test results). Randomly generated assembly-property values are then used in a newly developed version of WALL2DN model which is named 
as WALL2DN-MC. As a result, a better heat transfer simulation and more reliable fire resistance rating can be expected theoretically. Furthermore, the time dependent probability of insulation failure can also be predicted for use in risk-based applications, such as the CUrisk model. CUrisk is a fire risk computer model developed at Carleton University to evaluate fire safety designs for four-story, timer-frame commercial buildings [7]. 


\section{LITERATURE SURVEY}

\subsection{WALL2DN Model}

The WALL2DN model was developed to predict the fire-resistive performance of woodstud walls protected by gypsum board. The model can also predict the time to onset of charring of the studs and the time to failure of the wood-framed wall assembly due to heat transmission during a standard fire-resistance test [1].

The WALL2DN model employs the following two-dimensional heat conduction equation [3].

$$
C_{P} \rho\left(\frac{\partial T}{\partial t}\right)=\frac{\partial}{\partial x}\left(k \frac{\partial T}{\partial x}\right)+\frac{\partial}{\partial y}\left(k \frac{\partial T}{\partial y}\right)+Q
$$

where, $C_{P}$ is specific heat $(\mathrm{J} / \mathrm{kg} . \mathrm{K}), \rho$ is density $\left(\mathrm{kg} / \mathrm{m}^{3}\right), \mathrm{k}$ is thermal conductivity $\left(\mathrm{W} / \mathrm{m}^{2}\right.$ $\mathrm{K}), \mathrm{Q}$ is the rate of change of enthalpy due to water vaporization in the wood and calcination in gypsum board (J), $\mathrm{t}$ is time (s), and $\mathrm{x}$ and $\mathrm{y}$ are spatial co-ordinates $(\mathrm{m})$. The temperature dependent properties, $\mathrm{C}_{\mathrm{P}}, \mathrm{k}, \rho$, and $\mathrm{Q}$ for gypsum board and for a wood stud were obtained by experiments or from published literature [1,2], and will be introduced in the following sub-sections 2.1.1 through 2.1.3. 
An explicit finite-difference algorithm was used to solve the partial differential equation presented in Eqn 1. Figure 3 describes the nodal map in the gypsum board and wood stud for the finite difference calculations. For wall assemblies, the model sets the node spacing in the depth (x) direction and in the lateral (y) direction at $3.175 \mathrm{~mm}$, except that at the surface of gypsum board and wood stud where the spacing is $3.175 \mathrm{~mm}$ (lateral) $\mathrm{x} 1.5875$ $\mathrm{mm}$ (depth). Furthermore, a time step of 1 second is used for simulating temperature in the wood stud and gypsum board, and 0.01 second in the insulation $[1,2]$.

The boundary condition at the surface of the gypsum board on the fire-exposed side was derived by equating heat conduction with convective and radiative heat transfer at the surface [3]:

$$
-k\left(\frac{\partial T}{\partial x}\right)=h_{f}\left(T_{f}-T_{g f f}\right)+\varepsilon_{e f f} \sigma\left(T_{f}^{4}-T_{g f f}^{4}\right)
$$

The boundary condition at the surface of the gypsum board on the ambient side was assumed to only involve convective heat transfer [3]:

$$
-k\left(\frac{\partial T}{\partial x}\right)=h_{a}\left(T_{g a a}-T_{a}\right)
$$

where, $T_{f}$ is the furnace temperature, and $T_{g f f}$ and $T_{g a a}$ are the surface temperatures (K) of the gypsum board on fire-exposed side and ambient side respectively, $T_{a}$ is the ambient gas temperature, $h_{f}$ is the conductive heat transfer coefficient between the 
furnace gas and gypsum board on the fire exposed side $\left(\mathrm{W} / \mathrm{m}^{2} \mathrm{~K}\right), h_{a}$ is the convective heat transfer coefficient between the ambient gas and the gypsum board on the ambient side $\left(\mathrm{W} / \mathrm{m}^{2} \mathrm{~K}\right), \sigma$ is the Stephan-Boltzmann constant for radiation and $\varepsilon_{\text {eff }}$ is the effective emissivity calculated from the furnace gas emissivity $\varepsilon_{f}$ and the gypsum board surface emissivity $\varepsilon_{g}[3]$.

$$
\varepsilon_{e f f}=1 /\left(1 / \varepsilon_{f}+1 / \varepsilon_{g}-1\right)
$$

A value of 0.9 was assumed for $\varepsilon_{f}$ and $\varepsilon_{g}$. The heat transfer coefficient $h_{f}$ was assumed to be $25\left(\mathrm{~W} / \mathrm{m}^{2} \mathrm{~K}\right)$ and $h_{a}$ to be $9\left(\mathrm{~W} / \mathrm{m}^{2} \mathrm{~K}\right)$.

\subsubsection{Temperature Dependent Properties of Gypsum Board}

Gypsum board is a construction product that consists of a non-combustible core in which gypsum is the primary component with paper-laminated surfaces. Type $\mathrm{X}$ gypsum board has additives that give it better fire-resistive performance than regular gypsum board of the same thickness.

Gypsum is called calcium sulphate dihydrate, $\mathrm{CaSO}_{4} \cdot 2 \mathrm{H}_{2} \mathrm{O}$, a crystalline mineral in which about a maximum of $21 \%$ by weight is chemically combined water. In addition, gypsum board usually contains a little amount of free water [1]. 
When heated to temperatures greater than $80^{\circ} \mathrm{C}$, gypsum begins to undergo a thermal degradation process called calcination. In the process of calcination, the chemically combined water dissociates from the crystal lattice as expressed by the following chemical equation [1]:

$$
\mathrm{CaSO}_{4} \bullet 2 \mathrm{H}_{2} \mathrm{O} \rightarrow \mathrm{CaSO}_{4} \bullet 1 / 2 \mathrm{H}_{2} \mathrm{O}+3 / 2 \mathrm{H}_{2} \mathrm{O}
$$

Calcium sulphate hemihydrate $\left(\mathrm{CaSO}_{4} \bullet 1 / 2 \mathrm{H}_{2} \mathrm{O}\right)$ is commonly known as plaster of Paris. With continued heating, the remaining water within the calcium sulphate hemihydrate $\left(\mathrm{CaSO}_{4} \bullet 1 / 2 \mathrm{H}_{2} \mathrm{O}\right)$ will be released since the hemi-hydrate undergoes dehydration to become anhydrous calcium sulphate, $\mathrm{CaSO}_{4}$. As the gypsum reaches $125^{\circ} \mathrm{C}$, calcination is completed.

To obtain an accurate heat transfer prediction through the gypsum board, it is necessary to know the gypsum board's thermo-physical properties, such as density, specific heat and thermal conductivity. Much research and many tests have revealed a wide variability in values of these properties because the chemical formulation of the core of gypsum board varies from one manufacturer to another. Tests conducted by FPInnovation Forintek Division at NRCC [2] for determining the thermo-physical properties of two widely used commercial products: $12.7 \mathrm{~mm}(1 / 2 \mathrm{inch})$ Type $\mathrm{C}$ board; and $15.9 \mathrm{~mm}$ (3/4 inch) Type $\mathrm{X}$ board explored the following properties $[1,2]$ : 


\section{Density ( $\rho$ )}

The density of the $12.7 \mathrm{~mm}$ Type C gypsum board is $732 \mathrm{~kg} / \mathrm{m}^{3}$ and that of the 15.9 mm Type X gypsum board $648 \mathrm{~kg} / \mathrm{m}^{3}$. Both gypsum boards were tested in a thermogravimetric analyzer at a heating rate of $20^{\circ} \mathrm{C} / \mathrm{min}$ by NRCC. The results of the analysis for the two gypsum boards are shown in Figure 4. As the temperature of the boards increased between $100^{\circ} \mathrm{C}$ and $160^{\circ} \mathrm{C}$, both gypsum boards lost about $17.5 \%$ of their mass as water of crystallization and free water were almost completely driven off in the form of steam. These results show that the density of gypsum boards changes significantly when the temperature increases from $100^{\circ} \mathrm{C}$ to $160^{\circ} \mathrm{C}$. If a lower heating rate were employed, this mass loss would occur at even lower temperatures in comparison with the results discussed above $[1,2]$.

\section{Apparent Specific Heat $\left(\mathrm{C}_{\mathrm{P}}\right)$}

Tests to determine the specific heat of type $\mathrm{X}$ and type $\mathrm{C}$ gypsum boards were done by FPInnovation - Forintek Division at the NRCC using two different heating rates $2{ }^{\circ} \mathrm{C} / \mathrm{min}$ and $20^{\circ} \mathrm{C} / \mathrm{min}[1,2]$. The results from these tests are shown in Figure 5 for temperatures up to $200^{\circ} \mathrm{C}$. When temperatures are below the dehydration range, the specific heat of the boards is $0.95 \mathrm{~kJ} /\left(\mathrm{kg}{ }^{\circ} \mathrm{C}\right)$. Peaks appearing in Figure 5 are a result of gypsum dehydration. When lower heating rates are used, the peaks occur at lower temperatures. The area under the peaks in the curves shown in Figure 5 is the energy 
required to drive free water and the water of crystallization from the gypsum boards $[1]$.

Results of thermo-gravimetric analysis and differential scanning calorimetry of gypsum boards provided by a manufacturer indicated that at ambient temperature $3.4 \%$ of the mass of gypsum board specimens is free water and $14.65 \%$ is water of crystallization [2]. As noted in the beginning of this section, a $21 \%$ of pure gypsum is chemically bound water. The tested gypsum boards contains 14.65 percent chemically bound water in its core, which means that the core of the tested gypsum board is about $14.6 / 21.0 \times 100 \%=69.5 \%$ pure gypsum in comparison with a maximum of $100 \%$ ( $21 \%$ chemically bound water). Since the content of pure gypsum in gypsum boards differs from one manufacturer to another, the content of pure gypsum contained in gypsum boards in Canada is required to be not less than $65 \%$ pure gypsum $[7,8]$. This corresponds to a minimum of $13.65 \%$ water of crystallization $(65 \% \times 21.0 \%=13.65 \%)$.

Additionally, the contribution to the specific heat of gypsum boards due to the vaporized water of crystallization and free water in gypsum boards was considered in the WALL2DN model. For the temperature range of interest, $2.1 \mathrm{~kJ} /\left(\mathrm{kg}{ }^{\circ} \mathrm{C}\right)$ of water vapour has been applied in WALL2DN. 
Thermal Conductivity (k)

Results of the thermal conductivities for gypsum boards from the NRCC's tests are presented in Figure 6 [2]. Since steady-state methods were employed to determine thermal conductivities in the tests, the experimental results shown in Figure 6 are for dehydrated board. During the period in which water vapour is present in the board, water vapour can increase heat transfer by augmenting the thermal conductivity and by convection. Additionally, it is known that the effects of dehydration greatly depend on the pressure and concentration of vapour in the board and the porosity of the board $[1,2]$. Since it is difficult to quantify these effects, neither the pressure and concentration of vapour in the gypsum board nor the porosity of the board was directly addressed in the WALL2DN model. WALL2DN uses an effective thermal conductivity that considers the effects of water vapour on thermal conductivity and radiative heat transfer in the boards. The dashed curve presented in Figure 6 was loosely based on experimental data generated from NRCC [1] but calibrated to give reasonable agreement between the predictions of WALL2DN and experiment.

Expansion and Contraction

Figure 7 shows the temperature dependence of the shrinkage of the two gypsum boards tested by FPInnovation - Forintek Division at the NRCC [1]. The Type C core underwent less shrinkage than the Type $\mathrm{X}$ core throughout the temperature range tested. Results are also shown for gypsum boards laminated with paper of about 1 
mm thickness on each side. The paper would be consumed in the temperature range $200-350^{\circ} \mathrm{C}$. To properly model heat transfer, it is necessary to account for the expansion/contraction of gypsum boards. In the WALL2DN model, the combined effects of core shrinkage and paper burn-off are taken into consideration by assuming that board thickness varies with temperature as indicated in Figure 7 [1].

\section{Enthalpy}

The enthalpy of gypsum board can be calculated as the area under the specific heat versus temperature curve [1]:

$$
H(T)=\int_{T_{a}}^{T} C_{P}\left(T^{\prime}\right) d T^{\prime}
$$

where $H(T)$ is the enthalpy in $\mathrm{J} / \mathrm{kg}$ at temperature $\mathrm{T}, \mathrm{C}_{\mathbf{P}}\left(\mathrm{T}^{\prime}\right)$ is the specific heat at temperature $T^{\prime}, T^{\prime}$ is the dummy variable of integration, and $T_{a}$ is the ambient temperature. In Eqn 3, $\mathrm{C}_{\mathrm{P}}$ includes the contribution of water vapour mentioned in the previous section on "Specific Heat".

The relationship between gypsum board's enthalpy and temperature as used in the model is shown in Figure 8. For building this relationship, it was assumed that the crystallization water and free water would be completely vaporized in the temperature range between $100-200^{\circ} \mathrm{C}$ and the resulting water vapour would not migrate [1]. 


\subsubsection{Temperature Dependent Properties of Wood Studs}

Wood studs with gypsum boards on each side in a wall can be protected for a significant period of time during the event of a fire. However, the studs eventually become heated. When the temperature of wood studs rises to about $100^{\circ} \mathrm{C}$, free moisture contained within the wood's cellular structure starts vaporizing. In the temperature range between 200$350^{\circ} \mathrm{C}$, wood experiences a thermal degradation process known as pyrolysis in which wood gets decomposed into volatiles and char. In the pyrolysis process, a layer of char forms on the fireside of the stud, which begins to advance through the stud. The temperature at the interface between char and wood is generally assumed to be $288^{\circ} \mathrm{C}$ [9].

It is a complex task to model heat transfer and charring occurring in wood since values published in the literature for the thermo-physical properties of wood and the kinetic parameters governing pyrolysis exhibit a wide variability [10]. Accordingly, a simple provisional heat transfer model developed by Forintek was employed in WALL2DN. In the following few sections, the input data for wood used in the model are introduced.

\section{Density $(\rho)$}

The wood studs originally employed in WALL2D were of the species group SPF (spruce-pine-fir) and of Grade 2 or better. SPF is assumed to have density of 483 $\mathrm{kg} / \mathrm{m}^{3}$ at ambient temperature, and to contain the free moisture content of about 
$12.0 \%$. Two new wood species have recently been added to the WALL2DN model, Douglas Fir whose density is $550 \mathrm{~kg} / \mathrm{m}^{3}$ with free moisture content of $9.5 \%$, and Southern Pine whose density is $550 \mathrm{~kg} / \mathrm{m}^{3}$ with free moisture content of $9.6 \%[1,3]$.

Thermo-gravimetric analyses of wood done by FPInnovation - Forintek Division at the NRCC [2] at the heating rate of $5^{\circ} \mathrm{C}$ per minute (similar to the rate encountered in burning wood members) were summarized as a density-temperature curve shown in Figure 4. The slow decrease in density as temperature rises to $100^{\circ} \mathrm{C}$ is due to the vaporization and migration of free water. In the range of $200^{\circ} \mathrm{C}$ and $350^{\circ} \mathrm{C}$ the sharp decrease in density indicates that wood experiences pyrolysis [1].

$>$ Specific Heat $\left(\mathrm{C}_{\mathrm{w}}\right)$

The specific heat of oven-dry wood, $\mathrm{C}_{\mathrm{w}} \mathrm{J} /\left(\mathrm{kg}{ }^{\circ} \mathrm{C}\right)$ has a temperature dependence given by the following expression valid up to $200^{\circ} \mathrm{C}$ [11]

$$
C_{W}=1110+4.2 T
$$

where $\mathrm{T}$ is temperature in ${ }^{\circ} \mathrm{C}$.

In the WALL2DN model, this specific heat is used for wood. As with gypsum board, the specific heat of the free water in wood is considered to be $4.19 \mathrm{~kJ} /\left(\mathrm{kg}{ }^{\circ} \mathrm{C}\right)$, the 
heat of vaporization $2.26 \mathrm{MJ} / \mathrm{kg}$ and the specific heat of water vapour to be $2.1 \mathrm{~kJ} /(\mathrm{kg}$ $\left.{ }^{\mathrm{o}} \mathrm{C}\right)$.

In WALL2DN, wood pyrolysis has been assumed to be endothermic and the heat of pyrolysis was assumed to be $370 \mathrm{~kJ} / \mathrm{kg}$. As a result, the specific heat of wood is considered to drop linearly from its value at $200^{\circ} \mathrm{C}$ to $0.69 \mathrm{~kJ} /\left(\mathrm{kg}{ }^{\circ} \mathrm{C}\right)$ at $350^{\circ} \mathrm{C}$ as the wood is converted to char. For temperatures above $350^{\circ} \mathrm{C}$, the specific heat of char remains at $0.69 \mathrm{~kJ} /\left(\mathrm{kg}^{\circ} \mathrm{C}\right)$, which is the specific heat for charcoal [1].

Thermal Conductivity (k)

At ambient temperature, the thermal conductivity of wood, $\mathrm{k} \mathrm{W} /\left(\mathrm{m}{ }^{\circ} \mathrm{C}\right)$, can be determined in terms of its specific gravity, S, and moisture content, M [12],

$$
k=S x(0.200+0.0404 \times M)+0.0238
$$

For SPF with $\mathrm{S}=0.43$ and $\mathrm{M}=0.12$, the ambient temperature thermal conductivity is $\mathrm{k}=0.112 \mathrm{~W} /\left(\mathrm{m}^{\circ} \mathrm{C}\right)$. At higher temperatures, the thermal conductivity of wood (or char) was assumed to follow the relationship depicted in Figure 6 [1].

$>$ Enthalpy 
The relationship between the enthalpy of wood studs and temperature which is presented in Figure 8 was similar to the one used for gypsum board. In the procedure of deriving this relationship, free water was assumed to be vaporized in the temperature range $100-120^{\circ} \mathrm{C}$ and the resultant water vapour did not migrate [1].

\subsubsection{Temperature Dependent Properties of Insulations}

Insulation is often used to delay the temperature rise of structural members in order to enhance the fire-resistance rating of the protected structures. There are a lot of insulation materials available in the market, however, mineral wool and glass fibre are the two most widely used insulations in wood-framed walls.

The thermal properties of insulation play an important role in determining the fire resistance of wood-framed walls; however, there is not much information available on the thermal properties of various types of insulation. The following sections show some test results summarized by Forintek [3].

\section{Shrinking and Melting Characteristics of Insulation}

Insulation will shrink and then melt at high temperatures. The linear shrinkage of various types of insulation materials at elevated temperatures measured by Forintek is shown in Figure 9. The figure shows the shrinkage of rock-fibre insulation, glassfibre insulation, polystyrene foam and polyurethane foam as a function of 
temperature. As the figure indicates, polystyrene foam begins to shrink at $110^{\circ} \mathrm{C}$, polyurethane foam at $170^{\circ} \mathrm{C}$, glass-fibre insulation at $430^{\circ} \mathrm{C}$ and rock-fibre insulation at $650^{\circ} \mathrm{C}$. The space between the insulation and the exposed gypsum board gets larger (Figure 10 (b)) with the shrinkage and melting of insulation, and eventually the insulation may deform as shown in Figure 10 (c) due to gravitational effects. The thickness of insulation used in the WALL2DN model was based on the measured data shown in Figure 9. The enthalpy change due to the shrinkage of insulation was assumed to be zero [3].

Thermal Conductivity of Insulation

The thermal conductivity of glass-fibre in the WALL2DN model was assumed to be a function of temperature and density [13].

$$
\begin{aligned}
& \mathrm{K}_{\text {glass }}=\mathrm{a}+\mathrm{bT}^{1.5}+\mathrm{cT}^{3.0} \\
& \mathrm{a}=\mathrm{a}_{1}+\mathrm{a}_{2} \rho+\mathrm{a}_{3} / \rho \\
& \mathrm{b}=\mathrm{b}_{1}+\mathrm{b}_{2} \rho+\mathrm{b}_{3} / \rho \\
& \mathrm{c}=\mathrm{c}_{1}+\mathrm{c}_{2} \rho+\mathrm{c}_{3} / \rho
\end{aligned}
$$

where $\mathrm{T}$ is temperature $\left({ }^{\circ} \mathrm{C}\right)$ and $\rho$ is the density of the glass-fibre insulation. The coefficients $\mathrm{a}, \mathrm{b}$ and $\mathrm{c}$ are related to the density of the glass-fibre insulation. Coefficients $a_{1}, a_{2}, a_{3}, b_{1}, b_{2}, b_{3}, c_{1}, c_{2}$, and $c_{3}$ are constants as below. 


$$
\begin{array}{lll}
\mathrm{a}_{1}=1.492 \mathrm{E}-02 & \mathrm{~b}_{1}=2.777 \mathrm{E}-07 & \mathrm{c}_{1}=3.557 \mathrm{E}-10 \\
\mathrm{a}_{2}=3.274 \mathrm{E}-05 & \mathrm{~b}_{2}=6.090 \mathrm{E}-10 & \mathrm{c}_{2}=7.804 \mathrm{E}-13 \\
\mathrm{a}_{3}=1.202 \mathrm{E}-01 & \mathrm{~b}_{3}=2.235 \mathrm{E}-06 & \mathrm{c}_{3}=2.864 \mathrm{E}-09
\end{array}
$$

The thermal conductivity of rock-fibre insulation is almost independent of density and is defined as a function only of temperature [14].

$$
\mathrm{K}_{\mathrm{rock}}=\mathrm{a}+\mathrm{bT} \mathrm{T}^{1.5}+\mathrm{cT}^{3.0}
$$

where $\mathrm{T}$ is temperature $\left({ }^{\circ} \mathrm{C}\right)$ and coefficients $\mathrm{a}, \mathrm{b}$ and $\mathrm{c}$ are the constant values.

$$
a=0.035 \quad b=1.709 E-05 \quad c=6.394 E-11
$$

\section{2. Monte Carlo Methods}

Monte Carlo methods are a class of computational algorithms that employ repeated random sampling to compute results. The name Monte Carlo was gained from the Monte Carlo Casino in Monaco and was popularized during the Manhattan Project of World War II by physicists working on nuclear weapon projects $[15,16]$

Currently, Monte Carlo Methods are widely used to solve various problems with uncertainty in inputs by generating suitable random numbers and observing the numbers 
obeying some properties, such as shape of selected probability distribution functions [16, 17].

Figure 11 shows the Monte Carlo Methods as applied to an arbitrary physical system. It first assumes that the physical system can be described by selecting probability density functions (pdf's) based on well-established knowledge and experience. Then, the Monte Carlo simulation can proceed by sampling from these pdf's, which necessitates generating random numbers from the selected pdf's. Finally, the outcomes of calculations using the random samplings should be accumulated in an appropriate manner to summarize the findings. In summary, the essence of Monte Carlo Methods is the use of random sampling techniques to find a solution of the physical problem. It differs from a conventional numerical solution approach that starts with the mathematical model of the physical system, discretizes the differential equations and then solves a set of algebraic equations for the unknown system $[17,18,19]$.

The general description of Monte Carlo methods given above does not provide details of how to apply Monte Carlo into applications. It is only natural to consider that Monte Carlo methods could be used to simulate random or stochastic processes if these processes were considered to be described by pdf's. However, in many Monte Carlo applications, how to determine which pdf's are applicable to stochastic processes is actually very hard because it is difficult to find apparent stochastic content. Therefore, in many cases, artificial transformation in terms of pdf's might be posed for the purpose of 
simulating stochastic processes. Next, a generic view of the components of Monte Carlo methods will be introduced, including the Monte Carlo rubric $[18,20]$.

\subsubsection{Major Components of a Monte Carlo Algorithm}

Before going through the details of the Monte Carlo method, it is important to have a brief description of the major components of Monte Carlo methods since these components comprise the basis of most Monte Carlo applications and a good understanding of them will give a solid foundation to apply Monte Carlo methods in this study. The major components are $[21,22,23]$ :

- Probability distribution functions (pdf's) - the pdf's are used to describe the properties of the physical system (i.e. wood-framed wall assemblies), such as normal, triangular or lognormal pdfs, which are used in this study.

- Random number generator - a source of random numbers generated from the selected pdf's, such as normal random number generator employed in this study.

- Sampling rule - algorithms to generate sampling from the designated pdf's, such as mean and standard deviation which is the sampling rule used in a normal pdf.

- Scoring - the accumulated outcomes within the quantities of interest, such as histogram and cumulative probability curves presented in Chapter 4 of this study.

- Error estimation - an algorithm to allow estimating the statistical error (i.e. variance) as a function of the number of trials and other quantities. 
- Variance reduction techniques - techniques used within Monte Carlo applications to reduce the variance of random processes. These techniques may provide a solution to further reduce the number of required simulation runs in the procedure of Monte Carlo simulation.

The next section of this chapter introduces some components mentioned above in more detail. In addition, Chapter 3 will introduce several widely used Monte Carlo simulation methods, and will describe how to apply them to WALL2DN.

\subsubsection{Density Functions}

If there is a continuous range of values, such as real number between 0 and 1 , the probability of getting exactly a specific real number is zero, since there are infinite real numbers to choose from, and it would be impossible to find exactly the correct real. For example, the probability of selecting the real number $\mathrm{r}=0.111$ must be zero, as there exists an infinite number of alternative real numbers. Actually, there can be infinite real numbers between 0.110 and 0.112 , hence the probability for a given real number is zero. However, the probability of a random variable (r.v.) that takes on a value within a given interval, such as a real number between 0.110 and 0.112 , will be possible. To realize this, a probability density function (pdf) needs to be defined first $[18,22]$. 


\subsubsection{Probability Density Function (pdf)}

If a random variable $\mathrm{x}$ is distributed according to a pdf $\mathrm{f}(\mathrm{x})$, then the probability that $\mathrm{x}$ is in the interval $(x, x+d x)$ is given by $f(x) d x[15,18]$ :

$$
\operatorname{prob}\left(x \leq x^{\prime} \leq x+d x\right) \equiv P\left(x \leq x^{\prime} \leq x+d x\right)=f(x) d x
$$

As $f(x) d x$ is unitless, $f(x)$ should have units of inverse random variable units, such as $1 / m$ or $1 / \mathrm{s}$, depending on the units of $\mathrm{x}$. A typical pdf $\mathrm{f}(\mathrm{x})$ is shown in Figure 12, which illustrates the interpretation of the probability of finding the random variable in the interval $(x, x+d x)$ with the area under the curve $f(x)$ from $x$ to $x+d x$.

We can also calculate the probability of finding the random variable somewhere in the finite interval $[a, b][15,18]$ :

$$
\operatorname{prob}(a \leq x \leq b) \equiv P(a \leq x \leq b)=\int_{a}^{b} f(x) d x
$$

which is the area under the curve $f(x)$ from $x=a$ to $x=b$.

There are some important restrictions on pdf's. As $\mathrm{f}(\mathrm{x})$ is a probability density function, it must be positive for all values of the random variable $\mathrm{x}$. In addition, the probability of finding the random variable somewhere on the real axis must be unity. It turns out that these two conditions, which are summarized below, are the only necessary conditions for $f(x)$ to be a legitimate pdf $[15,18]$ 


$$
\begin{aligned}
& f(x) \geq 0 ;-\infty<x<\infty \\
& \int_{-\infty}^{+\infty} f(x) d x=1
\end{aligned}
$$

Since these restrictions are not very stringent, Monte Carlo methods do not need both of them together to solve applications that have no apparent randomness. In addition, an important quantity needs to be defined and introduced, which is intimately related to the pdf, known as the cumulative distribution function (cdf).

\subsubsection{Cumulative Distribution Function (cdf)}

The cumulative distribution function gives the probability that the random variable $\mathrm{x}$ is less than or equal to a given value, a $[18,22]$ :

$$
\begin{aligned}
c d f & \equiv \operatorname{prob}(x \leq a) \equiv F(x) \\
& =\int_{-\infty}^{a} f(x) d x
\end{aligned}
$$

Since $f(x) \geq 0$, and the integral of $\mathrm{f}(\mathrm{x})$ is normalized to unity, $F(x)$ must obey the following rules:

- $F(x)$ increases in a monotone fashion

- $F(-\infty)=0$

- $F(+\infty)=1$ 
A representative cdf is shown in Figure 13 illustrating the dependence of $F(x)$ as $x \rightarrow \pm \infty$.

\subsubsection{Stratified Sampling}

As described in the previous sections, a Monte Carlo simulation consists of some physical or mathematical system that can be described in terms of probability distribution functions (pdf's). These probability distribution functions describe the evolution of the overall system, such as space, energy or time. The goal of a Monte Carlo method is to simulate the physical system by random sampling from pdf's and by performing the necessary supplementary computations needed to describe the system evolution.

There are some commonly used forms of stratified sampling that reduce the number of runs necessary for a Monte Carlo simulation to achieve a reasonably accurate random distribution. Latin hypercube sampling (LHS) is one form of stratified sampling that is often applied to multiple variables. LHS can not only be incorporated into an existing Monte Carlo model fairly easy, but also works with variables following any analytical probability distribution $[24,25]$.

The concept behind LHS is not complex. Variables sampled use an even sampling method, and then randomly combined sets of these variables are used for one calculation of the targeted distribution function. The LHS sampling algorithm ensures that the 
distribution function can be sampled evenly, but with the same probability trend. To perform the LHS, the targeted distribution function needs to be divided into segments, one for each iteration of the Monte Carlo simulation. Next, a probability is randomly chosen within each segment using a uniform distribution, and then mapped into the correct representative value of the variables' actual distribution. LHS is capable of reducing the number of runs necessary to stabilize a Monte Carlo simulation by a large factor, and sometimes could take up to $30 \%$ fewer runs to generate a smooth distribution of outcomes. Furthermore, the process can be implemented in a quick, simple, and easy way [24].

\subsubsection{Variance Reduction Techniques}

Variance reduction techniques are methods for reducing the variance in the estimated solution to achieve a reduction of computational time for the Monte Carlo simulation. Importance sampling (IS) is a widely used variance reduction technique that can be applied into the Monte Carlo method. The idea behind IS is to determine certain values of input random variables in a simulation having more impact on the parameter being estimated than others. Since these chosen values are emphasized by sampling more frequently, the estimator variance may be reduced. Hence, how to choose a distribution that encourages the important values becomes core of the IS application. However, the use of biased distributions will lead to a biased estimator when it is applied directly in the simulation. Yet, if the simulation outcomes are weighted to correct for the use of the biased distribution, the unbiased IS estimator can be ensured. Generally, the weight is 
determined by the likelihood ratio which is the Radon-Nikodym derivative of the true underlying distribution with respect to the biased distribution function $[26,27]$.

The fundamental issue in implementing an IS simulation is how to design a good biased distribution which encourages the important regions of input variables. However, a problem with IS is that designing good biased distribution becomes more complicated and much harder as the system complexity increases. Usually, a successful approach to solve this problem is to break down a simulation into several smaller, more sharply defined sub-problems, and then IS strategies can be applied to each of the simpler subproblems $[28,29]$.

\subsubsection{Multivariate Probability Density Functions}

The term "multivariate" is often defined as an adjective to mean involving many variables, as opposed to one (univariate) or two (bivariate). A generalization to more than one random variable can be called multivariate probability. Generally, it is not easy to visualize distribution functions in a multi-dimensional space when the dimensionality is greater than three, or to plot them if the multi-dimension space is greater than two [22].

Multivariate distribution is used to do multivariate analysis which is the simultaneous statistical consideration of relationships among many measured properties for a given system. There are several commonly applied multivariate distributions, such as multivariate uniform, multivariate normal, Fisher, Dirichlet, Wishart, and so on [22]. 
Since, in this study, no multivariate distribution will be used in the WALL2DN model, no further description and discussion is presented here.

\subsubsection{Monte Carlo Implementation}

The Monte Carlo method is one of many methods for analyzing uncertainty propagation, where the goal is to determine how random variation, due to lack of knowledge, affects the sensitivity, performance and reliability of the system that is being modeled. Monte Carlo simulation is often categorized as a sampling method as the inputs are randomly generated from probability distributions to simulate the process of sampling from an actual application. Therefore, it becomes important to choose a distribution for the inputs that most closely matches data already existing, or best represents the most current situation of the specified application. The data generated from the simulation can be represented as probability distributions (i.e. histograms or cumulative curves) or converted to error bars, reliability predictions, tolerance zones, and confidence intervals, as shown in Figure $14[22,23]$. Figure 14 shows a typical process of Monte Carlo simulation in which input uncertainty data of $x_{1}, x_{2}$ and $x_{3}$ are calculated using a model of $f(x)$ on basis of the Monte Carlo method to generate predictions of $y_{1}$ and $y_{2}$ (distributions).

The steps for a Monte Carlo simulation application can be implemented as follows [23]: 
Step 1: Create a parametric-based model (i.e. heat transfer model WALL2DN as shown in Figure 3),

Step 2: Generate a set of random inputs $\left(\mathrm{x}_{1}, \mathrm{x}_{2}\right.$ and $\mathrm{x}_{3}$ in Figure 14),

Step 3: Execute the model,

Step 4: Repeat steps 2 and 3,

Step 5: Analyze the outcomes using histograms, summary statistics, and so on (predictions of $y_{1}$ and $y_{2}$ in Figure 14).

In the next chapter, several widely used and known probability distribution functions will be introduced, and used to demonstrate how to set up the relationships between the Monte Carlo methods and the experimental data of the properties of wood-framed wall assemblies in the WALL2DN-MC model.

\subsection{Significance of Applying Monte Carlo Method in WALL2DN}

In this study, the Monte Carlo method is applied to the heat transfer model, WALL2DN. WALL2DN uses equations to describe the thermo-physical properties of wall materials developed (summarized) by Forintek based on reported scattered data from published literature or experimental tests. The Monte Carlo method is used in this study to process the scattered test data of the thermo-properties instead of simply using the summarized data. The Monte Carlo method is used to process data for density, thermal conductivity, and specific heat. 
To get more representative simulation results, all data and curves for the thermo-physical properties of gypsum boards, wood studs and insulations have been considered by the Monte Carlo method. By doing this, an overall temperature-dependent behavior of woodframed wall assemblies in the WALL2DN-MC model can be reflected. Accordingly, it is expected that the simulation done by the WALL2DN-MC model might be more conservative than that done by the WALL2DN model.

By using a variety of published data of material properties of wood-framed wall assemblies the newly developed model can also calculate the probability of failure of the wall-assembly with time which is required in risk models, such as CUrisk model. 


\section{METHODOLOGY}

The Monte Carlo Method can be used to simulate processes with many varying scattered inputs. Typically, in any activity, there are a few crucial inputs, and these inputs, rather than some other minor factors, should be treated as the major variables in the simulation. For this reason a Monte Carlo simulation must be preceded by a sensitivity analysis to determine what the key parameters are.

In the following sections, three widely used functions in Monte Carlo simulations will be discussed as well as the methodology that will be used to implement them into the current WALL2DN model to generate the values of temperature-dependent assembly properties.

\subsection{Normal Probability Distribution Function}

Many sets of data fall well into a bell-shaped pattern as shown in Figure 15. For instance, the heights of people and scores on an exam all take on a bell-shaped pattern. Generally, such distributions of data can be modeled using a well-known pdf, the normal distribution or Gaussian distribution. The curve of a normal distribution is always symmetric from left to right [30].

Two characteristics distinguish one normal curve from another. The first characteristic is the point at the center of the normal curve, which corresponds to the mean represented by 
the Greek letter, $\mu$. Each normal distribution curve is symmetric about its mean as illustrated in Figure 16. The second characteristic of a normal curve is called variation which corresponds to the distribution of data about the central mean, and which is used to examine whether the data points are packed tightly around the mean at the center, or whether there is a large amount of variation about the center. The amount of variation is often measured by the standard deviation that is denoted by the lower case Greek letter, $\sigma$. The larger $\sigma$ is, the wider the spread in the data is; the smaller it is, the narrower the variation in the data is, as shown in Figure 17 [30].

The equation describing the normal distribution curve is given by $[30,31]$

$$
f(x)=\frac{1}{\sigma \sqrt{2 \pi}}\left[e^{-\frac{1}{2}\left(\frac{x-\mu}{\sigma}\right)^{2}}\right]
$$

The coefficient $1 /\left(\sigma(2 \pi)^{0.5}\right)$ ensures that the total area under the curve is precisely 1 , which means it accounts for $100 \%$ of the population. If $\mu=0$ and $\sigma=1$ are substituted into the equation above, the equation reduces to the following [30, 31]

$$
f(x)=\frac{1}{\sqrt{2 \pi}} e^{-\frac{1}{2} x^{2}}
$$

Equation 14 is usually referred to as the standard normal curve. As $\mathrm{x}$ increases in either the positive or negative direction, $-\mathrm{x}^{2}$ is increasingly negative so that the function $e^{-0.5 x^{2}}$ 
decreases and eventually approaches zero. The standard normal curve has its greatest height, $\mathrm{f}(0)=1 /\left(\sigma(2 \pi)^{0.5}\right)$, when $\mathrm{x}=0$, and it decays toward zero in both directions symmetrically with the increase of $\mathrm{x}$.

The standard deviation $\sigma$ appears in two places, first in the coefficient, where it affects the height of the normal curve at any point. Because $\sigma$ appears in the denominator of the coefficient, the larger $\sigma$ is, the lower the peak of the curve is, and the smaller $\sigma$ is, the higher the peak is. Second, and more importantly, the standard deviation $\sigma$ also appears in the denominator of the exponent: $-1 / 2((\mathrm{x}-\mu) / \sigma)^{2}$. As a result, the larger $\sigma$ is, the more slowly the curve dies out, and the smaller $\sigma$ is, the more rapidly the curve dies out (see Figure 17) [30].

Another property of any normal distribution function is the fact that the percentage of the population that lies between any two values of $x-$ say, $x_{L}$ for the left value and $x_{R}$ for the right value - is exactly equal to the area under the normal curve between $\mathrm{x}=\mathrm{x}_{\mathrm{L}}$ and $\mathrm{x}=$ $\mathrm{x}_{\mathrm{R}}$, as shown in Figure 18. Equivalently, the probability that any single randomly selected member of a normally distributed population lies between any two values of $\mathrm{x}$, say $\mathrm{x}_{\mathrm{L}}$ and $\mathrm{x}_{\mathrm{R}}$, is equal to the area under the normal curve between $\mathrm{x}=\mathrm{x}_{\mathrm{L}}$ and $\mathrm{x}=\mathrm{x}_{\mathrm{R}}$, as shown in Figure 18.

Rules of thumb for any normal distribution (refer to the Figure 19) are as below [30]: 
1. Approximately $68 \%$ of any normally distributed population lies within one standard deviation from the mean. This is located between $\mu-\sigma$ and $\mu+\sigma$.

2. Approximately $95 \%$ of any normally distributed population lies within two standard deviations from the mean. This is located between $\mu-2 \sigma$ and $\mu+2 \sigma$.

3. Approximately $99.7 \%$ of any normally distributed population lies within three standard deviations from the mean. This is located between $\mu-3 \sigma$ and $\mu+3 \sigma$.

\subsubsection{Parameter Estimation}

The parameters of the normal distribution are the mean $(\mu)$ and standard deviation $(\sigma)$ [30].

$$
\begin{aligned}
& \mu=\frac{1}{N} \sum_{i=N}^{i=1} x_{i} \\
& \text { variance }=\frac{1}{N} \sum_{i=N}^{i=1}\left(x_{i}-\mu\right)^{2} \\
& \sigma=\sqrt{\text { variance }}
\end{aligned}
$$

where, $\mathrm{x}_{\mathrm{i}}$ is the discrete sample data.

\subsubsection{Random Number Generation}

A common method for generating random numbers from a standard normal distribution is the Box-Muller algorithm [32] which can generate pairs of standard normal random numbers $\left(r_{1}\right.$ and $\left.r_{2}\right)$ from two standard uniform random numbers $\left(u_{1}\right.$ and $\left.u_{2}\right)$ : 


$$
\begin{aligned}
& r_{1}=\sin \left(2 \pi u_{2}\right) \times \sqrt{-2 \log \left(u_{1}\right)} \\
& r_{2}=\cos \left(2 \pi u_{2}\right) \times \sqrt{-2 \log \left(u_{1}\right)}
\end{aligned}
$$

A basic style pseudo code for a single standard normal random number is shown below:

$$
\mathrm{r} 1=\operatorname{Sqrt}(-2 \times \log (\operatorname{rgU}())) \times \operatorname{Sin}(2 \times \pi \times \operatorname{rgU}())
$$

where, $\mathrm{rgU}()$ is a unit uniform random number generator.

The standard normal number can be scaled for given values of mean $(\mu)$ and standard deviation $(\sigma)$ with this addition [32]:

$$
r=\sum_{i} \mu+r_{i} \cdot \sigma
$$

A common refinement is to generate random numbers in pairs and to use a flag to determine if a new pair should be generated or a previous value used.

\subsection{Triangular Probability Distribution Function}

The Triangular Distribution is typically considered as a subjective description of a population for which there is only limited sample data. It is based on the knowledge of the minimum and maximum and an inspired guess as to what the modal value might be. Despite being a simplistic description of a population, it is a very useful distribution for 
modeling processes where the relationship between variables is known, but data are scarce. Refer to Figure 20 [33].

\subsubsection{Parameters of Triangular PDF}

The parameters of a triangular distribution are listed as the table below [33]:

$\begin{array}{lll}\text { Parameter } & \text { Description } & \text { Characteristics } \\ \text { Min. } & \text { Minimum value } & \text { A float }>-\infty \text { and }<=\bmod \\ \text { Mod } & \text { Modal Value } & \text { A float }>=\min \text { or }<=\max \\ \text { Max. } & \text { Maximum value } & \text { A float }>=\bmod \text { and }<\infty\end{array}$

The range of generated random numbers will be determined by the min and max parameters.

3.2.2 Probability Distribution Functions of Triangular PDF [33]

$$
\begin{aligned}
& F(x)=\frac{(\bmod -\min )}{(\max -\min )} \quad \text { when } \quad x=\bmod \\
& F(x)=\frac{(x-\min )^{2}}{(\max -\min ) \times(\bmod -\min )} \quad \text { when } x<\bmod \\
& F(x)=1-\frac{(\max -x)^{2}}{(\max -\bmod ) \times(\max -\min )} \quad \text { when } x>\bmod
\end{aligned}
$$


where, min, mod and max are the minimum, modal and maximum values, respectively.

\subsubsection{Parameter Estimation}

The parameters of a triangular distribution can be derived directly from the dataset that is used to describe a model. Provided the dataset does not contain any anomalous points, the minimum and maximum can be obtained by sorting the values in ascending order and then only choosing the first and last points. Unless the modal value has been set subjectively, there is a regular manner using the Max, Min and Mean to estimate the modal value. The properties of a triangular pdf are determined based on the equations below [33]:

$$
\begin{aligned}
& \bmod =3 \times \text { mean }-\max -\min \\
& \text { variance }=\frac{\min ^{2}+\bmod ^{2}+\max ^{2}-\min \times \bmod -\min \times \max -\bmod \times \max }{18}
\end{aligned}
$$

In the real world, it might be very difficult and expensive to collect data, and only a few may be available to be used as input for some forms of Monte Carlo evaluation. The following simple example in which four observations are available demonstrates how to apply the approach mentioned above in practice.

$$
\{10.0 \%, 13.5 \%, 15.5 \%, 20.0 \%\}
$$


The mean value of the dataset is $14.75 \%$ based on Equation 15, using this value together with the min and max in Equation 23, gets the modal value as $14.25 \%$.

\subsubsection{Random Number Generation}

Random number generation (herein referred to as $\mathrm{t}$ ) for a triangular distribution needs to be derived by generating a continuous random uniform variable in the range 0 to 1

(herein referred to as $\mathrm{u}$ ) as the initial value of probability distribution functions of Trianguler pdf (Equations 21 and 22 in Section 3.2.2 of this Chapter) [33]:

$$
\mathrm{t}=\text { rgTriangle }(\mathrm{u})
$$

Using basic pseudo style code, the function of uniform random generator would look like as below:

$$
\begin{aligned}
& \mathrm{u}=\operatorname{rgU}() \\
& \text { If }[u<=(\bmod -\min ) /(\max -\min )] \text { then } \\
& t=\min +\operatorname{sqrt}\left(u^{*}(\max -\min ) *(\bmod -\min )\right) \\
& \text { else } \\
& t=\max -\operatorname{sqrt}((1-u) *(\max -\min ) *(\max -\bmod ))
\end{aligned}
$$

end if

where, $\operatorname{rgU}()$ is a unit uniform random number generator, and rgTriangle() is the triangular random number generator. 


\subsection{Lognormal Probability Distribution Function}

The Lognormal distribution is derived from the normal distribution. It describes a variable, $\mathrm{x}$, where $\log (\mathrm{x})$ is normally distributed. It is valid only for values of $\mathrm{x}$ greater than zero since this is the applicable condition for the function of natural logarithm. The lognormal distribution can describe many naturally occurring populations very well. Refer to Figure 21 as a description of the lognormal distribution.

There are three ways of defining a lognormal distribution [34]:

Lognormal - A

Mean and Standard Deviation of variable $\mathrm{x}$.

Lognormal - B

Mean of $\log (\mathrm{x})$ and Standard Deviation of $\log (\mathrm{x})$

Lognormal - C

Median of variable $\mathrm{x}$ and Standard Deviation of $\log (\mathrm{x})$

3.3.1 Parameters to Describe Lognormal PDF $[34,35]$

Lognormal - A

Parameter Description

Characteristics

Mean

Mean of $x$

A float $>0$ and $<\infty$

std. dev.

Standard Deviation of $\mathrm{x}$

A float $>0$ 


\section{Lognormal - B}

$\begin{array}{lll}\text { Parameter } & \text { Description } & \text { Characteristics } \\ \text { mean }(\log ) & \text { Mean of } \log (\mathrm{x}) & \text { A float }>0 \text { and }<\infty \\ \text { std. dev. }(\log ) & \text { Standard Deviation of } \log (\mathrm{x}) & \text { A float }>0\end{array}$

\section{Lognormal - C}

$\begin{array}{lll}\text { Parameter } & \text { Description } & \text { Characteristics } \\ \text { median } & \text { Median of } x & \text { A float }>0 \text { and }<\infty \\ \text { std. dev. }(\log ) & \text { Standard Deviation of } \log (\mathrm{x}) & \text { A float }>0\end{array}$

The range of random numbers generated for the lognormal distribution is from greater than zero to positive infinity.

Since the lognormal-B distribution function is selected using in the study, the relationship between the types of input for the lognormal-B distribution function is [34]:

$$
\begin{aligned}
& \text { stdev }_{\log }=\sqrt{\log \left[1+\left(\frac{\text { stdev }}{\text { mean }}\right)^{2}\right]} \\
& \text { mean }_{\log }=\log (\text { mean })-\frac{1}{2} \times\left[1+\left(\frac{\text { stdev }}{\text { mean }}\right)^{2}\right]
\end{aligned}
$$


The properties of lognormal PDF are shown as follows [34]:

$$
\text { variance }=\text { mean }^{2} \times\left[\operatorname{pow}\left(10.0, \text { stdev }_{\log }^{2}\right)-1\right]
$$

where, $\operatorname{pow}(x, y)$ means $x$ raised to the power $y$.

\subsubsection{Parameter Estimation}

The mean and standard deviation for the lognormal distribution are obtained from formulas derived from the standard normal distribution [34]:

$$
\begin{aligned}
& \text { mean }_{\log }=\frac{1}{N} \sum_{i=N}^{i=1} \log \left(x_{i}\right) \\
& \text { stdev }_{\log }=\frac{1}{N} \sqrt{N \sum_{i=N}^{i=1} \log \left(x_{i}\right)^{2}-\left(\sum_{i=N}^{i=1} \log \left(x_{i}\right)\right)^{2}}
\end{aligned}
$$

\subsubsection{Random Number Generation}

In this study, lognormal - B distribution will be used. The Box-Muller method described in section 3.1 of this Chapter for the Normal distribution can also be adapted for the lognormal distribution as follows $[34,35,36]$.

\section{Step 1}


Assuming the required distribution is defined in terms of the mean and standard deviation of the variable, use Equations (28) and (29) to derive mean $_{\log }$ and stdev $v_{\log }$

\section{Step 2}

Generate a standard normally distributed random number using the BoxMuller method:

$$
\mathrm{N}=\operatorname{Sqrt}(-2 * \log (\operatorname{rgU}())) * \operatorname{Sin}(2 * \pi * \operatorname{rgU}())
$$

\section{Step 3}

Scale the standard value with mean $\log _{\log }$ and stdev $_{\log }$ :

$$
\log \mathrm{N}=\operatorname{mean}_{\log }+\mathrm{N}^{*} \text { stdev }_{\log }
$$

\section{Step 4}

Exponentiate "LogN" to create a lognormal value:

$$
\log \mathrm{N}=\exp (\log \mathrm{N})
$$

\subsection{Relationships between Monte Carlo Methods and the Wood-framed Wall Assembly Properties of WALL2DN Model}

In the case of a wood structure, the engineering properties of the main components (i.e. wood studs and gypsum boards) are highly variable. Hence it's difficult to predict the behaviour of the fire resistance when exposed to fire. Furthermore, only a few discrete experimental data are available which makes it difficult to accurately describe the properties of the temperature-dependent components. For these reasons, a great deal of research has been conducted to find new ways to determine the temperature-dependent 
property characteristics of wood studs and gypsum boards, such as the summarized equations and curves $[1,2,3]$.

The WALL2D series of models have used published equations and curves to predict the behavior of wood-framed wall assemblies when exposed to fire. However, these equations and curves do not account for the variations of these properties. Therefore, a statistical method, Monte Carlo method, is proposed in this study for solving the deficiency of the original WALL2DN model. In addition, this approach will yield the probability of failure as a function of time.

\subsubsection{General Approach}

A Monte Carlo analysis first requires choosing a statistical distribution for each component input parameters, and then establishes the relationship between the component variable and the statistical distribution. In this study, three distribution functions (i.e., normal, triangular and lognormal pdf's) have been selected. This section describes the approach used to set up the relationships between Monte Carlo simulation techniques (meaning the statistical distributions) and the temperature-dependent properties of wood-framed assemblies in WALL2DN (meaning the component variables). 


\subsubsection{Relationship Establishment}

The literature of WALL2DN discussed in Section 2.1 revealed that there are nine properties that govern heat transfer through wood-framed walls. These properties will be discussed in this chapter to objectively establish relationships that will be used in the Monte Carlo simulation methods. The properties that will be considered are density, specific heat, thermal conductivity and shrinkage of gypsum board; density, specific heat and thermal conductivity of wood-studs; and density and thermal conductivity of insulation materials.

\subsubsection{Density}

The density discussed below includes the density of gypsum board, wood-stud and insulation material.

\section{Density of Gypsum Board}

As discussed in Section 2.1.1, the density of one manufacturer's $12.7-\mathrm{mm}$ firerated gypsum board is $732 \mathrm{~kg} / \mathrm{m}^{3}$, and the density of the same manufacturer's 15.9-mm fire-rated gypsum board is $648 \mathrm{~kg} / \mathrm{m}^{3}$. The temperature-dependent density curves for both boards are shown in Figure 4. 
In WALL2DN, the density of fire-rated gypsum boards at elevated temperatures is obtained using the following equations:

$$
\begin{array}{ll}
\rho=\rho_{0} & \mathrm{~T}<150^{\circ} \mathrm{C} \\
\rho=\rho_{0}[0.9831-0.1138(\mathrm{~T}-150.0) / 50.0] & 150^{\circ} \mathrm{C}<\mathrm{T}<200^{\circ} \mathrm{C} \\
\rho=\rho_{0}[0.8693-0.0227(\mathrm{~T}-200.0) / 100.0] & 200^{\circ} \mathrm{C}<\mathrm{T}<300^{\circ} \mathrm{C} \\
\rho=\rho_{0}[0.8466-0.0364(\mathrm{~T}-300.0) / 400.0] & 300^{\circ} \mathrm{C}<\mathrm{T}<700^{\circ} \mathrm{C} \\
\rho=\rho_{0}[0.8102+0.0843(\mathrm{~T}-700.0) / 200.0] & \mathrm{T}>700^{\circ} \mathrm{C}
\end{array}
$$

where, $\rho_{0}$ is the density of gypsum boards at ambient temperature, $732 \mathrm{~kg} / \mathrm{m}^{3}$ for 12.7-mm gypsum board and $648 \mathrm{~kg} / \mathrm{m}^{3}$ for 15.9-mm gypsum board.

There are few reported curves or experimental data available in relation to the density of gypsum boards at elevated temperature. For keeping the validation of model simulation, Monte Carlo simulation will not be considered applying to the property of density of gypsum boards in this study.

\section{Density of Wood-Stud}

In the WALL2DN model, fixed density values for different wood species groupings at ambient temperature were used, and temperature-dependent equation or curve was not employed. The assumption made in WALL2DN model might be that the density of wood studs up to the charring temperature of $288^{\circ} \mathrm{C}$ would 
remain the same as the density at ambient temperature. After charring the density would sharply drop and the charred portion would be considered to have little influence on the heat transfer simulation process. This characteristic described above for the density of wood can be clearly demonstrated in Figure 22 [37]. The intent of this study is to apply the Monte Carlo Method to the thermal properties of wood-framed wall assembly at elevated temperatures. Since there is only a range of the coefficient of variation of density of wood-stud (i.e. about 10\% [37]) at ambient temperature available and not many test data and reported curves at elevated temperature can be found, the Monte Carlo Method will not be applied to this property in the new model.

\section{Density of Insulations}

Since density values of glass-fibre and mineral-wool can be designated by users at the model initiating through the toolbar "MenulSettings" in WALL2DN, the Monte Carlo method will not be applied to the property of density of insulations.

\subsubsection{Specific Heat}

\section{Specific Heat of Gypsum Board}

In WALL2DN, the temperature-dependent specific heat of gypsum boards can be determined as follows: 


$$
\begin{array}{ll}
C p_{g}=\left(1-P_{W}\right) C p_{g, a}+P_{W} \cdot C p_{S} & \text { for } T \leq 500^{\circ} C \\
C p_{g}=\left(1-P_{W}\right) C p_{g, a} & \text { for } T>500^{\circ} C \\
P_{W}=m_{w}+0.21 \cdot m_{g} & \text { (32) }
\end{array}
$$

where $C p_{g}$ is specific heat of gypsum board at elevated temperature, $C p_{g, a}$ is the specific heat of gypsum board at ambient temperature, equal to $950 \mathrm{~J} / \mathrm{kg}{ }^{\circ} \mathrm{C}$, and $C p_{S}$ is specific heat of steam equal to $2100 \mathrm{~J} / \mathrm{kg}{ }^{\circ} \mathrm{C} . P_{W}$ is the fraction of water in the gypsum board, including both free and crystallization water. $m_{w}$ is mass of free water of gypsum board (3.4\%), and $m_{g}$ is the mass of gypsum board without free water $(96.5 \%)$. The value 0.21 is the maximum value of $21 \%$ by mass crystallization water in pure gypsum. Refer to Section 2.1.1 of Chapter 2.

The water content including in gypsum boards varies with one manufacturer to another manufacturer. According to the experimental results of a scanning calorimetry for gypsum board of one manufacturer, there was $3.4 \%$ of mass free water and $14.6 \%$ of mass chemically bound water [1]. This test result means that the percent of pure gypsum for this type of gypsum board, in comparison with a maximum of $21 \%$ of gypsum, is about $14.6 / 21.0 \times 100 \%=69.5 \%$ pure gypsum. In accordance with former Canadian standard for gypsum boards [8, 9], the minimum percentage of pure gypsum within any commercial gypsum board is $65 \%$. This indicated that the minimum value of chemically bound water should be 
$13.65 \%$. Based on this analysis, it can be claimed that the mass of chemically bound water of gypsum boards could be within the range of $13.65 \%$ to $21 \%$.

Accordingly, the data, $\{21 \%, 14.6 \%, 13.65 \%\}$, will be used in the model to determine the initial parameters of the three Monte Carlo simulation methods, normal pdf, triangular pdf, and lognormal pdf. The main parameters will then be used as inputs into the random number generators for generating a variety of specific heat values of gypsum boards, which will replace the constant $21 \%$ used in the WALL2DN model.

The details to establish the relationship between the three probability distribution functions (normal, triangle and lognormal) and the specific heat of gypsum board are as follows.

a) Normal pdf

The Normal pdf simulation, described in section 3.1, is implemented using the following steps.

\section{Step 1}

Determine the values of the mean and standard deviation by using Equations 15 through 17. 


$$
\begin{aligned}
\mu & =\frac{1}{N} \sum_{i=N}^{i=1} x_{i} \\
& =\frac{1}{3}(0.1365+0.146+0.21)=0.16417
\end{aligned}
$$

$$
\begin{aligned}
\text { variance } & =\frac{1}{N} \sum_{i=N}^{i=1}\left(x_{i}-\mu\right)^{2} \\
& =\frac{1}{3}\left[(0.1365-0.16417)^{2}+(0.146-0.16417)^{2}+(0.21-0.16417)^{2}\right] \\
& =1.065 \times 10^{-3}
\end{aligned}
$$

$$
\begin{aligned}
\sigma & =\sqrt{\text { variance }} \\
& =\sqrt{1.065 \times 10^{-3}}=0.03264
\end{aligned}
$$

\section{Step 2}

Determine the value of mass chemically bound water in gypsum boards by substituting mean, standard deviation and seed into the normal random number generator.

crystallizeWaterPercent $=$ DNRandom $(\mu, \sigma$, seed $)$

where DNRandom (double, double, int) is the normal random number generator.

\section{Step 3}

Calculate the fraction of water in the gypsum board, $P_{W}$, 


$$
P_{W}=m_{w}+\text { crystallizeWaterPercent } \cdot m_{g}
$$

and then determine the specific heat of gypsum board at the elevated temperature and associated time by substituting the $P_{W}$ into the Equations 30 and 31 discussed in the previous portion of this section.

b) Triangular pdf

The Triangular pdf simulation, described in section 3.2, is implemented using the following steps.

\section{Step 1}

Determine the values of maximum, minimum and modal values by using Equations 15 and 23.

$$
\begin{aligned}
\max & =0.21 \text { and } \min =0.1365 \\
\text { mean } & =\frac{1}{N} \sum_{i=N}^{i=1} x_{i} \\
& =\frac{1}{3}(0.1365+0.146+0.21)=0.16417 \\
\bmod & =3 \times \text { mean }-\max -\min \\
& =3 x 0.16417-0.21-0.1365=0.146
\end{aligned}
$$




\section{Step 2}

Determine the value of the mass of chemically bound water in gypsum boards by substituting max, min, mode and seed into the triangular random number generator.

crystallizeWaterPercent $=$ TriRandom $(\max , \min , \bmod$, seed $)$

where TriRandom (double, double, double, int) is the triangular random number generator.

\section{Step 3}

Calculate the fraction of water in the gypsum board, $P_{W}$, based on the Equation 33, and then determine the specific heat of gypsum board at the elevated temperature and associated time by substituting the $P_{W}$ into the Equations 30 and 31 discussed in the previous portion of this section.

c) Lognormal pdf

The Lognormal pdf simulation, described in section 3.3, is implemented using the following steps. 


\section{Step 1}

Determine the values of $\mu_{\log }$ and $\sigma_{\log }$ by using Equations 28 and 29 .

$$
\begin{aligned}
\mu_{\log } & =\frac{1}{N} \sum_{i=N}^{i=1} \log \left(x_{i}\right) \\
& =\frac{1}{3}[\log (0.1365)+\log (0.146)+\log (0.21)]=-1.8254 \\
\sigma_{\log } & =\frac{1}{N} \sqrt{N \sum_{i=N}^{i=1} \log \left(x_{i}\right)^{2}-\left(\sum_{i=N}^{i=1} \log \left(x_{i}\right)\right)^{2}} \\
& =\frac{1}{3} \sqrt{3 \cdot\left\{[\log (0.1365)]^{2}+[\log (0.146)]^{2}+[\log (0.21)]^{2}\right\}-} \\
& =0.18922
\end{aligned}
$$

Step 2

Generate a standard normal random number.

stdNormal $=$ NRandom $($ seed $)$

where NRandom(int) is the standard normal random number generator.

\section{Step 3}

Determine the value of the mass of chemically bound water in gypsum boards by substituting mean ${ }_{\log }$, $\operatorname{stdev}_{\log }$ and seed into the lognormal random number generator. 
crystallizeWaterPercent $=\operatorname{LogNRandom}\left(\mu_{\mathrm{log}}, \sigma_{\mathrm{log}}\right.$, seed $)$

where LogNRandom (double, double, int) is the lognormal random number generator.

\section{Step 4}

Calculate the fraction of water in the gypsum board, $P_{W}$, based on the Equation 33, and then determine the specific heat of gypsum board at the elevated temperature and associated time by substituting the $P_{W}$ into the Equations 30 and 31 discussed in the previous portion of this section.

Specific Heat of Wood-Stud

In WALL2DN, the temperature dependent specific heat of wood-studs was determined as follows:

$$
\begin{array}{ll}
C p_{w}=1110+4.2 \cdot T & \text { for } T<200^{\circ} C \\
S_{p h}=-\left(2.1 \cdot m_{F W}+1.26 \cdot m_{F D}\right) / 300 & 200^{\circ} C \leq T<350^{\circ} C \\
B_{p h}=2.1 \cdot m_{F W}+1.95 \cdot m_{F D} & 200^{\circ} C \leq T<350^{\circ} C
\end{array}
$$


where $C p_{w}$ is the specific heat at temperatures less than $200^{\circ} \mathrm{C}, S_{p h}$ is the slope of the specific heat curve between $200^{\circ} \mathrm{C}-350^{\circ} \mathrm{C}, B_{p h}$ is the intercept of the specific heat curve between $200^{\circ} \mathrm{C}-350^{\circ} \mathrm{C}, m_{F W}$ is the mass fraction of water within the wood-stud, which is a constant for the selected wood species in WALL2DN, $m_{F D}$ is the mass fraction of dry-wood within the wood-stud, which is also a constant for the selected wood species. The numbers of 2.1, 1.95 and 1.26 are values derived from the temperature vs. specific-heat curve used in WALL2DN. The value of 2.1 means the specific heat of water vapour $(2.1 \mathrm{~kJ} / \mathrm{kg}$ ${ }^{\circ} \mathrm{C}$ ), the value of 1.95 means the specific heat of wood-stud at a temperature of $200^{\circ} \mathrm{C}\left(1.95 \mathrm{~kJ} / \mathrm{kg}^{\circ} \mathrm{C}\right)$, and the value of 1.26 means the specific heat of woodstud at a temperature of $350^{\circ} \mathrm{C}\left(1.26 \mathrm{~kJ} / \mathrm{kg}^{\circ} \mathrm{C}\right)$.

Values of the specific heat of wood studs were also reported in Janssens [38], Fredlund [38], Knudon [38] and Robert White [39]. The equations below can be derived based on Figure $23[38,39]$.

$$
\begin{array}{lll}
C p_{w}=1750+5.5 \cdot T & \text { for } T<200^{\circ} C & \text { Janssens Curve [38] } \\
C p_{w}=1450+3.0 \cdot T & \text { for } T<200^{\circ} C & \text { Fredlund Curve [38] } \\
C p_{w}=1250+5.0 \cdot T & \text { for } T<200^{\circ} C & \text { Knudon et al Curve [38] } \\
C p_{w}=1125+4.52 \cdot T & \text { for } T<200^{\circ} C & \text { Robert H White Equation [39] }
\end{array}
$$


When the temperature of the wood stud is between $200^{\circ} \mathrm{C}-350^{\circ} \mathrm{C}$, the specific heat values at the temperature points of $200^{\circ} \mathrm{C}$ and $350^{\circ} \mathrm{C}$ can be determined based on Figure 23.

$1.95 \mathrm{~kJ} / \mathrm{kg}^{\circ} \mathrm{C}$ at $200^{\circ} \mathrm{C}$, and $1.45 \mathrm{~kJ} / \mathrm{kg}^{\circ} \mathrm{C}$ at $350^{\circ} \mathrm{C}$

---- Janssens Curve [38]

$1.95 \mathrm{~kJ} / \mathrm{kg}^{\circ} \mathrm{C}$ at $200^{\circ} \mathrm{C}$, and $1.30 \mathrm{~kJ} / \mathrm{kg}^{\circ} \mathrm{C}$ at $350^{\circ} \mathrm{C}$

----- Fredlund Curve [38]

$1.85 \mathrm{~kJ} / \mathrm{kg}^{\circ} \mathrm{C}$ at $200^{\circ} \mathrm{C}$, and $1.22 \mathrm{~kJ} / \mathrm{kg}^{\circ} \mathrm{C}$ at $350^{\circ} \mathrm{C}$

Knudon et al Curve [38]

Accordingly, the subsets of specific heat $\{1.11,1.125,1.25,1.45,1.75\},\{1.85$, $1.95,1.95,1.95\}$ and $\{1.22,1.26,1.30,1.45\}$ at the temperature points of $0^{\circ} \mathrm{C}$, $200^{\circ} \mathrm{C}$ and $350^{\circ} \mathrm{C}$, respectively, and the subset of intercept $\{3.0,4.2,4.52,5.0$, 5.5 will be used to determine the initial parameters (i.e., mean, mode, standard deviation, etc.) of the three probability distribution functions, and then these initial parameters will be put into the related random number generator to generate a variety of values (i.e., intercepts and slopes) used to calculate the specific heat of wood studs at elevated temperatures, which will replace the constant parameter values used in WALL2DN. 
The steps used to establish the relationship between the three probability distribution functions (normal, triangular and lognormal) and the specific heat of wood studs are implemented in the model as follows.

a) Normal pdf

The normal pdf simulation, described in section 3.1 , is implemented using the following steps.

\section{Step 1}

Determine the values of mean and standard deviation of specific heat of wood studs at temperatures between $200^{\circ} \mathrm{C}$ and $350^{\circ} \mathrm{C}$, and of the mean and standard deviation of the intercept and slope of specific heat of wood studs at temperatures less than $200^{\circ} \mathrm{C}$ by using Equations 15 through 17.

$$
\begin{aligned}
& \begin{aligned}
\text { mean } 200= & \frac{1}{N} \sum_{i=N}^{i=1} x_{i} \\
= & \frac{1}{4}(1.95 \times 3+1.85)=1.925
\end{aligned} \\
& \begin{aligned}
\text { var iance200 } & =\frac{1}{N} \sum_{i=N}^{i=1}\left(x_{i}-\text { mean } 200\right)^{2} \\
& =\frac{1}{4}\left[(1.85-1.925)^{2}+3 x(1.95-1.925)^{2}\right] \\
& =1.875 \times 10^{-3}
\end{aligned}
\end{aligned}
$$




$$
\begin{aligned}
& \text { stdev200 }=\sqrt{\text { variance } 200} \\
& =\sqrt{1.875 \times 10^{-3}}=0.0433 \\
& \text { mean } 350=\frac{1}{4}(1.22+1.26+1.30+1.45)=1.3075 \\
& \begin{aligned}
\operatorname{variance} 350= & \frac{1}{4}\left[(1.22-1.3075)^{2}+(1.26-1.3075)^{2}+\right. \\
& \left.(1.30-1.3075)^{2}+(1.45-1.3075)^{2}\right] \\
= & 7.569 \times 10^{-3}
\end{aligned}
\end{aligned}
$$$$
\text { stdev350 }=\sqrt{7.569 \times 10^{-3}}=0.087
$$$$
\text { meanB }_{p h}=\frac{1}{5}(1.11+1.125+1.25+1.45+1.75)=1.337
$$$$
\operatorname{variance}_{p h}=\frac{1}{5}\left[(1.11-1.337)^{2}+(1.125-1.337)^{2}+\right.
$$$$
\left.(1.25-1.337)^{2}+(1.45-1.337)^{2}+(1.75-1.337)^{2}\right]
$$$$
=5.7475 \times 10^{-2}
$$

stdev $B_{p h}=\sqrt{5.7475 \times 10^{-2}}=0.23974$

$$
\text { meanS }_{p h}=\frac{1}{5}(3.0+4.2+4.52+5.0+5.5)=4.444
$$

$$
\begin{aligned}
\operatorname{variance}_{p h}= & \frac{1}{5}\left[(3.0-4.444)^{2}+(4.2-4.444)^{2}+\right. \\
& \left.(4.52-4.444)^{2}+(5.0-4.444)^{2}+(5.5-4.444)^{2}\right] \\
= & 0.71494
\end{aligned}
$$


stdev $S_{p h}=\sqrt{0.71494}=0.84554$

\section{Step 2}

Determine the values of specific heat of wood studs at temperatures between $200^{\circ} \mathrm{C}$ and $350^{\circ} \mathrm{C}$ and of the intercept and slope of specific heat of wood studs at temperatures less than $200^{\circ} \mathrm{C}$ by substituting the mean, standard deviation and seed into the normal random number generator.

$$
\begin{aligned}
& \left.C p_{w} 200=\text { DNRandom (mean200, stdev200, seed }\right) \\
& \left.C p_{w} 350=\text { DNRandom (mean } 350, \text { stdev } 350, \text { seed }\right) \\
& B_{p h}=D N R a n d o m\left(\text { mean }_{p h}, \text { stdev } B_{p h}, \text { seed }\right) \\
& S_{p h}=D N R a n d o m\left(\text { mean }_{p h}, \text { stdev } S_{p h}, \text { seed }\right)
\end{aligned}
$$

where DNRandom (double, double, int) is the normal random number generator.

\section{Step 3}

Calculate the specific heat of wood stud at temperatures less than $200^{\circ} \mathrm{C}$ and the intercept and slope of the specific heat curve of wood stud at the elevated temperatures between $200^{\circ} \mathrm{C}$ and $350^{\circ} \mathrm{C}$ 
by substituting the values calculated at Step 2 into the equations discussed in the previous portion of this section.

$$
\begin{aligned}
& C p_{w}=B_{p h}+S_{p h} \cdot T \quad T<200^{\circ} C \\
& S_{p h}=-\left(2.1 \cdot m_{F W}+m_{F D} \cdot C p_{w} 350\right) / 300 \quad 200^{\circ} C \leq T<350^{\circ} C \\
& B_{p h}=2.1 \cdot m_{F W}+C p_{w} 200 \cdot m_{F D} \quad 200^{\circ} C \leq T<350^{\circ} C
\end{aligned}
$$

b) Triangular pdf

The triangular pdf simulation, described in section 3.2 , is implemented using the following steps.

\section{Step 1}

Determine the values of max, min and mod of the specific heat of wood studs at temperatures between $200^{\circ} \mathrm{C}$ and $350^{\circ} \mathrm{C}$, and of $\max , \min$ and mod of the intercept and slope of the specific heat of wood studs at temperatures less than $200^{\circ} \mathrm{C}$ by using Equations 15 and 23 .

$\max 200=1.95 \min 200=1.85$ and mean $200=1.925$ 


$$
\begin{aligned}
\bmod 200 & =3 \times \text { mean } 200-\max 200-\min 200 \\
& =3 \times 1.925-1.95-1.85=1.975
\end{aligned}
$$

$\max 350=1.45 \min 350=1.22$ and mean $350=1.3075$

$$
\begin{aligned}
\bmod 350 & =3 \times \text { mean } 350-\max 350-\min 350 \\
& =3 x 1.3075-1.45-1.22=1.2525
\end{aligned}
$$

$$
\begin{aligned}
& \max B_{p h}=1.75 \quad \min B_{p h}=1.11 \text { and } \\
& \operatorname{mean} B_{p h}=1.337
\end{aligned}
$$

$\bmod B_{p h}=3 x 1.337-1.75-1.11=1.151$

$\max S_{p h}=5.5 \min S_{p h}=3.0$ and $\operatorname{mean} S_{p h}=4.444$

$$
\begin{array}{r}
\bmod S_{p h}=3 \times \text { mean } S_{p h}-\max S_{p h}-\min S_{p h} \\
=3 x 4.444-5.5-3.0=4.832
\end{array}
$$

\section{Step 2}

Determine the values of the specific heat of wood studs at temperatures between $200^{\circ} \mathrm{C}$ and $350^{\circ} \mathrm{C}$ and of the intercept and slope of the specific heat of wood studs at temperatures less than $200^{\circ} \mathrm{C}$ by substituting max, min, mode and seed into the triangular random number generator.

$C p_{w} 200=$ TriRandom $(\max 200, \min 200, \bmod 200$, seed $)$

$$
C p_{w} 350=\text { TriRandom }(\max 350, \min 350, \bmod 350, \text { seed })
$$


$B_{p h}=\operatorname{TriRandom}\left(\max B_{p h}, \min B_{p h}, \bmod B_{p h}\right.$, seed $)$

$S_{p h}=\operatorname{TriRandom}\left(\max S_{p h}, \min S_{p h}, \bmod S_{p h}\right.$, seed $)$

where TriRandom (double, double, double, int) is the triangular random number generator.

Step 3

Calculate the specific heat of wood stud when the temperature is less than $200^{\circ} \mathrm{C}$ and the intercept and slope of specific heat curve of wood stud at the elevated temperatures between $200^{\circ} \mathrm{C}$ and $350^{\circ} \mathrm{C}$ by substituting the values calculated at Step 2 into Equations 37 through 39.

c) Lognormal pdf

The lognormal pdf simulation, described in Section 3.3, is implemented using the following steps.

\section{Step 1}

Determine the values of $\mu_{\log }$ and $\sigma_{\log }$ of the specific heat of wood studs at temperature between $200^{\circ} \mathrm{C}$ and $350^{\circ} \mathrm{C}$, and of $\mu_{\log }$ and $\sigma_{\log }$ of the 
intercept and slope of the specific heat of wood studs at temperatures less than $200^{\circ} \mathrm{C}$ by using Equations 28 and 29.

$$
\begin{aligned}
\mu_{\log } 200 & =\frac{1}{N} \sum_{i=N}^{i=1} \log \left(x_{i}\right) \\
& =\frac{1}{4}[3 x \log (1.95)+\log (1.85)]=0.65467
\end{aligned}
$$

$$
\begin{aligned}
\sigma_{\log } 200 & =\frac{1}{N} \sqrt{N \sum_{i=N}^{i=1} \log \left(x_{i}\right)^{2}-\left(\sum_{i=N}^{i=1} \log \left(x_{i}\right)\right)^{2}} \\
& =\frac{1}{4} \sqrt{4 \cdot\left\{3 \cdot[\log (1.95)]^{2}+[\log (1.85)]^{2}\right\}-} \\
& \frac{[3 \cdot \log (1.95)+\log (1.85)]^{2}}{} \\
= & 0.0228
\end{aligned}
$$

$$
\begin{aligned}
\mu_{\log } 350 & =\frac{1}{4}[\log (1.22)+\log (1.26)+\log (1.30)+\log (1.45)] \\
& =0.266
\end{aligned}
$$

$$
\begin{aligned}
\sigma_{\log } 350= & \frac{\frac{1}{4} \sqrt{4 \cdot\left\{[\log (1.22)]^{2}+[\log (1.26)]^{2}+[\log (1.30)]^{2}+[\log (1.45)]^{2}\right\}-}}{[\log (1.22)+\log (1.26)+\log (1.30)+\log (1.45)]^{2}} \\
= & 0.06163
\end{aligned}
$$

$$
\begin{aligned}
\mu_{\log } B_{p h} & =\frac{1}{5}[\log (1.11)+\log (1.125)+\log (1.25)+\log (1.45)+\log (1.75)] \\
& =0.2753 \\
\sigma_{\log } B_{p h} & =\frac{1}{5} \sqrt{5 \cdot\left\{[\log (1.11)]^{2}+[\log (1.125)]^{2}+[\log (1.25)]^{2}+[\log (1.45)]^{2}\right.} \\
& {\left.[\log (1.75)]^{2}\right\}-[\log (1.11)+\log (1.125)+\log (1.25)+\log (1.45)+\log (1.75)]^{2} } \\
& =0.17138
\end{aligned}
$$




$$
\begin{aligned}
\mu_{\log } S_{p h}= & \frac{1}{5}[\log (3.0)+\log (4.2)+\log (4.52)+\log (5.0)+\log (5.5)] \\
= & 1.47128 \\
\sigma_{\log } S_{p h}= & \frac{1}{5} \sqrt{5 \cdot\left\{[\log (3.0)]^{2}+[\log (4.2)]^{2}+[\log (4.52)]^{2}+[\log (5.0)]^{2}\right.} \\
& \frac{\left.[\log (5.5)]^{2}\right\}-[\log (3.0)+\log (4.2)+\log (4.52)+\log (5.0)+\log (5.5)]^{2}}{=} \\
= & 0.20745
\end{aligned}
$$

\section{Step 2}

Generate a standard normal random number.

stdNormal $=$ NRandom $($ seed $)$

where NRandom(int) is the standard normal random number generator.

\section{Step 3}

Determine the values of the specific heat of wood studs at temperatures between $200^{\circ} \mathrm{C}$ and $350^{\circ} \mathrm{C}$ and of the intercept and slope of the specific heat of wood studs at temperatures less than $200^{\circ} \mathrm{C}$ by substituting $\mu_{\log }, \sigma_{\log }$ and seed into the lognormal random number generator.

$C p_{w} 200=\operatorname{LogNRandom}\left(\mu_{\log } 200, \sigma_{\log } 200\right.$, seed $)$

$C p_{w} 350=\log N R a n d o m\left(\mu_{\log } 350, \sigma_{\log } 350\right.$, seed $)$ 
$B_{p h}=\operatorname{LogNRandom}\left(\mu_{\log } B_{p h}, \sigma_{\log } B_{p h}\right.$, seed $)$

$S_{p h}=\operatorname{LogNRandom}\left(\mu_{\log } S_{p h}, \sigma_{\log } S_{p h}\right.$, seed $)$

where LogNRandom (double, double, int) is the lognormal random number generator.

\section{Step 4}

Calculate the specific heat of wood stud when the temperature is less than $200^{\circ} \mathrm{C}$ and the intercept and slope of specific heat curve of wood stud at the elevated temperatures between $200^{\circ} \mathrm{C}$ and $350^{\circ} \mathrm{C}$ by substituting the values calculated at Step 3 into the Equations 37 through 39.

\subsubsection{Thermal Conductivity}

The thermal conductivity of wood-stud wall assembly includes the thermal conductivity of gypsum board, thermal conductivity of wood-studs and thermal conductivity of insulations.

Thermal Conductivity of Gypsum Board 
In WALL2DN, the temperature-dependent thermal conductivity of gypsum boards is shown in Figure 6 [2]. The curve consists of two linear segments; one between $0^{\circ} \mathrm{C}$ and $200^{\circ} \mathrm{C}$ and the other between $200^{\circ} \mathrm{C}$ and $1000^{\circ} \mathrm{C}$, the values of thermal conductivity at these temperature points are:

$$
\begin{array}{ll}
K_{g, 0}=0.18 & T=0^{\circ} C \\
K_{g, 200}=0.08 & T=200^{\circ} C \\
K_{g, 1000}=0.32 & T=1000^{\circ} C
\end{array}
$$

The slope of each segment can be calculated using:

$$
\begin{array}{ll}
S_{G B}=\left(K_{g, 200}-K_{g, 0}\right) / 200 & \text { for } T \leq 200^{\circ} C \\
S_{G B}=\left(K_{g, 1000}-K_{g, 200}\right) / 800 & \text { for } 200^{\circ} C<T \leq 1000^{\circ} C
\end{array}
$$

The temperature-dependent thermal conductivity at elevated temperatures will be determined using the equations below.

$$
\begin{aligned}
K_{g} & =\left[\left(K_{g, 200}-K_{g, 0}\right) / 200\right] \cdot T+K_{g, 0} \quad \text { for } T \leq 200^{\circ} C \\
& =-0.0005 \cdot T+0.18 \quad(42) \\
K_{g} & =\left[\left(K_{g, 1000}-K_{g, 200}\right) / 800\right] \cdot(T-1000)+K_{g, 1000} \quad \text { for } 200^{\circ} C<T \leq 1000^{\circ} C \\
& =0.0003 \cdot(T-1000)+0.32 \quad(43)
\end{aligned}
$$


Figure 24 presents the thermal conductivity values of two gypsum boards, 12.7 mm Type $\mathrm{C}$ and $15.8 \mathrm{~mm}$ Type $\mathrm{X}$, from tests conducted by Forintek at the National Research Council of Canada [1]. From this figure, the following values of thermal conductivity at three temperature points of $0^{\circ} \mathrm{C}, 200^{\circ} \mathrm{C}$ and $1000^{\circ} \mathrm{C}$ can be summarized in the subsets:

$$
\begin{array}{ll}
K_{g, 0}=\{0.18,0.23,0.24,0.25\} & T=0^{\circ} \mathrm{C} \\
K_{g, 200}=\{0.08,0.12,0.124,0.132\} & T=200^{\circ} \mathrm{C} \\
K_{g, 1000}=\{0.32,0.25,0.315,0.21\} & T=1000^{\circ} \mathrm{C}
\end{array}
$$

The steps used to establish the three probability distribution functions (normal, triangle and lognormal) for thermal conductivity of gypsum board are as follows.

\section{a) Normal pdf}

The normal pdf simulation, described in section 3.1 , can be obtained using the next three steps.

\section{Step 1}

Determine the values of the mean and standard deviation of the thermal conductivity of gypsum boards at temperatures 0,200 and $1000^{\circ} \mathrm{C}$ using Equations 15 through 17. 


$$
\begin{aligned}
\operatorname{meanK}_{g, 0} & =\frac{1}{N} \sum_{i=N}^{i=1} x_{i} \\
& =\frac{1}{4}(0.18+0.23+0.24+0.25)=0.225
\end{aligned}
$$

$$
\begin{aligned}
\operatorname{variance}_{g, 0} & =\frac{1}{N} \sum_{i=N}^{i=1}\left(x_{i}-\text { mean }_{g, 0}\right)^{2} \\
& =\frac{1}{4}\left[(0.18-0.225)^{2}+(0.23-0.225)^{2}+(0.24-0.225)^{2}+(0.25-0.225)^{2}\right] \\
& =7.25 \times 10^{-4}
\end{aligned}
$$

$$
\begin{aligned}
& \text { stdevK } K_{g, 0}=\sqrt{\text { variance } K_{g, 0}} \\
& =\sqrt{7.25 \times 10^{-4}}=0.026926 \\
& \text { meanK }_{g, 200}=\frac{1}{4}(0.08+0.12+0.124+0.132)=0.114 \\
& \text { variance }_{g, 200}=\frac{1}{4}\left[(0.08-0.114)^{2}+(0.12-0.114)^{2}+\right. \\
& \left.(0.124-0.114)^{2}+(0.132-0.114)^{2}\right] \\
& =4.04 \times 10^{-4}
\end{aligned}
$$

stdevK $K_{g, 200}=\sqrt{4.04 \times 10^{-4}}=0.0201$

$\operatorname{meanK}_{g, 1000}=\frac{1}{4}(0.32+0.25+0.315+0.21)=0.27375$

$$
\begin{aligned}
\text { varianceK }_{g, 1000} & =\frac{1}{4}\left[(0.32-0.27375)^{2}+(0.25-0.27375)^{2}+\right. \\
& \left.(0.315-0.27375)^{2}+(0.21-0.27375)^{2}\right] \\
& =2.117 \times 10^{-3}
\end{aligned}
$$


$\operatorname{stdevK}_{g, 1000}=\sqrt{2.117 \times 10^{-3}}=0.046$

\section{Step 2}

Determine the values of the thermal conductivity of gypsum boards at temperatures 0,200 and $1000^{\circ} \mathrm{C}$ by substituting the mean, standard deviation and seed into the normal random number generator.

$K_{g, 0}=\operatorname{DNRandom}\left(\right.$ meanK $_{g, 0}$, stdev $K_{g, 0}$, seed $)$

$K_{g, 200}=\operatorname{DNRandom}\left(\right.$ mean $K_{g, 200}$, stdev $K_{g, 200}$, seed $)$

$K_{g, 1000}=D N R a n d o m\left(\right.$ mean $K_{g, 1000}$, stdev $K_{g, 1000}$, seed $)$

where DNRandom(double, double, int) is the normal random number generator.

\section{Step 3}

Calculate the thermal conductivity of gypsum boards at the temperatures less than $200^{\circ} \mathrm{C}$ and at temperatures between $200^{\circ} \mathrm{C}$ and $1000^{\circ} \mathrm{C}$ by substituting the values calculated at Step 2 into the equations used in the WALL2DN demonstrated in the previous portion of this section.

$$
K_{g}=\left[\left(K_{g, 200}-K_{g, 0}\right) / 200\right] \cdot T+K_{g, 0} \quad T \leq 200^{\circ} C
$$




$$
K_{g}=\left[\left(K_{g, 1000}-K_{g, 200}\right) / 800\right] \cdot(T-1000)+K_{g, 1000} \quad 200^{\circ} C<T \leq 1000^{\circ} C
$$

b) Triangular pdf

The triangular pdf simulation, described in section 3.2 , can be obtained using the next three steps.

\section{Step 1}

Determine the values of $\max , \min$ and $\bmod$ of the thermal conductivity of gypsum boards at temperatures 0,200 and $1000^{\circ} \mathrm{C}$ by using Equations 15 and 23.

$$
\begin{aligned}
& \max K_{g, 0}=0.25 \min K_{g, 0}=0.18 \text { and mean } K_{g, 0}=0.225 \\
& \begin{aligned}
\bmod K_{g, 0} & =3 \times \text { mean }_{g, 0}-\max K_{g, 0}-\min K_{g, 0} \\
& =3 x 0.225-0.25-0.18=0.245 \\
\max K_{g, 200} & =0.132 \min K_{g, 200}=0.08 \text { and }{\text { mean } K_{g, 200}=0.114}^{\bmod K_{g, 200}}=3 \times \text { mean } K_{g, 200}-\max K_{g, 200}-\min K_{g, 200} \\
& =3 x 0.114-0.132-0.08=0.13
\end{aligned}
\end{aligned}
$$

$\max K_{g, 1000}=0.32 \min K_{g, 1000}=0.21$ and $\operatorname{meanK} K_{g, 1000}=0.27375$ 

$\begin{aligned} \bmod K_{g, 1000} & =3 \times \operatorname{mean} K_{g, 1000}-\max K_{g, 1000}-\min K_{g, 1000} \\ & =3 x 0.27375-0.32-0.21=0.29125\end{aligned}$

Step 2

Determine the values of the thermal conductivity of gypsum boards at temperatures 0,200 and $1000^{\circ} \mathrm{C}$ by substituting the max, min, mod and seed into the triangular random number generator.

$K_{g, 0}=\operatorname{TriRandom}\left(\max K_{g, 0}, \min K_{g, 0}, \bmod K_{g, 0}\right.$, seed $)$

$K_{g, 200}=\operatorname{TriRandom}\left(\max K_{g, 200}, \min K_{g, 200}, \bmod K_{g, 200}\right.$, seed $)$

$K_{g, 1000}=\operatorname{TriRandom}\left(\max K_{g, 1000}, \min K_{g, 1000}, \bmod K_{g, 1000}\right.$, seed $)$

where TriRandom (double, double, double, int) is the triangular random number generator.

\section{Step 3}

Calculate the thermal conductivity of gypsum boards at temperatures less than $200^{\circ} \mathrm{C}$ and at temperatures between $200^{\circ} \mathrm{C}$ and $1000^{\circ} \mathrm{C}$ by substituting the values calculated at Step 2 in the Equations 44 and 45 . 
c) Lognormal pdf

The lognormal pdf simulation, described in section 3.3 , can be obtained using the next four steps.

\section{Step 1}

Determine the values of $\mu_{\log }$ and $\sigma_{\log }$ of the thermal conductivity of gypsum boards at temperatures 0,200 and $1000^{\circ} \mathrm{C}$ by using Equations 28 and 29 .

$$
\begin{aligned}
\mu_{\log } K_{g, 0} & =\frac{1}{N} \sum_{i=N}^{i=1} \log \left(x_{i}\right) \\
& =\frac{1}{4}[\log (0.18)+\log (0.23)+\log (0.24)+\log (0.25)] \\
& =-1.49947
\end{aligned}
$$

$$
\begin{aligned}
\sigma_{\log } K_{g, 0}= & \frac{1}{N} \sqrt{N \sum_{i=N}^{i=1} \log \left(x_{i}\right)^{2}-\left(\sum_{i=N}^{i=1} \log \left(x_{i}\right)\right)^{2}} \\
= & \frac{1}{4} \sqrt{4 \cdot\left\{[\log (0.18)]^{2}+[\log (0.23)]^{2}+[\log (0.24)]^{2}+[\log (0.25)]^{2}\right\}-} \\
& \frac{[\log (0.18)+\log (0.23)+\log (0.24)+\log (0.25)]^{2}}{=} \\
= & 0.127767
\end{aligned}
$$

$$
\begin{aligned}
\mu_{\log } K_{g, 200} & =\frac{1}{4}[\log (0.08)+\log (0.12)+\log (0.124)+\log (0.132)] \\
& =-2.1896
\end{aligned}
$$




$$
\begin{aligned}
& \sigma_{\log } K_{g, 200}=\frac{1}{4} \sqrt{4 \cdot\left\{[\log (0.08)]^{2}+[\log (0.12)]^{2}+[\log (0.124)]^{2}+[\log (0.132)]^{2}\right\}-} \\
& \overline{[\log (0.08)+\log (0.12)+\log (0.124)+\log (0.132)]^{2}} \\
& =0.197
\end{aligned}
$$

$$
\begin{aligned}
\mu_{\log } K_{g, 1000}= & \frac{1}{4}[\log (0.32)+\log (0.25)+\log (0.315)+\log (0.21)] \\
= & -1.3104 \\
\sigma_{\log } K_{g, 1000}= & \frac{1}{4} \sqrt{4 \cdot\left\{[\log (0.32)]^{2}+[\log (0.25)]^{2}+[\log (0.315)]^{2}+[\log (0.21)]^{2}\right\}-} \\
& \frac{[\log (0.32)+\log (0.25)+\log (0.315)+\log (0.21)]^{2}}{=} \\
= & 0.17435
\end{aligned}
$$

Step 2

Generate a standard normal random number.

stdNormal $=$ NRandom $($ seed $)$

where NRandom(int) is the standard normal random number generator.

\section{Step 3}

Determine the values of thermal conductivity of gypsum boards at temperatures 0,200 and $1000^{\circ} \mathrm{C}$ by substituting $\mu_{\log }, \sigma_{\log }$ and seed into the lognormal random number generator. 


$$
\begin{aligned}
& K_{g, 0}=\log N \text { Random }\left(\mu_{\log } K_{g, 0}, \sigma_{\log } K_{g, 0}, \text { seed }\right) \\
& K_{g, 200}=\operatorname{LogNRandom}\left(\mu_{\log } K_{g, 200}, \sigma_{\log } K_{g, 200}, \text { seed }\right) \\
& K_{g, 1000}=\operatorname{LogNRandom}\left(\mu_{\log } K_{g, 1000}, \sigma_{\log } K_{g, 1000}, \text { seed }\right)
\end{aligned}
$$

where, LogNRandom (double, double, int) is the lognormal random number generator.

\section{Step 4}

Calculate the thermal conductivity of gypsum boards at temperatures less than $200^{\circ} \mathrm{C}$ and at temperatures between $200^{\circ} \mathrm{C}$ and $1000^{\circ} \mathrm{C}$ by substituting the values calculated in Step 3 into the Equations 44 and 45.

\section{Thermal Conductivity of Wood-Studs}

The summarized curve of temperature-dependent thermal conductivity of woodstuds used in WALL2DN is shown in Figure 6 [2]. The curve is separated as three linear segments at temperature points of $0^{\circ} \mathrm{C}, 200^{\circ} \mathrm{C}, 350^{\circ} \mathrm{C}$ and $800^{\circ} \mathrm{C}$. The values of thermal conductivity at these temperature points are: 


$$
\begin{array}{rlrl}
K_{w, 0} & =0.112(\text { SPF }) & T & =0^{\circ} \mathrm{C} \\
& =0.127 \text { (Doug Fir }) & \\
& =0.141(\text { S.Pine }) & & \\
K_{w, 200} & =0.178 & T & =200^{\circ} \mathrm{C} \\
K_{w, 350} & =0.085 & T & =350^{\circ} \mathrm{C} \\
K_{w, 800} & =0.16 & T & =800^{\circ} \mathrm{C}
\end{array}
$$

The slope of each linear segment can be calculated as follows:

$$
\begin{array}{ll}
S_{W S-1}=\left(K_{w, 200}-K_{w, 0}\right) / 200 & \text { for } T \leq 200^{\circ} C \\
S_{W S-2}=\left(K_{w, 350}-K_{w, 200}\right) / 150 & \text { for } 200^{\circ} C<T \leq 350^{\circ} C \\
S_{W S-3}=\left(K_{w, 800}-K_{w, 350}\right) / 1073 & \text { for } 350^{\circ} C<T \leq 800^{\circ} C
\end{array}
$$

The temperature-dependent thermal conductivity, $\mathrm{Kw}$, at elevated temperatures can be determined using:

$$
\begin{aligned}
& K_{w}=K_{w, 0}+S_{W S-1} \cdot T \quad \text { for } T \leq 200^{\circ} C \quad \\
& K_{w}=\left[\left(K_{w, 200}-200 \cdot S_{W S-2}\right)+T \cdot S_{W S-2}\right]+S_{W S-3} \cdot(T+273)^{3} \cdot(T-200) / 150 \\
& \text { for } 200^{\circ} C<T \leq 350^{\circ} C \\
& K_{w}=K_{w, 350}+S_{W S-3} \cdot(T+273)^{3} \quad \text { for } 350^{\circ} C<T \leq 800^{\circ} C
\end{aligned}
$$

Additional curves of thermal conductivity of wood-stud are presented in Figure 25 [38]. Based on the curves from Figures 6 and 25, values of thermal 
conductivity at temperatures of $0^{\circ} \mathrm{C}, 200^{\circ} \mathrm{C}, 350^{\circ} \mathrm{C}$ and $800^{\circ} \mathrm{C}$ can be obtained and summarized in the subsets listed below:

$$
\begin{array}{ll}
K_{w, 0}=\{0.125,0.12,0.11,(0.112 \text { or } 0.127 \text { or } 0.141)\} & T=0^{\circ} C \\
K_{w, 200}=\{0.18,0.14,0.19,0.178\} & T=200^{\circ} C \\
K_{w, 350}=\{0.125,0.059,0.045,0.085\} & T=350^{\circ} C \\
K_{w, 800}=\{0.168,0.132,0.078,0.16\} & T=800^{\circ} C
\end{array}
$$

Using these curves, Monte Carlo methods are used to generate a variety of thermal conductivity values for wood studs.

The steps used to establish the three probability distribution functions (normal, triangular and lognormal) for the thermal conductivity of wood studs are the following.

a) Normal pdf

The normal pdf simulation is obtained using the following next three steps.

\section{Step 1}

Determine the values of the mean and standard deviation of the thermal conductivity of wood studs at temperatures $0,200,350$ and 
$800^{\circ} \mathrm{C}$ by using Equations 15 through 17 . The thermal conductivity of SPF wood species will be calculated to demonstrate how to determine the parameters of the normal pdf.

$$
\begin{aligned}
& \text { mean }_{w, 0}= \frac{1}{N} \sum_{i=N}^{i=1} x_{i} \\
&= \frac{1}{4}(0.125+0.12+0.11+0.112)=0.11675 \\
& \text { variance }_{w, 0}= \frac{1}{N} \sum_{i=N}^{i=1}\left(x_{i}-\text { meanK }_{w, 0}\right)^{2} \\
&= \frac{1}{4}\left[(0.125-0.11675)^{2}+(0.12-0.11675)^{2}+\right. \\
&\left.(0.11-0.11675)^{2}+(0.112-0.11675)^{2}\right] \\
&= \\
&=3.669 \times 10^{-5}
\end{aligned}
$$

$$
\begin{aligned}
& \begin{aligned}
\text { stdevK }_{w, 0}= & \sqrt{\text { var ianceK }_{w, 0}} \\
= & \sqrt{3.669 \times 10^{-5}}=0.006057 \\
\text { meanK }_{w, 200}= & \frac{1}{4}(0.18+0.14+0.19+0.178)=0.172 \\
\text { varianceK }_{w, 200}= & \frac{1}{4}\left[(0.18-0.172)^{2}+(0.14-0.172)^{2}+\right. \\
& \left.(0.19-0.172)^{2}+(0.178-0.172)^{2}\right] \\
= & 3.62 \times 10^{-4}
\end{aligned}
\end{aligned}
$$

stdev $K_{w, 200}=\sqrt{3.62 \times 10^{-4}}=0.01903$

$$
\text { meanK }_{w, 350}=\frac{1}{4}(0.125+0.059+0.045+0.085)=0.0785
$$




$$
\begin{aligned}
& \text { variance } K_{w, 350}=\frac{1}{4}\left[(0.125-0.0785)^{2}+(0.059-0.0785)^{2}+\right. \\
& \left.(0.045-0.0785)^{2}+(0.085-0.0785)^{2}\right] \\
& =9.266 \times 10^{-4} \\
& \operatorname{stdevK}_{w, 350}=\sqrt{9.266 \times 10^{-4}}=0.03044 \\
& \text { meanK }_{w, 800}=\frac{1}{4}(0.168+0.132+0.078+0.16)=0.1345 \\
& \text { variance }_{w, 800}=\frac{1}{4}\left[(0.168-0.1345)^{2}+(0.132-0.1345)^{2}+\right. \\
& \left.(0.078-0.1345)^{2}+(0.16-0.1345)^{2}\right] \\
& =1.243 \times 10^{-3}
\end{aligned}
$$

\section{Step 2}

Determine the values of thermal conductivity of wood studs at temperatures $0,200,350$ and $800^{\circ} \mathrm{C}$ by substituting the mean, standard deviation and seed into the normal random number generator.

$$
\begin{aligned}
& K_{w, 0}=D N R a n d o m\left(\text { meanK }_{w, 0}, \text { stdevK } K_{w, 0}, \text { seed }\right) \\
& K_{w, 200}=D N R a n d o m\left(\text { mean } K_{w, 200}, \text { stdev } K_{w, 200}, \text { seed }\right) \\
& K_{w, 350}=D N R a n d o m\left(\text { mean } K_{w, 350}, \text { stdev } K_{w, 350}, \text { seed }\right)
\end{aligned}
$$


$K_{w, 800}=\operatorname{DNRandom}\left(\right.$ mean $_{w, 800}$, stdev $K_{w, 800}$, seed $)$

where DNRandom (double, double, int) is the normal random number generator.

\section{Step 3}

Determine the slopes of each segment of thermal conductivity curve, and then calculate the thermal conductivity of wood studs at temperatures less than $200^{\circ} \mathrm{C}$, at temperatures between $200^{\circ} \mathrm{C}$ and $350^{\circ} \mathrm{C}$ and at temperatures greater than $350^{\circ} \mathrm{C}$ respectively by substituting the values calculated in Step 2 into the Equations 46 through 51 .

b) Triangular pdf

The triangular pdf simulation is obtained using the following three steps.

\section{Step 1}

Determine the values of $\max , \min$ and $\bmod$ of the thermal conductivity of wood studs at temperatures of $0,200,350$ and $800^{\circ} \mathrm{C}$ by using the Equations 15 and 23 . The thermal conductivity of SPF wood species will be calculated to demonstrate how to determine the parameters of the triangular pdf. 
$\max K_{w, 0}=0.125 \min K_{w, 0}=0.11$ and $\operatorname{mean} K_{w, 0}=0.11675$

$\bmod K_{w, 0}=3 \times \operatorname{meanK}_{w, 0}-\max K_{w, 0}-\min K_{w, 0}$

$$
=3 x 0.11675-0.125-0.11=0.11525
$$

$\max K_{w, 200}=0.19 \min K_{w, 200}=0.14$ and $\operatorname{mean} K_{w, 200}=0.172$

$\bmod K_{w, 200}=3 x 0.172-0.19-0.14=0.186$

$\max K_{w, 350}=0.125 \min K_{w, 350}=0.045$ and $\operatorname{mean} K_{w, 350}=0.0785$

$\bmod K_{w, 350}=3 x 0.0785-0.125-0.045=0.0655$

$\max K_{w, 800}=0.168 \min K_{w, 800}=0.078$ and $\operatorname{meanK} K_{w, 800}=0.1345$

$\bmod K_{w, 800}=3 x 0.1345-0.168-0.078=0.1575$

\section{Step 2}

Determine the values of thermal conductivity of wood studs at temperatures of $0,200,350$ and $800^{\circ} \mathrm{C}$ by substituting the max, min, mod and seed into the triangular random number generator.

$K_{w, 0}=\operatorname{TriRandom}\left(\max K_{w, 0}, \min K_{w, 0}, \bmod K_{w, 0}\right.$, seed $)$

$K_{w, 200}=\operatorname{TriRandom}\left(\max K_{w, 200}, \min K_{w, 200}, \bmod K_{w, 200}\right.$, seed $)$ 
$K_{w, 350}=\operatorname{TriRandom}\left(\max K_{w, 350}, \min K_{w, 350}, \bmod K_{w, 350}\right.$, seed $)$

$X K 4=$ TriRandom $(\max X K 4, \min X K 4, \bmod X K 4$, seed $)$

where TriRandom (double, double, double, int) is the triangular random number generator.

\section{Step 3}

Determine the slopes of each segment of thermal conductivity curve, and calculate the thermal conductivity of wood stud at elevated temperatures by using the Equations 46 through 51 .

c) Lognormal pdf

The lognormal pdf simulation is implemented using the following four steps.

\section{Step 1}

Determine values of $\mu_{\log }$ and $\sigma_{\log }$ of the thermal conductivity of wood studs at temperatures $0,200,350$ and $800^{\circ} \mathrm{C}$ by using Equations 28 and 29. The thermal conductivity of SPF wood species will be calculated to demonstrate how to determine the parameters of the lognormal pdf. 


$$
\begin{aligned}
\mu_{\log } K_{w, 0} & =\frac{1}{N} \sum_{i=N}^{i=1} \log \left(x_{i}\right) \\
& =\frac{1}{4}[\log (0.125)+\log (0.12)+\log (0.11)+\log (0.112)] \\
& =-2.149
\end{aligned}
$$

$$
\begin{aligned}
& \sigma_{\log } K_{w, 0}=\frac{1}{N} \sqrt{N \sum_{i=N}^{i=1} \log \left(x_{i}\right)^{2}-\left(\sum_{i=N}^{i=1} \log \left(x_{i}\right)\right)^{2}} \\
& =\frac{1}{4} \sqrt{4 \cdot\left\{[\log (0.125)]^{2}+[\log (0.12)]^{2}+[\log (0.11)]^{2}+[\log (0.112)]^{2}\right\}} \\
& \overline{[\log (0.125)+\log (0.12)+\log (0.11)+\log (0.112)]^{2}} \\
& =0.0541
\end{aligned}
$$

$$
\begin{aligned}
\mu_{\log } K_{w, 200}= & \frac{1}{4}[\log (0.18)+\log (0.14)+\log (0.19)+\log (0.178)] \\
& =-1.7669 \\
\sigma_{\log } K_{w, 200}= & \frac{1}{4} \sqrt{4 \cdot\left\{[\log (0.18)]^{2}+[\log (0.14)]^{2}+[\log (0.19)]^{2}+[\log (0.178)]^{2}\right\}-} \\
& {[\log (0.18)+\log (0.14)+\log (0.19)+\log (0.178)]^{2} } \\
= & 0.117686 \\
\mu_{\log } K_{w, 350}= & \frac{1}{4}[\log (0.125)+\log (0.059)+\log (0.045)+\log (0.085)] \\
& =-2.619 \\
\sigma_{\log } K_{w, 350}= & \frac{1}{4} \sqrt{4 \cdot\left\{[\log (0.125)]^{2}+[\log (0.059)]^{2}+[\log (0.045)]^{2}+[\log (0.085)]^{2}\right\}-} \\
& \frac{[\log (0.125)+\log (0.059)+\log (0.045)+\log (0.085)]^{2}}{0.38465}
\end{aligned}
$$




$$
\begin{aligned}
\mu_{\log } K_{w, 800}= & \frac{1}{4}[\log (0.168)+\log (0.132)+\log (0.078)+\log (0.16)] \\
= & -2.048 \\
\sigma_{\log } K_{w, 800}= & \frac{1}{4} \sqrt{4 \cdot\left\{[\log (0.168)]^{2}+[\log (0.132)]^{2}+[\log (0.078)]^{2}+[\log (0.16)]^{2}\right\}-} \\
& \frac{[\log (0.168)+\log (0.132)+\log (0.078)+\log (0.16)]^{2}}{=} \\
= & 0.304
\end{aligned}
$$

\section{Step 2}

Generate a standard normal random number.

stdNormal $=$ NRandom $($ seed $)$

where NRandom(int) is the standard normal random number generator.

\section{Step 3}

Determine the values of the thermal conductivity of wood studs at temperatures $0,200,350$ and $800^{\circ} \mathrm{C}$ by substituting $\mu_{\log }, \sigma_{\log }$ and seed into the lognormal random number generator.

$$
\begin{aligned}
& K_{w, 0}=\log N \text { Random }\left(\mu_{\log } K_{w, 0}, \sigma_{\log } K_{w, 0}, \text { seed }\right) \\
& K_{w, 200}=\log N \text { Random }\left(\mu_{\log } K_{w, 200}, \sigma_{\log } K_{w, 200}, \text { seed }\right) \\
& K_{w, 350}=\log N \text { Random }\left(\mu_{\log } K_{w, 350}, \sigma_{\log } K_{w, 350}, \text { seed }\right)
\end{aligned}
$$


$K_{w, 800}=\log N$ Random $\left(\mu_{\log } K_{w, 800}, \sigma_{\log } K_{w, 800}\right.$, seed $)$

where LogNRandom (double, double, int) is the lognormal random number generator.

\section{Step 4}

Determine the slopes of each segment of the thermal conductivity curve, and calculate the thermal conductivity of wood stud at elevated temperatures by substituting the values calculated in Step 3 into the Equations 46 through 51.

\section{Thermal Conductivity of Insulations}

In accordance with the introduction in Section 3.4.2.1 and Equations 7 and 8 in Section 2.1 .3 of this thesis, the thermal conductivity of glass-fibre and mineralwool are a function of temperature and density, and function of temperature only, respectively. The density of glass-fibre in WALL2DN is designated by users. Therefore, no Monte Carlo method is applied for the thermal conductivity of insulations in this study. 


\subsubsection{Gypsum Board Shrinkage}

In WALL2DN, the shrinkage of gypsum board was summarized as a function of temperature [3] shown as a solid curve in Figure 26. The curve has been divided into two linear segments:

$$
\begin{array}{lc}
S P_{G B}=(2.4 / 900) \cdot(T-100) & \text { for } 100^{\circ} C<T<700^{\circ} C \\
S P_{G B}=(8.2 / 270) \cdot(T-700)+1.6 & \text { for } T \geq 700^{\circ} C
\end{array}
$$

where $S P_{G B}$ is shrinkage percentage of gypsum board, 2.4/900 and 8.2/270 are the slopes of the two segments, respectively. 1.6 is the intercept at temperature $700^{\circ} \mathrm{C}$, and $\mathrm{T}$ is temperature.

In accordance with the survey in Section 2.1.1 of this study, Figure 26 and WALL2DN programming code, slopes of the curves for shrinkage percentage of gypsum board can be obtained as follows:

$$
\begin{array}{rr}
\text { Slope } 700=\{1.6267 / 900,1.92 / 900,2.2267 / 900,2.373 / 900,2.52 / 900 & \\
\text { Slope } 900=\{5.22 / 270,7.61 / 270,9.57 / 270\} & \text { for } 100^{\circ} C<T<700^{\circ} C \\
& \text { for } T \geq 700^{\circ} C
\end{array}
$$

The values of slope and intercept shown above can be used to calculate the initiating parameters (i.e., mean, standard deviation) of the three Monte Carlo simulation methods. 
The steps used to establish the three probability distribution functions (normal, triangular and lognormal) and the shrinkage percentage of gypsum board can be implemented as follows. For the purpose of simplifying the random number generation, the sets of Slope 700 and Slope 900 are simplified by removing the constants 900 and 270 :

Slope $700=\{1.6267,1.92,2.2267,2.373,2.52,2.4\}$

Slope $900=\{5.22,7.61,9.57,8.2\}$

a) Normal pdf

The normal pdf simulation is implemented using the following three steps.

\section{Step 1}

Determine the values of mean and standard deviation of the slopes of shrinkage percentage of gypsum boards at temperatures of 700 and $900^{\circ} \mathrm{C}$ by using Equations 15 through 17.

$$
\begin{aligned}
& \text { meanSlope } 700=\frac{1}{N} \sum_{i=N}^{i=1} x_{i} \\
& =\frac{1}{6}(1.6267+1.92+2.2267+2.373+2.523+2.4)=2.1782
\end{aligned}
$$




$$
\begin{aligned}
& \begin{aligned}
& \text { varianceSlope } 700=\frac{1}{N} \sum_{i=N}^{i=1}\left(x_{i}-\text { meanSlope } 700\right)^{2} \\
&= \frac{1}{6}\left[(1.6267-2.1782)^{2}+(1.92-2.1782)^{2}+(2.2267-2.1782)^{2}+\right. \\
&\left.(2.373-2.1782)^{2}+(2.523-2.1782)^{2}+(2.4-2.1782)^{2}\right]=0.0965
\end{aligned} \\
& \begin{aligned}
\text { stdevSlope } 700 & =\sqrt{\text { varianceSlope } 700} \\
= & \sqrt{0.0965}=0.3107
\end{aligned}
\end{aligned}
$$

meanSlope $900=\frac{1}{4}(5.22+7.61+9.57+8.2)=7.65$

$$
\begin{array}{r}
\text { varianceSlope } 900=\frac{1}{4}\left[(5.22-7.65)^{2}+(7.61-7.65)^{2}+\right. \\
\left.(9.57-7.65)^{2}+(8.2-7.65)^{2}\right]=2.47385
\end{array}
$$

stdevSlope $900=\sqrt{2.47385}=1.5728$

\section{Step 2}

Determine the slopes of shrinkage percentage of gypsum boards at temperatures of 700 and $900^{\circ} \mathrm{C}$ by substituting the mean, standard deviation and seed into the normal random number generator.

slope $700=$ DNRandom $($ meanSlope 700, stdevSlope 700, seed $)$

slope $900=$ DNRandom $($ meanSlope 900, stdevSlope 900, seed $)$

where DNRandom (double, double, int) is the normal random number generator. 


\section{Step 3}

Calculate the shrinkage percentage, $S P_{G B}$, of gypsum boards at temperatures less than $700^{\circ} \mathrm{C}$ and more than $700^{\circ} \mathrm{C}$ by substituting the values calculated in Step 2 into the equations below.

$$
\begin{array}{lr}
S P_{G B}=(\text { slope } 700 / 900) \cdot(T-100) & \text { for } T<700^{\circ} C \\
S P_{G B}=(\text { slope } 900 / 270) \cdot(T-700)+S P_{B G} 700 & \text { for } T \geq 700^{\circ} C
\end{array}
$$

b) Triangular pdf

The triangular pdf simulation is obtained using the following three steps.

\section{Step 1}

Determine the values of max, min and mod of the slopes of shrinkage percentage of gypsum boards at temperatures of 700 and $900^{\circ} \mathrm{C}$ by using the Equations 15 and 23.

$$
\begin{aligned}
& \max \text { Slope } 700=2.52 \min \text { Slope } 700=1.6267 \text { and } \\
& \text { meanSlope } 700=2.1782 \\
& \bmod \text { Slope } 700=3 \times \text { meanSlope } 700-\max \text { Slope } 700-\min \text { Slope } 700 \\
& \quad=3 \times 2.1782-2.52-1.6267=2.3879
\end{aligned}
$$


$\max$ Slope $900=9.57 \min$ Slope $900=5.22$ and

meanSlope $700=7.65$

$\bmod$ Slope $900=3 \times$ meanSlope $900-\max$ Slope $900-\min$ Slope 900

$=3 \times 7.65-9.57-5.22=8.16$

\section{Step 2}

Determine the slopes of shrinkage percentage of gypsum boards at temperatures of 700 and $900^{\circ} \mathrm{C}$ by substituting the max, min, mod and seed into the triangular random number generator.

slope $700=$ TriRandom $(\max$ Slope $700, \min$ Slope $700, \bmod$ Slope 700, seed $)$

slope $900=$ TriRandom $(\max$ Slope $900, \min$ Slope $900, \bmod$ Slope 900, seed $)$

where TriRandom (double, double, double, int) is the triangular random number generator.

\section{Step 3}

Calculate the shrinkage percentage, $S P_{G B}$, of gypsum boards at temperatures less than $700^{\circ} \mathrm{C}$ and more than $700^{\circ} \mathrm{C}$ by substituting the values calculated in Step 2 into the Equations 54 and 55. 
c) Lognormal pdf

The lognormal pdf simulation is realized using the following four steps.

\section{Step 1}

Determine the values of $\mu_{\log }$ and $\sigma_{\log }$ of slopes of shrinkage percentage of gypsum boards at temperatures of 700 and $900^{\circ} \mathrm{C}$ using Equations 28 and 29.

$$
\begin{aligned}
& \mu_{\log } X \text { Slope } 700=\frac{1}{N} \sum_{i=N}^{i=1} \log \left(x_{i}\right) \\
& =\frac{1}{6}[\log (1.6267)+\log (1.92)+\log (2.2267)+ \\
& \log (2.373)+\log (2.52)+\log (2.4)] \\
& =0.7672
\end{aligned}
$$

$$
\begin{aligned}
\sigma_{\log } \text { Slope } & 700=\frac{1}{N} \sqrt{N \sum_{i=N}^{i=1} \log \left(x_{i}\right)^{2}-\left(\sum_{i=N}^{i=1} \log \left(x_{i}\right)\right)^{2}} \\
= & \frac{1}{6} \sqrt{6 \cdot\left\{[\log (1.6267)]^{2}+[\log (1.92)]^{2}+[\log (2.2267)]^{2}+[\log (2.373)]^{2}+\right.} \\
& \frac{\left.[\log (2.52)]^{2}+[\log (2.4)]^{2}\right\}-[\log (1.6267)+\log (1.92)+\log (2.2267)+}{\log (2.373)+\log (2.52)+\log (2.4)]^{2}}=0.1522
\end{aligned}
$$

$$
\begin{aligned}
\mu_{\log } \text { Slope } 900 & =\frac{1}{4}[\log (5.22)+\log (7.61)+\log (9.57)+\log (8.2)] \\
& =2.0112
\end{aligned}
$$




$$
\begin{aligned}
\sigma_{\log } \text { Slope } 900=\frac{1}{4} \sqrt{4 \cdot\left\{[\log (5.22)]^{2}+[\log (7.61)]^{2}+[\log (9.57)]^{2}+[\log (8.2)]^{2}\right\}-} & \frac{[\log (5.22)+\log (7.61)+\log (9.57)+\log (8.2)]^{2}}{} \\
= & 0.223
\end{aligned}
$$

\section{Step 2}

Generate a standard normal random number.

stdNormal $=$ NRandom $($ seed $)$

where NRandom (int) is the standard normal random number generator.

\section{Step 3}

Determine the slopes of shrinkage percentage of gypsum boards at temperatures of 700 and $900^{\circ} \mathrm{C}$ by substituting $\mu_{\log }, \sigma_{\log }$ and seed into the lognormal random number generator.

slope $700=$ LogNRandom $\mu_{\log }$ Slope $700, \sigma_{\log }$ Slope 700, seed $)$

slope $900=\log N$ Random $\left(\mu_{\log }\right.$ Slope $900, \sigma_{\log }$ Slope 900, seed $)$

where LogNRandom (double, double, int) is the lognormal random number generator.

\section{Step 4}


Calculate the shrinkage percentage, $S P_{G B}$, of gypsum boards at temperatures less than $700^{\circ} \mathrm{C}$ and more than $700^{\circ} \mathrm{C}$ by substituting the values calculated in Step 3 into the Equations 54 and 55.

In accordance with the discussions above, the established relationships between the three Monte Carlo simulation methods and the temperature-dependent properties of wood framed wall assemblies need to be programmed in WALL2DN-MC.

\subsection{Solution Procedure}

The program in the WALL2DN-MC model is designed primarily for generating various property values of wood-framed wall assemblies through three Monte Carlo random number generators, which is based on objectively established relationships between Monte Carlo simulation methods and the temperature-dependent properties of wood-stud walls as described the previous sections of this chapter. The solution procedure employed in WALL2DN-MC is shown in the flowcharts presented in Figures 27 and 28. 


\section{RESULTS AND DISCUSSIONS}

\subsection{Introduction}

The numerical simulations performed in this study fall into three categories: exploratory runs, time predictions and prediction of probability of insulation failure.

1. The scope of exploratory runs was to show the impact on the results of the different pdf approaches and the types of walls, and to examine the influence of the variabilities in each of the temperature-dependent properties of wood-framed wall assemblies on the simulation results. Furthermore, simulations were performed to determine the number of Monte Carlo simulation runs required to get acceptable results.

2. The purpose of time predictions was to obtain and analyze time-dependent results, such as temperatures, at specific locations. Average prediction values obtained from the WALL2DN-MC model at designated locations were used to verify the predictability of the WALL2DN-MC model and to compare the results with those of the WALL2DN and also with data from real-scale physical tests.

3. Simulations were done to predict the probability of insulation failure for different types of wood-framed wall assemblies. 
The objectives of the simulations performed using the WALL2DN-MC model can be further classified as the following detailed aspects on basis of three categories.

Determine the number of simulation runs required by the Monte Carlo simulation to get acceptable results.

Evaluate the impact of the three Monte Carlo probability distribution functions on the probability of insulation failure.

Investigate the influence of the variabilities of the temperature-dependent woodframed wall assembly properties on the model results.

$>$ Compare the heat transfer results of the WALL2DN-MC model with those generated from the WALL2DN model.

Compare the heat transfer results of the WALL2DN-MC model with full-scale experimental test data.

Evaluate the impact of different wall constructions and fire-resistance rating walls on the probability of insulation failure.

Three key parameters predicted by the model are used in the analysis since they play a key role in predicting the failure of wall assemblies. They are: time to insulation failure; finish rating; and time to onset of charring. The assembly will experience insulation failure when the temperature at point " $\mathrm{D}$ " in Figure 3 rises by $139^{\circ} \mathrm{C}$ from its value at the beginning of the test. The ability of the gypsum board to protect wood studs is expressed in terms of its "finish rating" which is the time at which the temperature at the interface 
between the gypsum board on the fireside of the wall and the wood stud (Point " $\mathrm{A}$ " in Figure 3) rises by $139^{\circ} \mathrm{C}$. In addition, "time to charring" is an important predictor of the structural response of wood-framed walls in the event of fire. Time to charring is the time at which the temperature at the interface between the gypsum board on the fireside of the wall and the wood studs (Point " $\mathrm{A}$ " in Figure 3) reaches $288^{\circ} \mathrm{C}$ [9].

In the following sections, temperature-time predictions generated by the WALL2DN-MC model are compared with predictions of the WALL2DN model and experimental data obtained from tests performed by Forintek at NRCC $[1,2,3]$.

\subsection{Typical Results of WALL2DN-MC Model}

\subsubsection{Features of WALL2DN-MC's Interface}

Since the Monte Carlo method has been applied to the WALL2DN-MC model, the new outputs, such as time-temperature graph and time of insulation failure are different from those of the WALL2DN model. Furthermore, a couple of new features, such as histogram and cumulative curve for time of insulation failure, are also shown on the output screen.

As Figure 29 shows these new features include the following graphs used to display the simulation results:

1. Time-temperature curve at the top-left corner of the screen. 
Due to the application of the Monte Carlo method, the time-temperature curve at different locations generated by the WALL2DN-MC model is not a single curve, but a cluster of multiple curves.

2. Progress bar below the time-temperature curve.

A progress bar shows the simulation progress as well as the number of runs, which helps users to know when the simulation will finish.

3. Histogram of insulation failure at the bottom-left screen.

A histogram of insulation failure shows the frequency of insulation failure predicted by the model at different times.

4. Cumulative probability of insulation failure at the bottom-right screen.

This graph shows the cumulative probability of insulation failure with time.

In addition, the WALL2DN-MC model computes and reports outputs such as the average value of finish rating, time to charring, insulation failure time, and some key parameters such as the mean, mode, and standard deviation of the different Monte Carlo predictions.

\subsubsection{Typical Results of WALL2DN-MC Model}

Since three Monte Carlo pdf's have been applied in the WALL2DN-MC model, there are three types of typical outputs associated with normal, lognormal and triangular pdf's. 
The simulation results shown in Figures 29 - 40 were obtained using normal, lognormal and triangular pdf's. All simulations used the same type of wall assembly and considered the variation of all five temperature-dependent properties.

\subsubsection{Typical Results of Normal pdf}

Figure 29 shows the output screen of the WALL2DN-MC model displaying results obtained when all five properties were considered to have a normal distribution. The temperature-time graph shown in the upper-left side of Figure 29 indicates that the temperature at the specific measurement points (i.e. finish rating, time to onset of charring and insulation failure time) fluctuates within a range. This happens because the values of the temperature-dependent properties of wood-framed wall assembly randomly change with temperature at each simulation step for every simulation run due to application of the Monte Carlo method.

From this graph, it appears that some of the temperature curves measured on the non-fireside gypsum board overlapped with some of the temperature curves measured on the fireside gypsum board. It seems that the temperature measured on the non-fire-side gypsum board is greater than that measured on the fire-side gypsum board. This overlap occurs due to the Monte Carlo simulation which shifts the temperature distribution in the assembly up or down depending on the set of properties used. 
The output screen also shows a histogram and a cumulative probability curve. The histogram is reproduced in Figure 30 which is generated based on results of 1,000 simulation runs with all five properties selected. Figure 30 clearly shows that the majority of failure times fall between 47.5 and 51.5 minutes. The failure time of approximately one-fourth of the simulation runs is around the 48.5 minute.

Because Figure 30 was generated using the normal pdf for the properties, one may expect that the output values will also have a normal pdf. The shape of the distribution of failure time however has a shape that is closer to a lognormal distribution. To gain insight into the impact of the various properties on the time to insulation failure, the model was used to carry out simulations with only one property allowed to vary, while all other properties followed the fixed equations used in the WALL2DN model. The results of these runs are shown in Figure 31. The figure shows that when only the thermal conductivity of gypsum board is considered in the Monte-Carlo simulation, the time to insulation failure occurs much earlier than the other properties. The shape of the curve when only thermal conductivity of gypsum board is considered to be variable is similar to the curve of Figure 30. The time to insulation failure produced by considering the other properties occurs within a narrow range and at times longer than the times obtained with the thermal conductivity of gypsum board. It is clear from these results that the thermal conductivity of gypsum board plays a dominant role in the calculation. The effect of the other properties is very small. 
Figure 32 presents the cumulative probability of insulation failure with time. It shows that the cumulative probability increases rapidly at the beginning and then the rate of increase decreases.

\subsubsection{Typical Results of Lognormal pdf}

Figure 33 presents the overall output screen of the WALL2DN-MC model displaying results with the use of a lognormal pdf for all properties. The histogram is reproduced in Figure 34 which is generated based on results of 1,000 simulation runs. Figure 35 presents five curves that show the frequency of insulation failure time based on results of 300 simulation runs, when only one property was allowed to vary during the simulation and the other four properties followed the fixed equations used in the WALL2DN model. The output graphs and curves, such as histogram and cumulative probability curves, shown in Figures 34 through 36 are very similar to those shown in Figures 30 through 32 for the normal pdf simulations. For example, the range of calculated insulation failure time in Figure 34 is the same as that in Figure 30, which falls between 47.5 and 51.5 minutes, and one-fourth of insulation failure time occurs at 48.5 minutes. The curve of the frequency of insulation failure time shown in Figure 34 is also similar to that shown in Figure 30.

Figure 35 shows that frequency of the time to insulation failure obtained when only one property was allowed to vary in the simulation while the other properties followed the equations used in the WALL2DN model. As with the case with the normal pdfs, Figure 
35 shows that the thermal conductivity of gypsum board results in a wider range of the time to failure while the other properties yield much narrower ranges occurring at later times. The shape of the curve of the thermal conductivity of gypsum board is similar to the curve of Figure 34, indicating again the dominance of the thermal conductivity of gypsum board on the time to insulation failure.

Figure 36 presents the cumulative probability of insulation failure with time based on 1,000 simulation runs..

\subsubsection{Typical Results of triangular pdf}

Figure 37 presents the overall output screen of the WALL2DN-MC model displaying results with the use of a triangular pdf. The temperature-time graph shown in the upperleft side of Figure 37 is similar to those of the normal and lognormal pdf's, but the temperature-time curves fluctuate within a larger range from 47 to 54 minutes as shown in Figure 38 which is generated based on results of 1,000 simulation runs with all five properties selected.

The histogram at the lower-left side of Figure 37 and the reproduced histogram shown in Figure 38 look like a uniform shape other than a triangular shape. Since the histogram curve of number of runs as a function of insulation failure time look like a uniform distribution, the probability cumulative curve become a straight line as shown in Figure 40. 
To investigate the impact of the various properties on the results, Figure 39 presents five curves that show the frequency of insulation failure time generated from results of 300 simulation runs, when only one property was allowed to vary during the simulation and the other four properties followed the fixed equations used in the WALL2DN model.

Figure 39 shows that the curve of the thermal conductivity of gypsum board has a wider range of insulation failure time from 46 minute to 57 minute and the other four curves have a much narrower range. The results of these simulations also show that the thermal conductivity of gypsum board is the dominating property while all other properties do not influence the results considerably.

\subsection{Exploratory Runs}

\subsubsection{Required Number of Monte Carlo Runs}

This section describes how the required number of Monte Carlo runs for each of the three distribution functions was determined in order to achieve good results. For these simulations, a wall assembly having a 45-minute fire resistance rating was used. Details of this wall assembly are listed in Table 1.

In order to determine the number of runs required to achieve good results, the following assessment were made: 
- Stability of histogram curves

The histogram curves produced by the simulations were monitored until a stable shape was achieved.

- Percentage Difference

In accordance with Probability Theory and Statistics, percentage difference was used to determine the required number of runs.

\subsubsection{Required Runs with the Normal pdf}

A number of simulations were performed to determine the required number of runs when all five temperature-dependent properties were used in the Monte Carlo simulations. Histograms of the normal pdf simulations performed to determine the required number of runs is shown in Figure 41. Histograms obtained from 100, 500 and 1,000 runs are presented.

Figure 41 shows that the histogram curves of 500 and 1,000 runs have approximately the same trend at all points of 0.5 -minute time intervals from 47.5 - through 51.5 -minute. From this straightforward observation, a conservative number of 1,000 runs is considered as the required number of runs for getting a stable output for the normal pdf.

The 1,000 required runs determined above were based on a visual observation only. In accordance with Probability and Statistics, percentage difference can be used to compare 
the similarity of the outputs of the same quantity in order to whether stable output is achieved [40]. The percentage difference can be calculated by dividing the absolute difference of the two values by their average. This is presented as an equation as below [41].

$$
\text { Percentage Difference }=\frac{\mid \text { Value }_{1}-\text { Value }_{2} \mid}{\left(\text { Value }_{1}+\text { Value }_{2}\right) / 2}
$$

Table 2 shows the standard deviation and mean of the normal pdf with different runs. The calculations of percentage difference with different runs by using Eqn 56 are presented in Table 2 as well.

Based on the calculations of percentage difference of standard deviation and mean shown in Table 2, it is found that the values of percentage difference for both standard deviation and mean of insulation failure temperature at runs of more than 200 become very small, and are in order of decrease with increased simulation runs. For instance, the values of percentage difference of standard deviation at 200,500 and 1,000 runs are $0.0078 \%$, $0.0054 \%$ and $0.0018 \%$ respectively. It means that the simulation outputs after 200 runs already are stable. When combined with the analysis of histogram curves done above, a conservative number of 1,000 run is considered as the required runs for getting a stable output. 
In accordance with the analysis above, it can be concluded that a minimum of 1,000 simulation runs provides a better result for the normal pdf when all five properties of the wood-framed wall assembly are considered.

\subsubsection{Required Runs with the Lognormal pdf}

The results of the simulations performed to determine the number of runs for the lognormal pdf are shown in Figure 42. In Figure 42, histograms of insulation failure time obtained with 100, 500 and 1,000 runs are presented.

In Figure 42, the histogram curves of 500 and 1,000 runs are very close at all points from 47.5 through 51.5-minutes, so 1,000 can be chosen as the number of required runs for the lognormal pdf.

Additionally, percentage difference was used to compare the similarity of the outputs of the same quantity and determine getting a stable output. The calculations of percentage difference of standard deviation and mean for the lognormal pdf with different runs by using Eqn 56 are presented in Table 3.

Based on the calculations of percentage difference of standard deviation and mean shown in Table 3, it is seen that the values of percentage difference for both standard deviation and mean of insulation failure temperature at runs of more than 200 become very small. The percentage difference values of the standard deviation are in order of decrease with 
increased simulation runs, but the percentage difference values of the mean fluctuated randomly. Although the simulation outputs after 200 runs start getting stable as analyzed above, a conservative number of 1,000 run is considered as the required runs for getting better outputs when combined with the analysis of histogram curves done above.

In accordance with the analysis above, a minimum of 1,000 simulation runs is required to get a good result for the lognormal pdf when all five properties of the wood-framed wall assembly are used in the simulation.

\subsubsection{Required Runs with the Triangular pdf}

The results of the simulations performed to determine the number of simulation runs for the triangular pdf are shown in Figure 43. The figure shows histograms obtained with 100,500 and 1,000 runs.

As the figure shows, the curves of 500 and 1,000 runs are very close, which indicate that 1,000 runs are required to good results for the triangular pdf.

Additionally, percentage difference was used to determine getting a stable output. The calculations of percentage difference of standard deviation and mean for the triangular pdf with different runs by using Equation 56 are presented in Table 4. 
Based on the calculations of percentage difference of standard deviation and mean shown in Table 4, it is seen that the values of percentage difference for both variance and mode of insulation failure temperature at runs of more than 200 are less than $1 \%$, and are in order of decrease with increased simulation runs. Although the percentage difference of variance and mode shows that simulation outputs after 200 run start getting stable, a conservative number of 1,000 run is chosen as the required runs for getting better outputs when combined with the analysis of histogram curves done above.

In accordance with the analysis above, a minimum of 1,000 simulation runs is required to get better results for the triangular pdf when all five properties of wood-framed wall assembly are used in the simulation.

\subsubsection{Impact of Types of Probability Distribution Functions}

This section describes the impact of the three probability distribution functions on the probability of insulation failure. For this, three different wall assemblies were considered. These wall assemblies are the ones used in Test G1, Test 5 and Test 6, details of which are given in Table 5. In accordance with the full-scale testing results, all three tests failed structurally before insulation failure occurred. The assembly in Test G1 failed at 40 minutes; in Test 5 at 50 minutes and in Test 6 at 60 minutes. 
For all cases, all simulations considered the variation of all five temperature-dependent properties selected and the number of runs was set to 500. The results obtained for the three pdf's based on the three tested wall assemblies are shown in Figures 44 through 46 .

Figure 44 shows the simulation results for the wall assembly of Test G1. A solid line depicts the histogram of the normal pdf, a dash line for a lognormal and a dash dot line for a triangular pdf. Figure 44 shows that the earliest failure occurred at 46 minutes for all three pdf's, and the latest at 48.5 minutes for the normal and lognormal pdf's and at 49.5 minutes for the triangular pdf. The distributions of insulation failure for the normal and lognormal pdf look similar, however the distribution for the lognormal pdf is more concentrated than that of the normal pdf. The distribution of insulation failure for the triangular pdf has a triangular shape and a wider range of insulation failure time than those of the normal and lognormal pdf's.

Figure 45 shows the simulation results for the wall assembly of Test 5 listed in Table 5, which had a minimum of 50-minute tested fire resistance rating. The three different types of lines shown in Figure 45 show the results of the three pdf's. The figure shows that the earliest failure occurred at 47.5 minutes for the normal and lognormal pdf's and at 47.0 minutes for the triangular pdf, and the latest at 51.5 minutes for the normal and lognormal pdf's and at 54.0 minutes for the triangular pdf. Furthermore, the distributions of insulation failure for the normal and lognormal pdf look very similar. The distribution of insulation failure for the triangular pdf has a wider range of insulation failure time than those of the normal and lognormal pdf's. 
Figure 46 shows the simulation results for the wall assembly of Test 6 for the three different pdf's. The figure shows that the earliest failure occurred at 57.5 minutes for the normal, 58.0 minutes for the lognormal pdf's and 56.5 minutes for the triangular pdf, and the latest at 61.0 minutes for the normal and lognormal pdf's and 64.5 minutes for the triangular pdf. The distribution of insulation failure for the triangular pdf has a wider range of insulation failure time than those of the normal and lognormal pdf's.

Based on the analysis above, for all tests the curve of the triangular pdf has a wider range of insulation failure time than those of the normal and lognormal pdf. The curves of the normal and lognormal pdf have approximately the same range of insulation failure time and a similar shape.

\subsubsection{Influence of Wall Assembly Properties}

The three probability distribution functions were applied to the five temperaturedependent properties of wood-framed walls in the WALL2DN-MC model for this study. In this section, the influence of the five properties on model predictions is analyzed.

These simulations considered Test 5. Each simulation was done with 300 and 500 runs. Figures 47 through 52 show the simulation results obtained from these simulations. 
Figure 47 shows the results obtained from a 500-run simulation using the normal pdf for two cases: first with only the three properties of gypsum board used with pdfs and second with the two properties of the wood studs. Figure 47 shows that the earliest failure occurred at 48.0 minutes and the latest at 51.0 minutes when only the properties of gypsum board are used. When the model considered the two wood properties, the earliest failure was 50.5 minutes and the latest at 53.5 minutes.

When the lognormal pdf is selected, the insulation failure time ranges from 48 to 51 minutes with the gypsum board properties and from 50.5 to 53.5 minutes with the wood properties. These results are shown in Figure 48.

Figure 49 presents the results of a 500-run simulation using a triangular pdf for the property distributions. The figure shows that the earliest failure occurred at 46.0 minutes and the latest at 57.0 minutes for three properties of gypsum board, and the earliest failure of 49.5 minutes and the latest at 54.0 when the properties of wood stud are used.

This analysis shows that the curves of the normal and lognormal pdf's are almost the same for either the failure time range or the curve shape. However, the curves of the triangular pdf have a wider range of insulation failure time than those of the normal and lognormal pdf's. Additionally, it is found that the insulation failure with only the three properties of gypsum board for all three pdfs occurred earlier than that with the two properties of the wood studs. This verified that the gypsum board on the fire side protects wood studs from directly being exposed to the fire for a certain time until shrinkage of 
gypsum boards occurs at high temperatures so that the joints between adjacent gypsum board sheets open and then the edge of gypsum board and wood studs are exposed directly to fire.

To get further insight of the impact of the various properties on the time to insulation failure, the model was used to carry out simulations with only one property allowed to vary, while all other properties followed the fixed equations used in the WALL2DN model. The results of these runs are shown in Figures 50 through 52 for the three distribution functions. All three figures show that when only the thermal conductivity of gypsum board is considered in the Monte-Carlo simulation, the time to insulation failure occurs much earlier than the other properties. Additionally, the shape of the curve when the thermal conductivity of gypsum board is varied is similar to the curve of Figures 30 , 34 and 38 in which all five properties were selected in the Monte Carlo simulation. Thus, it is clear from these curves that the thermal conductivity of gypsum board plays a dominant role in the calculation of the WALL2DN-MC model. All three figures show that when only the thermal conductivity of wood stud is considered in the Monte-Carlo simulation, the time to insulation failure occurs much earlier than the other properties except for the thermal conductivity of gypsum board. This demonstrates that the thermal conductivity of wood stud also plays a very important role in the calculation. The effect of the other properties is very small.

Based on the analysis above, two conclusions can be drawn: 
- The properties of gypsum board have more influence on the results of WALL2DN-MC than the properties of wood studs.

- The uncertainties in the values of thermal conductivity of gypsum board plays an important role on model predictions followed by the thermal conductivity of wood stud. The effect of other properties on model predictions is very small.

\subsection{Time Predictions}

The three important time values used to evaluate heat transfer in non-bearing wall assemblies are: insulation failure; finish rating; and time to charring. A wall assembly will experience insulation failure when the temperature at point " $D$ " in Figure 3 increases by $139^{\circ} \mathrm{C}$ from its value at the beginning of the test. The ability of gypsum board to protect wood studs is expressed in terms of its "finish rating" which is the time at which the temperature at the interface between the gypsum board on the fireside of the wall and the wood stud (Point "A" in Figure 3) increases by $139^{\circ} \mathrm{C}$. In addition, "time to charring" is the time at which the temperature at the interface between the gypsum board on the fireside of the wall and the wood studs (Point "A" in Figure 3) reaches $288^{\circ} \mathrm{C}$ [9].

\subsubsection{Comparisons with WALL2DN}

To investigate the predictive ability of the new model, testing was conducted using six different wall constructions as listed in Table 6 with three probability distribution functions. Both the WALL2DN-MC and WALL2DN models were employed to predict 
the performance of these walls. The predictions of the finish rating, time to charring and time to insulation failure of both the WALL2DN and WALL2DN-MC models are shown in Table 7 of Tables.

The WALL2DN-MC model predictions shown are the average values of the predictions of all runs used in the simulation. The comparisons on finish rating, time to charring and insulation failure show that the average prediction values of the WALL2DN-MC model compare well with those of the WALL2DN model. Furthermore, it is interesting to observe that for all six simulations the predictions of the WALL2DN-MC model are sooner than those of the WALL2DN model by one to two minutes. This means that the results of the WALL2DN-MC model are more conservative than those of the WALL2DN model.

\subsubsection{Comparisons with Experiments}

To compare the WALL2DN-MC model predictions with experimental data, five smallscale or full-scale fire resistance experiments conducted by Forintek at the NRCC are used $[1,2]$. Details of these tests are shown in Table 8 of Tables.

The average prediction values of the finish rating, time of charring and insulation failure, presented in Table 9 of Tables were generated using all five properties in the Monte Carlo simulation. 
As the table shows the WALL2DN-MC model predictions are slightly less than or closer to the experimental data than the predictions of the WALL2DN model. For instance, time to charring for Test 2 and Test 5 is 22 minutes 33 seconds and 20 minutes 10 seconds respectively, which compare well with the experimental results of 22 minutes 54 seconds and 20 minutes. Time to insulation failure for Test 2 and Test 4 is 53 minutes 45 seconds and 65 minutes 03 seconds, which are less than the WALL2DN model results of 56 minutes 59 seconds and 68 minutes 47 seconds but closer to the experimental data of 51 minutes 08 seconds and 66 minutes 40 seconds. The time to insulation failure for Test 6 is 58 minutes 36 seconds, which is slightly less than the 60 minute rating of this wall.

The predicted values presented in Table 9 of Tables demonstrate that the WALL2DNMC model is more conservative than those of the WALL2DN model and closer to the experimental data when different wall assemblies are simulated.

\subsection{Probability of Insulation Failure}

To find out the probability of insulation failure, two different types of walls have been simulated with normal, lognormal and triangular pdf's. The generated curves are shown in Figures 53 and 54 for an insulated 60-minute rated wall, and in Figures 55 and 56 for a non-insulated 45-minute rated wall. For all cases, the simulations considered the variation of all five temperature-dependent properties and the number of runs was set to 1,000 . 


\subsubsection{Insulated Walls - 60 Minute Rating}

Figure 53 shows the histogram of insulation failure time for the normal, lognormal and triangular pdf's for the insulated 60-minute rating wall assembly listed in Table 1 of Tables. The figure shows that the earliest failure occurred at 61.5 minutes for the lognormal and triangular pdf's and 61 minutes for the normal pdf, and the latest at 65.5 minutes, 64.5 minutes and 66.5 minutes for the normal, lognormal and triangular pdf's respectively.

Figure 54 shows the cumulative probability as a function of insulation failure time for the normal, lognormal and triangular pdf's for an insulated 60-minute rating wall assembly. The cumulative probability of failure for all three pdf's shows that the earliest failure occurred after 60 minutes, which compares well with of the 60 -minute fire resistance rating of this wall. It is also clear from these curves that the cumulative probability of failure for the normal and lognormal pdf's always occurs ahead of the triangular pdf, and the cumulative probability of failure for the normal pdf occurs ahead of the lognormal pdf before about 63 minutes but their positions are reversed after 63 minutes. As discussed above, it demonstrates that the values of insulation failure time generated using the normal or lognormal pdf's are more conservative than those obtained from the triangular pdf. 


\subsubsection{Non-insulated Walls - 45 Minute Rating}

Figure 55 shows the histogram of insulation failure time for the normal, lognormal and triangular pdf's for a non-insulated 45-minute rating wall assembly listed in Table 1 of Tables. Figure 55 shows that the earliest failure occurred at 47.5 minutes for the normal and lognormal pdf's and 47 minutes for the triangular pdf, and the latest at 51.5 minutes for the normal and lognormal pdf's and 54 minutes for the triangular pdf.

Figure 56 shows the cumulative probability as function of insulation failure time for the normal, lognormal and triangular pdf's for this wall assembly. The cumulative probability of failure for all three pdf's indicate that the earliest failure occurred after 45 minutes, which compares well with the 45 -minute fire resistance rating of this wall.

These simulations demonstrate that the model can predict very well the probability of insulation failure of both, insulated and non-insulated wall assemblies. In addition the results show that:

The values of insulation failure time generated using the normal or lognormal pdf's are more conservative than those obtained from the triangular pdf for both the insulated and non-insulated wall assemblies.

The triangular pdf results in a wider range of time to failure than the other two pdf's for both the insulated and non-insulated wall assemblies. 
Based on the analysis done above, it demonstrated that the lognormal pdf may provide with better simulation outputs than other two pdfs do. 


\section{CONCLUSIONS}

\subsection{Conclusions}

The results in the present study allow the following conclusions to be drawn:

The Monte Carlo method is well suited to consider the variability of properties of timber frame wall assemblies and to predict the probability of the time to insulation failure.

The developed model provides good results for both insulated and non-insulated wall assemblies.

The uncertainty in thermal conductivity of gypsum board plays an important role on the model predictions followed by the thermal conductivity of wood stud. The effect of the other properties to uncertainty of model predictions is very small.

$>$ The study has shown that to get good results the Monte Carlo simulations should perform 1,000 runs. 
Based on the discussion and analysis done in Chapter 4 of this study, it is demonstrated that the lognormal pdf may provide better simulation outputs than other two pdfs.

\subsection{Recommendations}

The following are recommended for future development and research.

Collect variability data of other wall properties and include them in the Monte Carlo simulations.

In accordance with the simulation results generated from the WALL2DN-MC model, the distribution of insulation failure for the normal pdf always looks like a lognormal shape for any types of wall assemblies. Further research needs to be conducted to find reasons for this.

The developed model can consider only continuous probability distribution functions. It is necessary to modify the WALL2DN-MC model to allow the use of discrete probability distribution functions.

Consider the use of stratified samplings (i.e. Latin Hypercube sampling) and other techniques to reduce the number of runs required by the simulations. 
$>$ Investigate the use of multivariate techniques which also can be introduced into WALL2DN-MC to the correlated variables.

V Validate the model with additional experimental data when available. 


\section{REFERENCE}

1. J. R. Mehaffey, P. Cuerrier and G. Carisse, "A Model for Predicting Heat Thansfer through Gypsum-Board/Wood-Stud Walls Exposed to Fire", Fire and Materials, Vol. 18, 297-305 (1994).

2. H. Takeda and J. R. Mehaffey, "WALL2D: a Model for Predicting Heat Transfer through Wood-Stud Walls Exposed to Fire", Fire and Materials, Vol. 22, 133140 (1998).

3. H. Takeda, "WALL2DN: A model to Predict Fire Resistance of Non-Load Bearing Wood-Stud Walls", Forintek Canada Corp., Internal Material.

4. Standard Test Methods for Fire Tests of Building Construction and Materials, ASTM E119, Annual Book of ASTM Standards, Vol. 04.07, ASTM, Philadelphia, pp. 331-51 (1992).

5. Standard Methods of Fire Endurance Tests of Building Construction and Materials, CAN/ULC-S101-M89, Underwriters' Laboratories of Canada, Scarborough, Ontario (1989).

6. George Hadjisophocleous and Zhuman Fu, "Development and Case Study of a Risk Assessment Model CUrisk for Building Fire" Fourth International Symposium on Fire Safety Science, Beijing, China, pp. 877-887, 2005.

7. Standard Calculation Methods for Structural Fire Protection, American Society of Civil Engineers and Society of Fire Protection Engineers, 2002, ISBN 0-78440649-9.

8. Gypsum Boards Products, CSA A82.27-M1977, Canadian Standards Association, Rexdale, Ontario (1977).

9. Gypsum Board, CAN/CSA A82.27-M91, Canadian Standards Association, Rexdale, Ontario (1991)

10. R.H. White and E. V. Nordheim, Fire Technology 28, 5 (1992).

11. Draft Eurocode 5, Part X: Structural Fire Design for Timber Structure, p. 19, May (1989).

12. Wood Handbook: Wood as an Engineering Material, Agriculture Handbook 72, Forest Products Laboratory, US Department of Agriculture, Washington, DC (1987). 
13. M. K. Kumaran and D. G. Stepheson, "Heat Transport through Thermal Insulation: An Application of the Principles of Thermodynamics of Irreversible Process", ASME Winter Annual Meeting (86-WA/HT-70), pp 1-4 (1986).

14. M. K. Kumaran and D. G. Stepheson, "Heat Transport through Fibrous Insulation Materials", Journal of Thermal Insulation, 11: 236-269 (1988).

15. Bernd A. Berg, Markov Chain Monte Carlo Simulations and Their Statistical Analysis (With Web-Based Fortran Code), World Scientific 2004, ISBN 981-238935-0.

16. Arnaud Doucet, Nando de Freitas and Neil Gordon, Sequential Monte Carlo methods in practice, 2001, ISBN 0-387-95146-6.

17. P. Kevin MacKeown, Stochastic Simulation in Physics, 1997, ISBN 981-3083-263.

18. C.P. Robert and G. Casella. "Monte Carlo Statistical Methods" (second edition). New York: Springer-Verlag, 2004, ISBN 0-387-21239-6.

19. Harvey Gould \& Jan Tobochnik, An Introduction to Computer Simulation Methods, Part 2, Applications to Physical Systems, 1988, ISBN 0-201-16504-X.

20. R.Y. Rubinstein and D.P. Kroese (2007). "Simulation and the Monte Carlo Method" (second edition). New York: John Wiley \& Sons, ISBN 978-0-47017793-8.

21. N. Metropolis and S. Ulam, "The Monte Carlo Method", Journal of the American Statistical Association, volume 44, number 247, pp. 335-341 (1949).

22. Fishman, G.S., (1995) Monte Carlo: Concepts, Algorithms, and Applications, Springer Verlag, New York.

23. R. E. Caflisch, Monte Carlo and quasi-Monte Carlo methods, Acta Numerica vol. 7, Cambridge University Press, 1998, pp. 1-49.

24. B. D. Ripley, Stochastic Simulation, 1987, Wiley \& Sons.

25. Sequential Monte Carlo Methods in Practice, by A Doucet, N de Freitas and N Gordon. Springer, 2001. ISBN 978-0387951461.

26. R. Srinivasan, Importance sampling - Applications in communications and detection, Springer-Verlag, Berlin, 2002. 
27. P. J.Smith, M.Shafi, and H. Gao, "Quick simulation: A review of importance sampling techniques in communication systems," IEEE J.Select.Areas Commun., vol. 15, pp. 597-613, May 1997.

28. Arouna. Adaptative Monte Carlo Method, A Variance Reduction Technique. Monte Carlo Methods and Their Applications. 2004.

29. M. Ferrari, S. Bellini, "Importance Sampling simulation of turbo product codes," ICC2001, The IEEE International Conference on Communications, vol. 9, pp. 2773-2777, June 2001.

30. Patel, J. K. and Read, C. B. "Handbook of the Normal Distribution." New York: Dekker, 1982.

31. Whittaker, E. T. and Robinson, G. "Normal Frequency Distribution." Ch. 8 in The Calculus of Observations: A Treatise on Numerical Mathematics, 4th ed. New York: Dover, pp. 164-208, 1967.

32. Box, G. E. P. and Muller, M. E. "A Note on the Generation of Random Normal Deviates." Ann. Math. Stat. 29, 610-611, 1958.

33. Evans, M.; Hastings, N.; and Peacock, B. "Triangular Distribution." Ch. 40 in Statistical Distributions, $3^{\text {rd }}$ ed. New York: Wiley, pp. 187-188, 2000.

34. Crow, E. L. and Shimizu, K. (Ed.). "Lognormal Distributions: Theory and Application." New York: Dekker, 1988.

35. Balakrishnan, N. and Chen, W. W. S. Handbook of Tables for Order Statistics from Lognormal Distributions with Applications. Amsterdam, Netherlands: Kluwer, 1999.

36. Kenney, J. F. and Keeping, E. S. Mathematics of Statistics, Pt. 2, 2nd ed. Princeton, NJ: Van Nostrand, p. 123, 1951.

37. The SFPE Handbook of Fire Protection Engineering, Third Edition, ISBN: 087765-451-4. NFPA, the United States of America, pp 1-175. (2002).

38. P. Clancy, "Advances in Modelling Heat Transfer Through Wood Framed Walls in Fire", Fire and Materials, Fire Mater. 25, 241-254 (2001), DOI: 10.1002/fam. 773 .

39. Robert H. White, "Analytical Methods for Determining Fire Resistance of Timber Members", SFPE Handbook of Fire Protection Engineering, 2d ed. Boston, MA: Society of Fire Protection Engineers: 4-217-4-229; 1995. Chapter 11.

40. Cox DR, Hinkley DV. “Theoretical Statistics”, Chapman \& Hall, 1974. 
41. Julius S. Bendat, Allan G. Piersol, "Random Data: Analysis and Measurement Procedures, $3^{\text {rd }}$ ed. ISBN: 978-0-471-31733-3. 
TABLES 


\begin{tabular}{|c|c|c|}
\hline 45 & Full & $\begin{array}{l}\text { One layer of } 12.7 \mathrm{~mm} \text { Type C gypsum board on each side of wood } \\
\text { studs, 2"x4" wood stud, 16" spacing, joint open, 8" nail, no insulation } \\
\text { in cavity }\end{array}$ \\
\hline 60 & Full & $\begin{array}{l}\text { One layer of } 15.9 \mathrm{~mm} \text { Type C gypsum board on each side of wood } \\
\text { studs, } 2 \text { "x4" wood stud, 16" spacing, joint open, 8" nail, Glass Fibre }\end{array}$ \\
\hline
\end{tabular}

Table 1 Fire Resistance Tests for Probability of Insulation Failure 


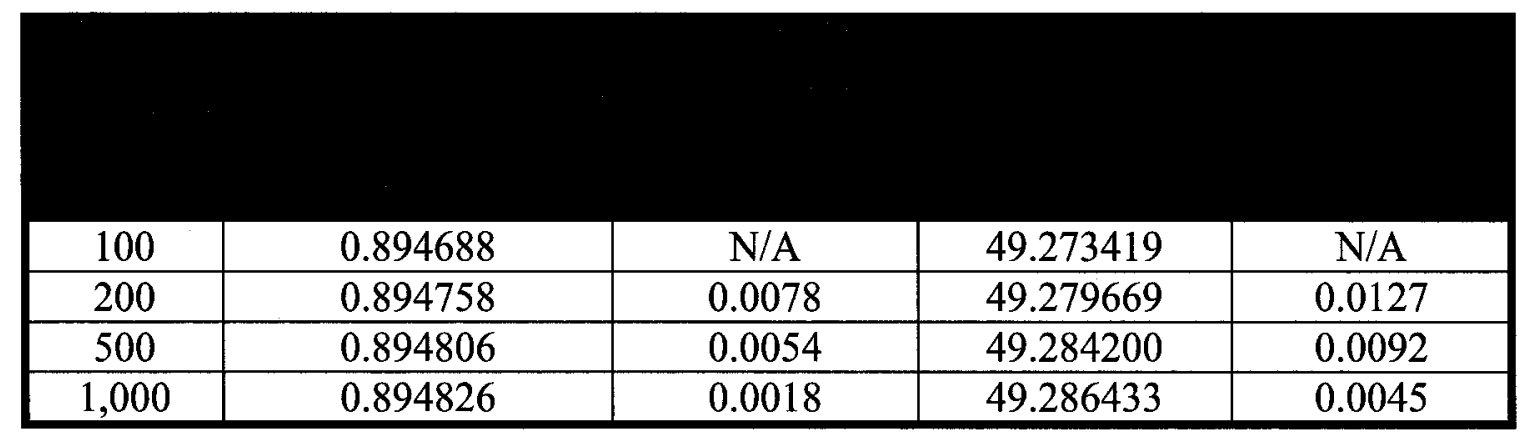

Table 2 Standard Deviation, Mean and Percentage Difference with Different Runs for Normal PDF 


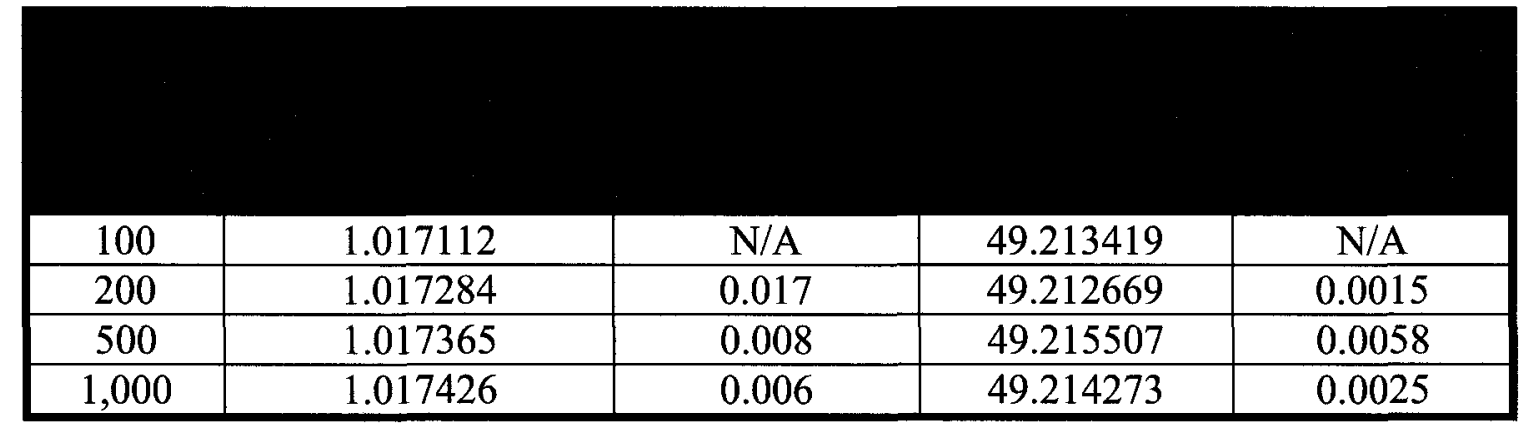

Table 3 Standard Deviation, Mean and Percentage Difference with Different Runs for Lognormal PDF 


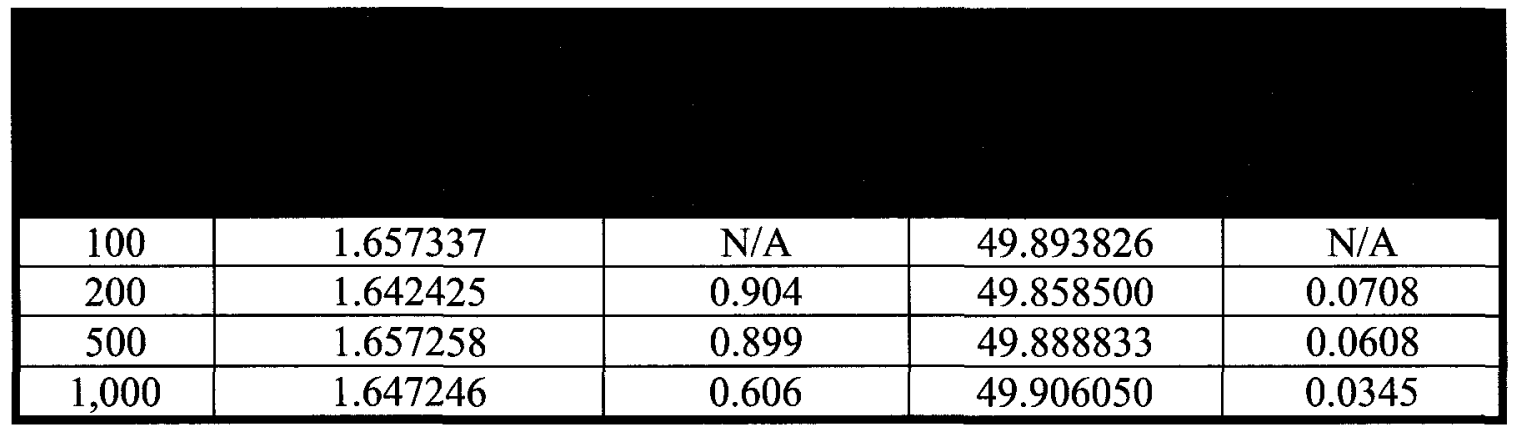

Table 4 Variance, Mode and Percentage Difference with Different Runs for Triangular PDF 


\begin{tabular}{|c|c|c|}
\hline G1 & Full & $\begin{array}{l}\text { One layer of } 12.7 \mathrm{~mm} \text { Type X gypsum board on each side of wood } \\
\text { studs, 2"x4" wood stud, 16" spacing, joint open, } 16 \text { " nail, glass-fibre }\end{array}$ \\
\hline 5 & Full & $\begin{array}{l}\text { One layer of } 12.7 \mathrm{~mm} \text { Type C gypsum board on each side of wood studs, } \\
2 \text { "x4" wood stud, } 16 \text { " spacing, joint open, } 8 \text { " nail, no insulation in cavity }\end{array}$ \\
\hline 6 & Full & $\begin{array}{l}\text { One layer of } 15.9 \mathrm{~mm} \text { Type X gypsum board on each side of wood studs, } \\
\text { 2"x4" wood stud, } 16 \text { " spacing, joint open, } 8 \text { " nail, no insulation in cavity }\end{array}$ \\
\hline
\end{tabular}

Table 5 Full-Scale Fire Resistance Tests Presented in Wall2DN 


\begin{tabular}{|c|c|c|}
\hline 1 & Normal & $\begin{array}{l}\text { One layer of } 12.7 \mathrm{~mm} \text { Type C gypsum board on each side of } \\
\text { wood studs, 2"x4" SPF wood stud, no insulation, joint open }\end{array}$ \\
\hline 2 & Normal & $\begin{array}{l}\text { One layer of } 12.7 \mathrm{~mm} \text { Type C gypsum board on each side of } \\
\text { wood studs, } 2 \text { "x4" SPF wood stud, glass-fibre, joint open }\end{array}$ \\
\hline 3 & Lognormal & $\begin{array}{l}\text { One layer of } 15.9 \mathrm{~mm} \text { Type X gypsum board on each side of } \\
\text { wood studs, 2"x4" SPF wood stud, no insulation, joint open }\end{array}$ \\
\hline 4 & Lognormal & $\begin{array}{l}\text { One layer of } 15.9 \mathrm{~mm} \text { Type X gypsum board on each side of } \\
\text { wood studs, 2"x4" SPF wood stud, glass-fibre, joint open }\end{array}$ \\
\hline 5 & Triangular & $\begin{array}{l}\text { One layers of } 12.7 \mathrm{~mm} \text { Type X gypsum board on each side of } \\
\text { wood studs, 2"x4" SPF wood stud, mineral wool, joint open }\end{array}$ \\
\hline 6 & Triangular & $\begin{array}{l}\text { One layers of } 12.7 \mathrm{~mm} \text { Type C gypsum board on each side of } \\
\text { wood studs, } 2 \text { "x4" SPF wood stud, mineral wool, joint open }\end{array}$ \\
\hline
\end{tabular}

Table 6 Description of Different Wall Assemblies 


\begin{tabular}{|c|c|c|c|c|c|c|}
\hline \multicolumn{1}{|c|}{} \\
\hline 1 & $17: 09$ & $15: 44$ & $21: 46$ & $20: 10$ & $52: 49$ & $49: 04$ \\
\hline 2 & $16: 25$ & $14: 57$ & $18: 56$ & $17: 41$ & $50: 55$ & $49: 47$ \\
\hline 3 & $20: 39$ & $18: 39$ & $25: 23$ & $23: 24$ & $62: 38$ & $58: 36$ \\
\hline 4 & $19: 17$ & $17: 20$ & $22: 12$ & $20: 41$ & $59: 54$ & $58: 15$ \\
\hline 5 & $15: 22$ & $14: 24$ & $18: 15$ & $17: 61$ & $101: 22$ & $97: 59$ \\
\hline 6 & $16: 53$ & $15: 45$ & $20: 34$ & $19: 21$ & $107: 20$ & $103: 18$ \\
\hline
\end{tabular}

Table 7 Comparison of the Old and the New Model Predictions 


\begin{tabular}{|c|c|c|}
\hline \multicolumn{2}{|c|}{} & Four layers of 12.7 mm Type C gypsum board (no studs) \\
\hline 2 & Small & $\begin{array}{c}\text { One layer of 12.7 mm Type C gypsum board on each side of } \\
\text { wood studs, 2"x4" wood stud, 16" spacing, joint not open }\end{array}$ \\
\hline 3 & Small & $\begin{array}{c}\text { One layer of 15.9 mm Type X gypsum board on each side of } \\
\text { wood studs, 2"x4" wood stud, 16" spacing, joint not open }\end{array}$ \\
\hline 4 & Small & $\begin{array}{c}\text { Two layer of 15.9 mm Type X gypsum board on each side of } \\
\text { wood studs, 2"x4" wood stud, 16" spacing, joint not open }\end{array}$ \\
\hline 5 & Full & $\begin{array}{c}\text { One layer of 12.7 mm Type C gypsum board on each side of } \\
\text { wood studs (loaded), 2"x4" wood stud, 16" spacing, joint open }\end{array}$ \\
\hline 6 & Full & $\begin{array}{c}\text { One layer of 15.9 mm Type X gypsum board on each side of } \\
\text { wood studs (loaded), 2"x4" wood stud, 16" spacing, joint open }\end{array}$ \\
\hline
\end{tabular}

Table 8 Fire Resistance Tests 


\begin{tabular}{|c|c|c|c|c|c|c|c|c|c|}
\hline \multicolumn{10}{|c|}{} \\
\hline 2 & $19: 11$ & $18: 18$ & $17: 00$ & $22: 54$ & $23: 41$ & $22: 33$ & $51: 08$ & $56: 59$ & $53: 45$ \\
\hline 3 & $24: 09$ & $21: 59$ & $20: 26$ & $28: 19$ & $27: 33$ & $26: 17$ & $66: 40$ & $68: 47$ & $65: 03$ \\
\hline 4 & $59: 38$ & $61: 00$ & $58: 06$ & $69: 39$ & $73: 11$ & $71: 57$ & $135: 00^{1}$ & $150: 00^{4}$ & $150: 00^{4}$ \\
\hline 5 & $16: 11$ & $17: 10$ & $15: 44$ & $20: 00$ & $21: 46$ & $20: 10$ & $50: 00^{2}$ & $52: 50$ & $49: 04$ \\
\hline 6 & $21: 50$ & $20: 40$ & $18: 39$ & $25: 25$ & $25: 23$ & $23: 24$ & $60: 00^{3}$ & $62: 38$ & $58: 36$ \\
\hline
\end{tabular}

1. Test 4 was terminated at $135 \mathrm{~min}$. Insulation failure had not yet occurred.

2. Test 5 was terminated at $50 \mathrm{~min}$ due to structural failure. Insulation failure had not yet occurred.

3. Test 6 was terminated at $60 \mathrm{~min}$ due to structural failure. Insulation failure had not yet occurred.

4. It means that test was terminated at $180 \mathrm{~min}$ in the model. Insulation failure had not yet occurred.

Table 9 Comparison of Model Predictions and Real-Scale Test Results 


\section{FIGURES}




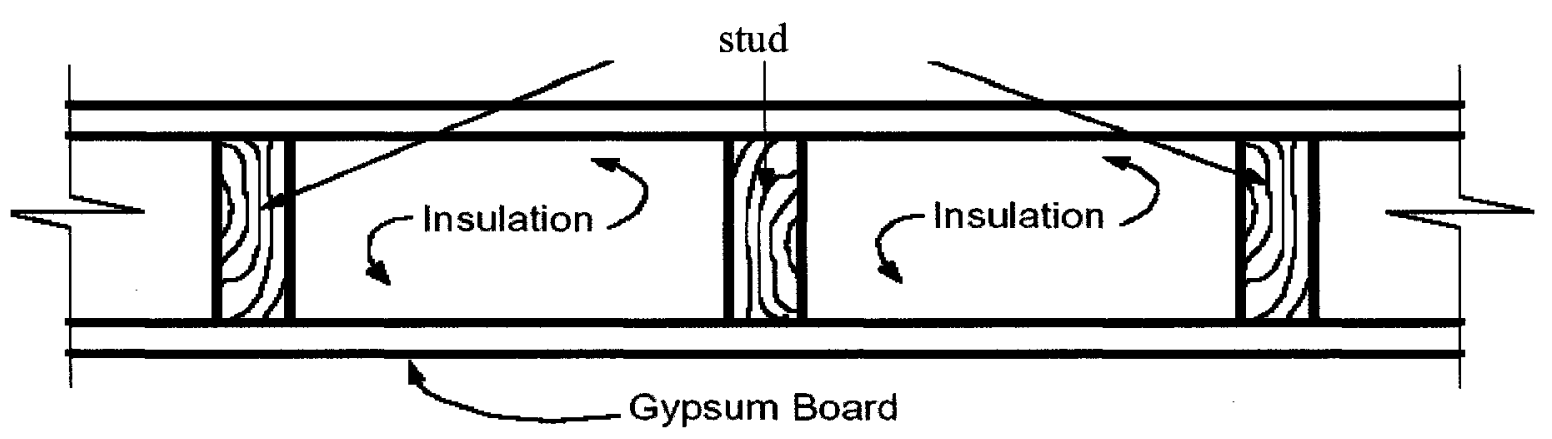

Figure 1 The structure of a typical wood-framed wall 


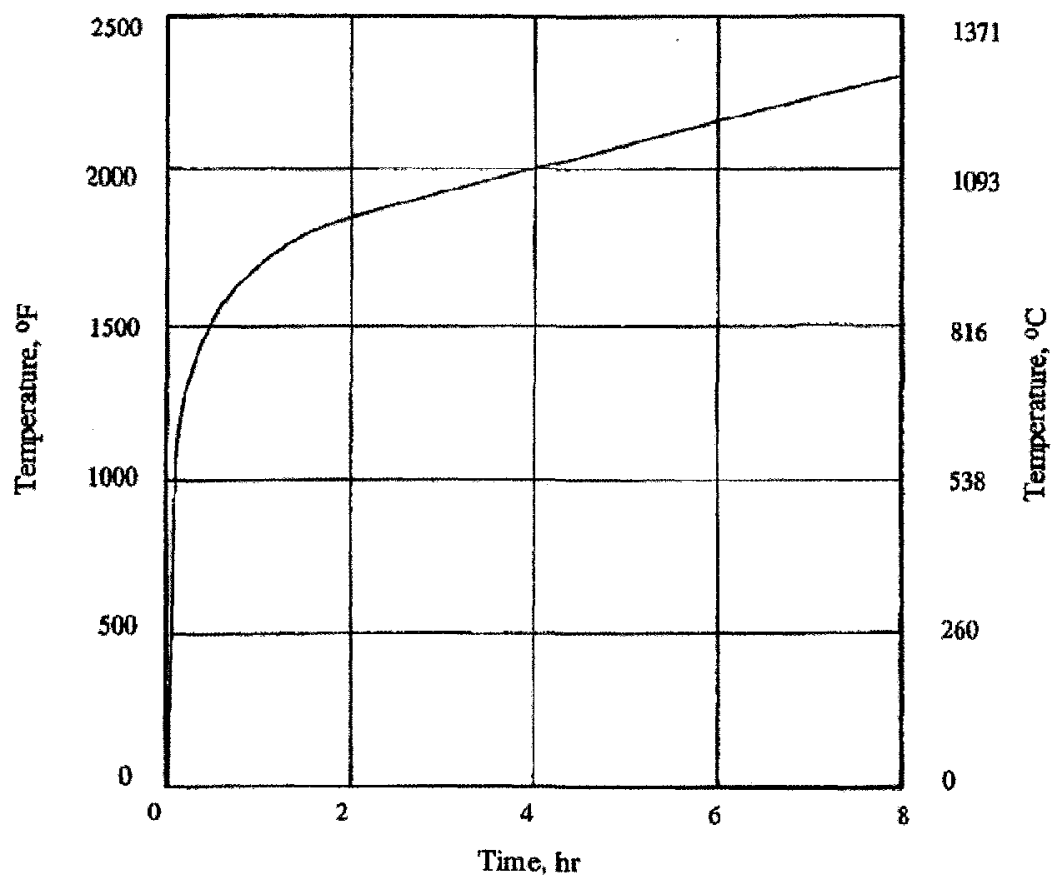

Figure 2 ASTM E119 and CAN/ULC-S101 Standard Time-Temperature Curve 


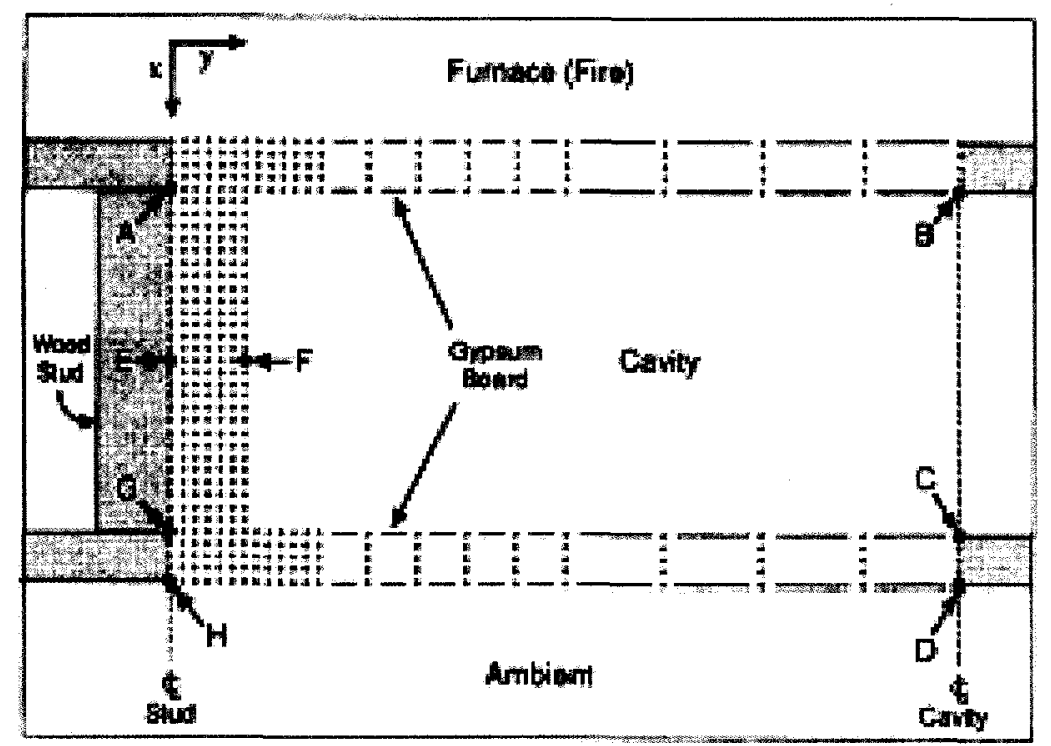

Figure 3 A Cross-Sectional View of a Wall with Points at Which Comparison Between Theory and Experiment is undertaken (points A - D) [1,2] 


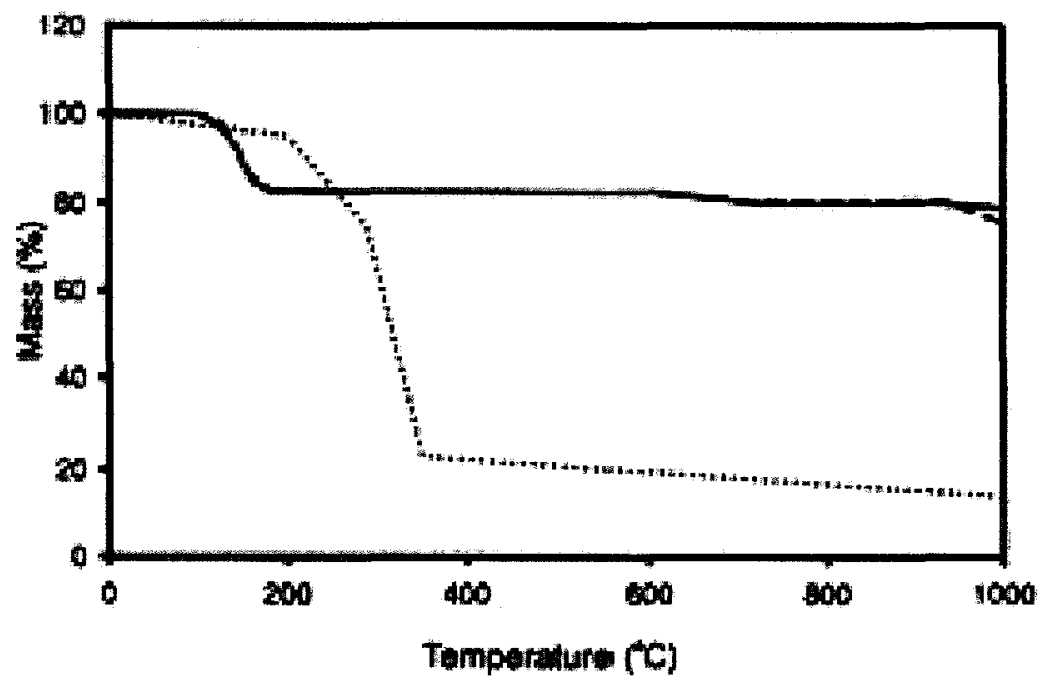

Figure 4 Mass (density) as a Function of Temperature for Gypsum Board (Type $\mathrm{X}$ - solid line; Type $\mathrm{C}$ - dashed line) and for Wood (dotted line) $[1,2]$ 
杰 


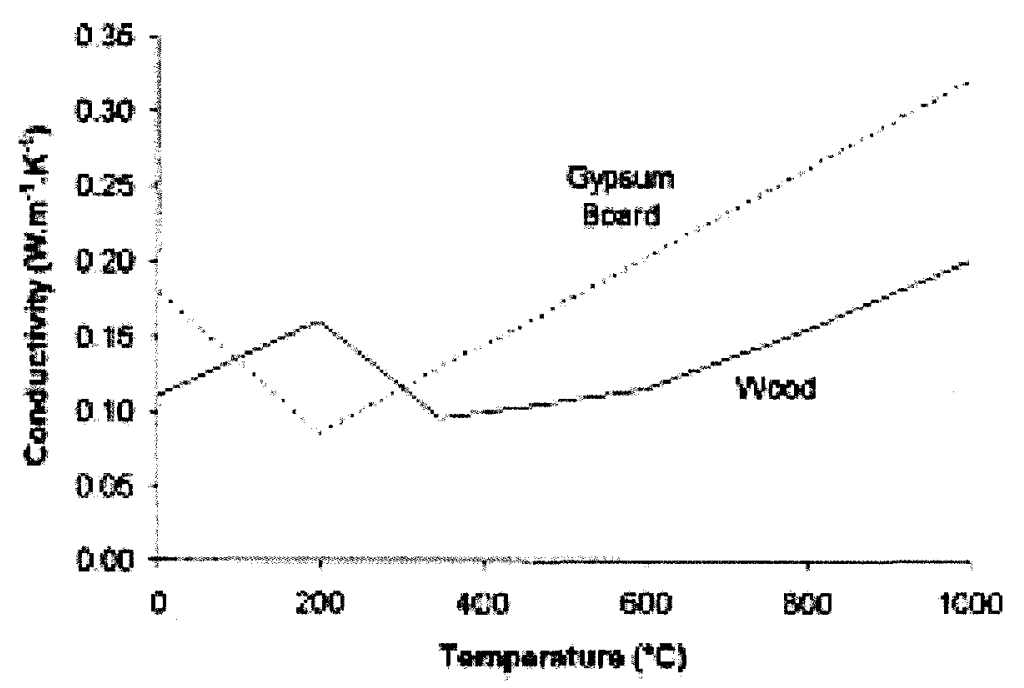

Figure 6 Thermal Conductivity as a Function of Temperature for Gypsum Board (dashed line) and for Wood (solid line) [1, 2] 


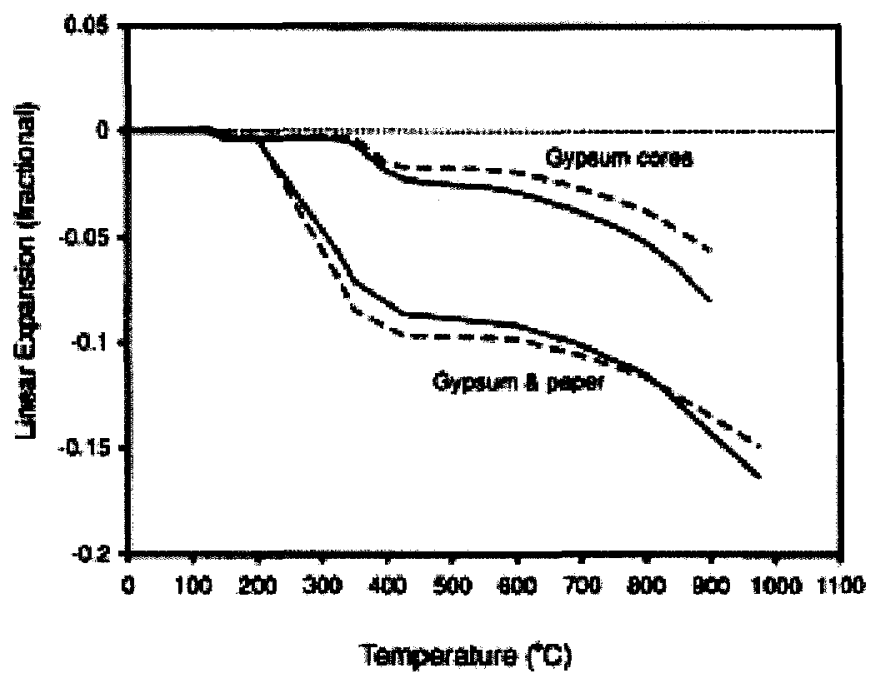

Figure 7 Expansion (contraction) as a Function of Temperature for Gypsum Board (Type X - solid line; Type C - dashed line) [1, 2] 


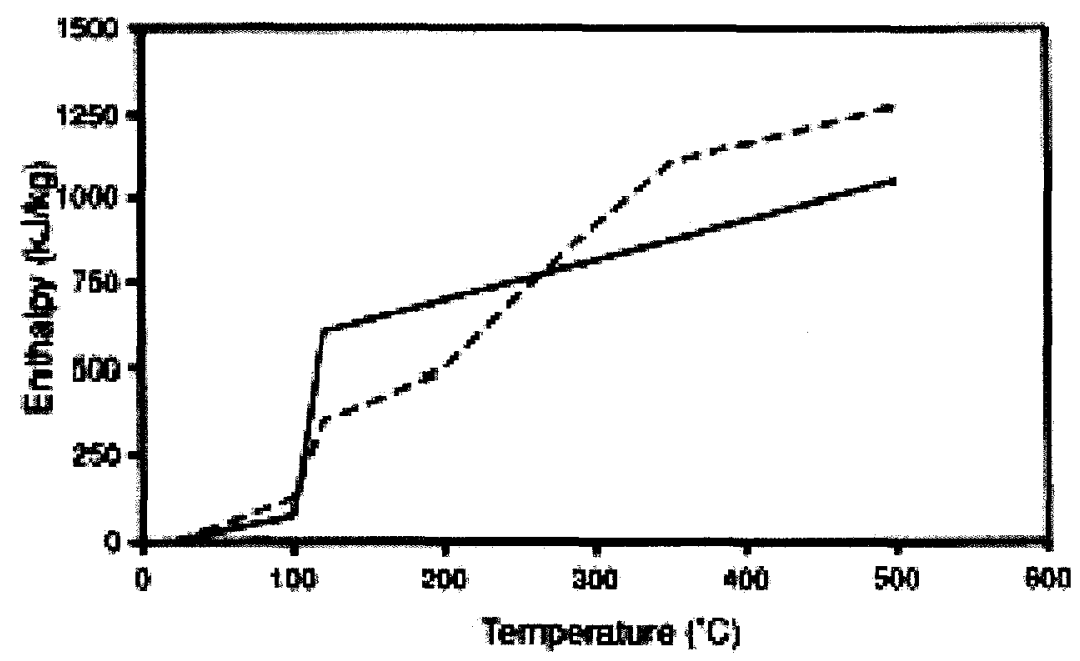

Figure 8 Enthalpy as a Function of Temperature for Gypsum Board (solid line) and for Wood (dashed line) $[1,2]$ 


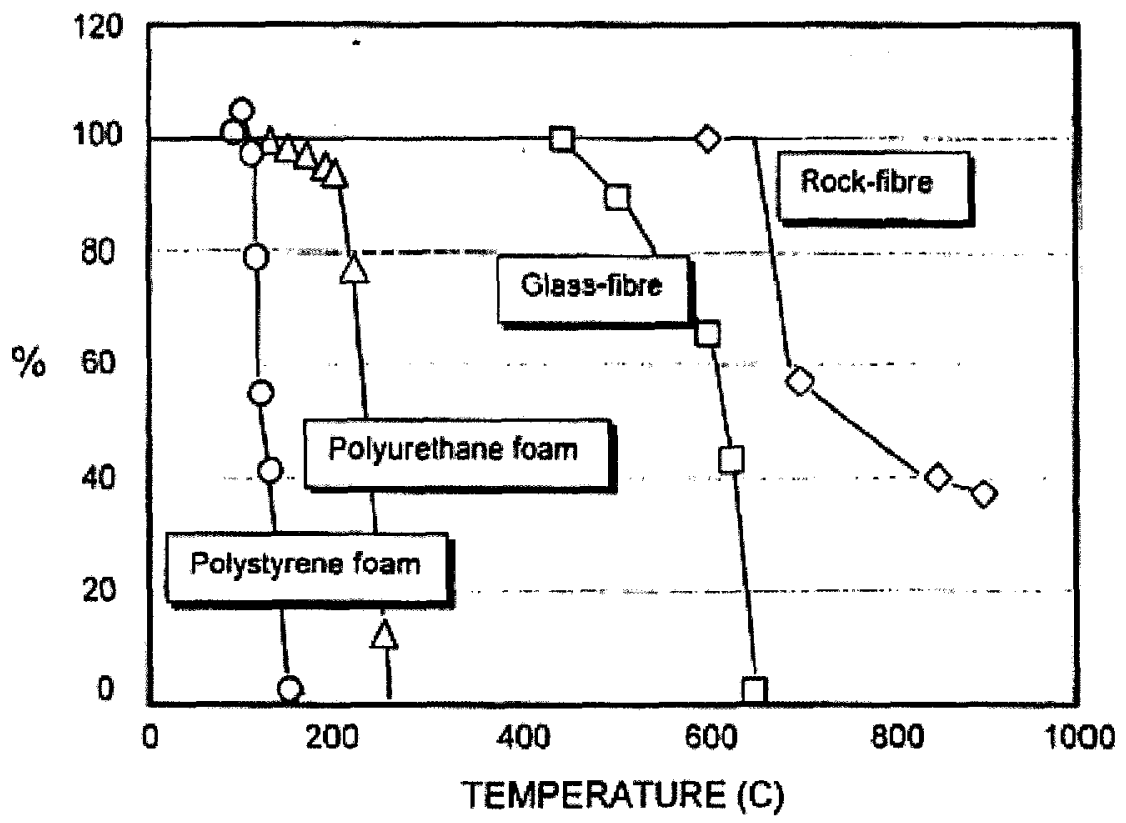

Figure 9 Linear Shrinkage of Polystyrene Foam, Polyurethane Foam, Glass-Fibre Insulation and Rock-Fibre Insulation as a Function of Temperature [3]. 


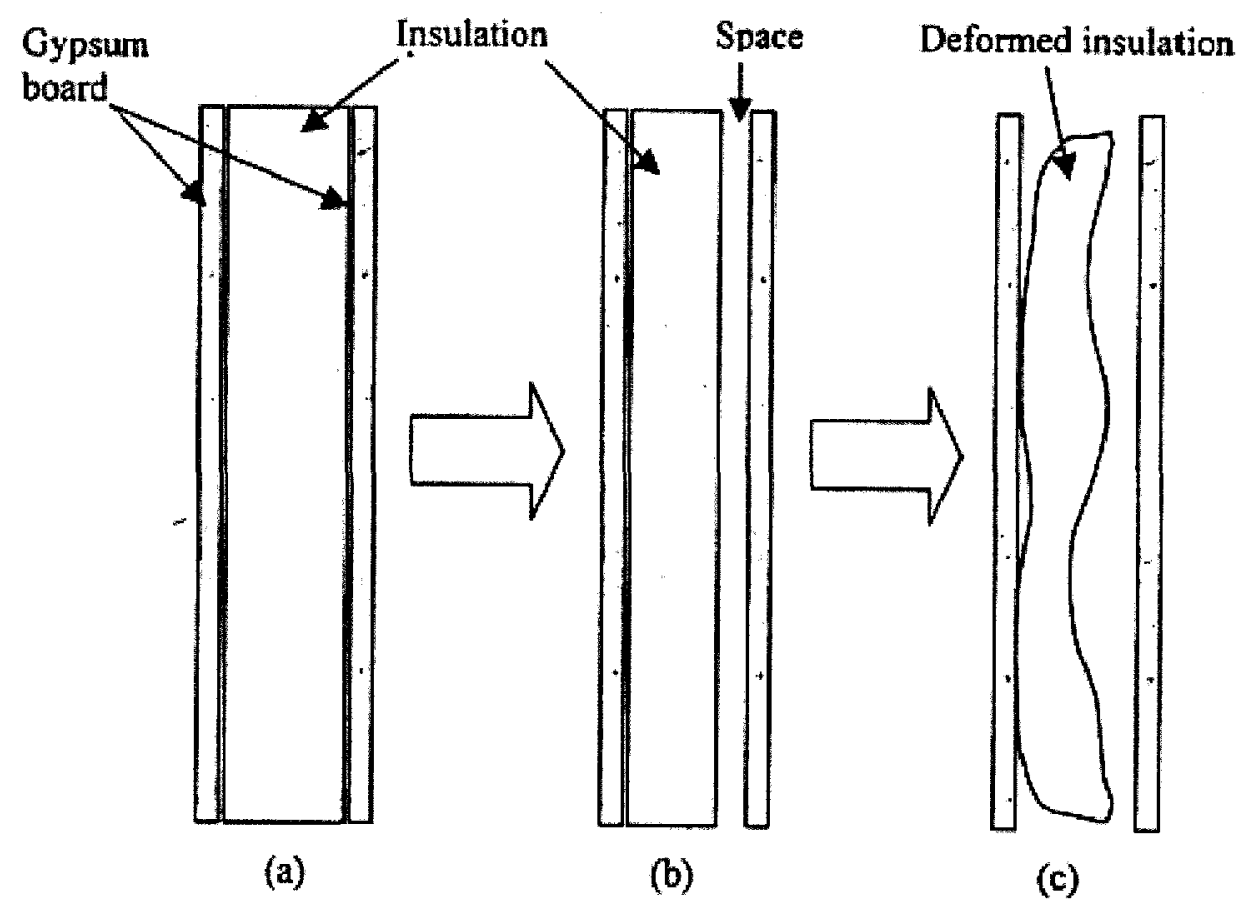

Figure 10 Insulation Shrinking and Melting [3]:

(a) Fully Filled Cavity with Insulation, (b) Empty Space Appear, (c) Insulation Deform by Gravitational Effect. 


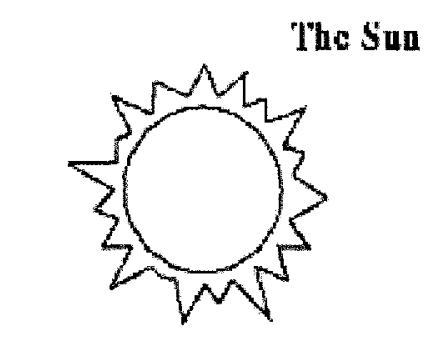

Physical System

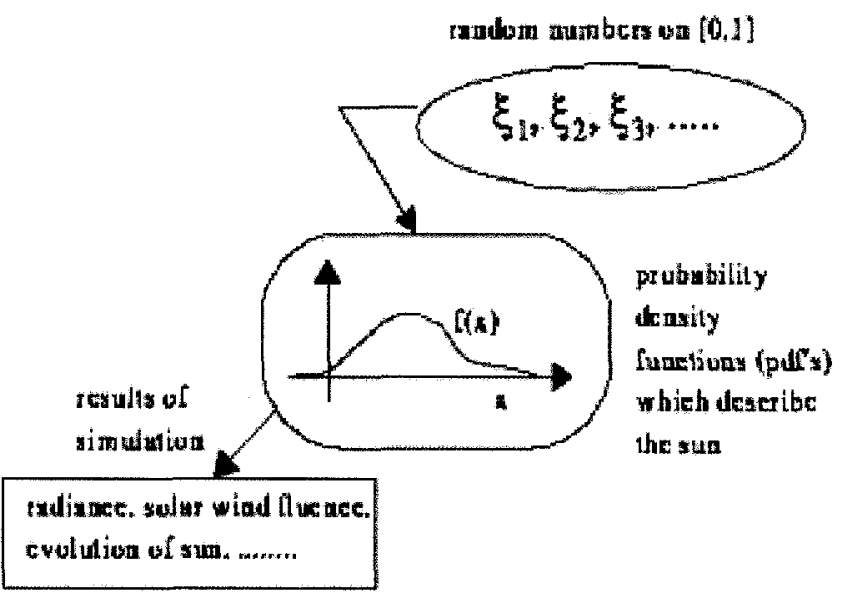

Statistical Simulation

Figure 11 Monte Carlo Simulation in Physical System 


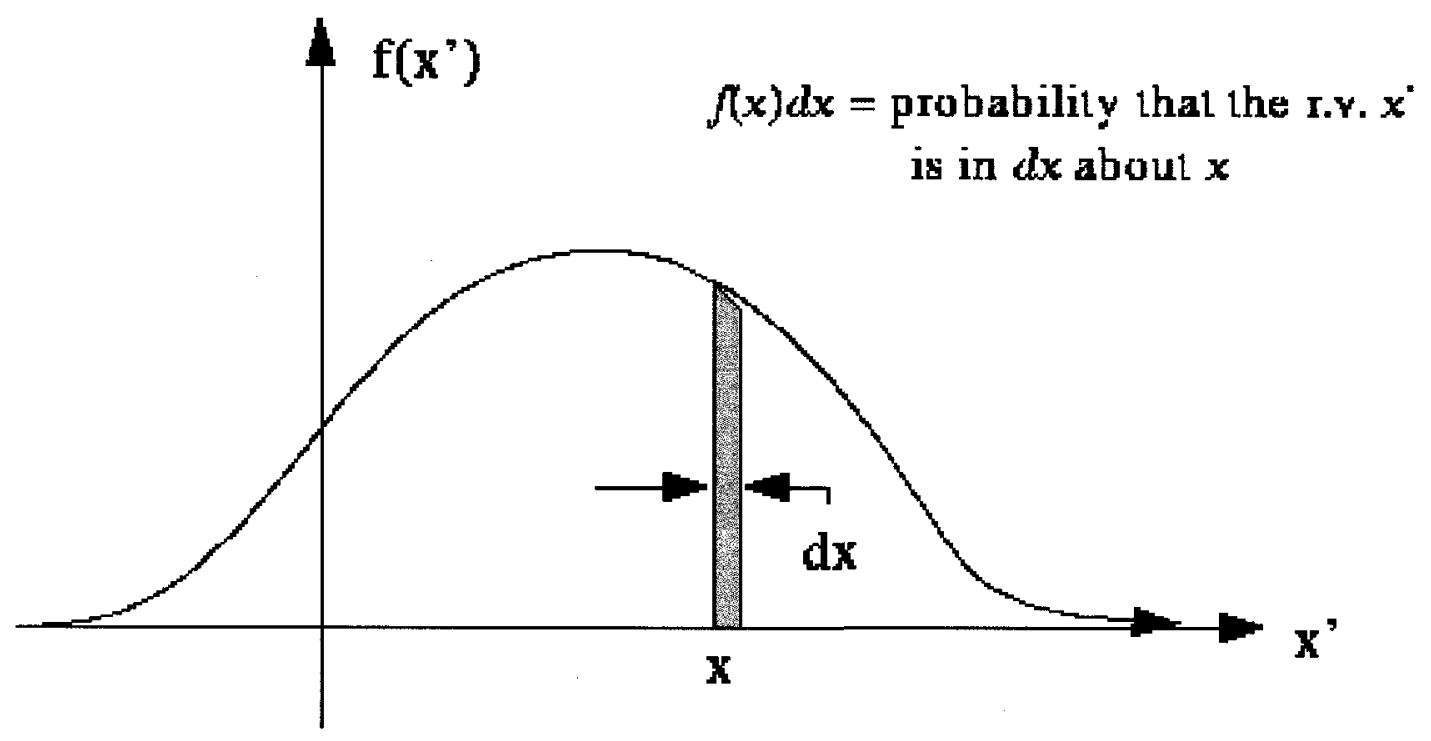

Figure 12 Typical Probability Distribution Function (pdf) 


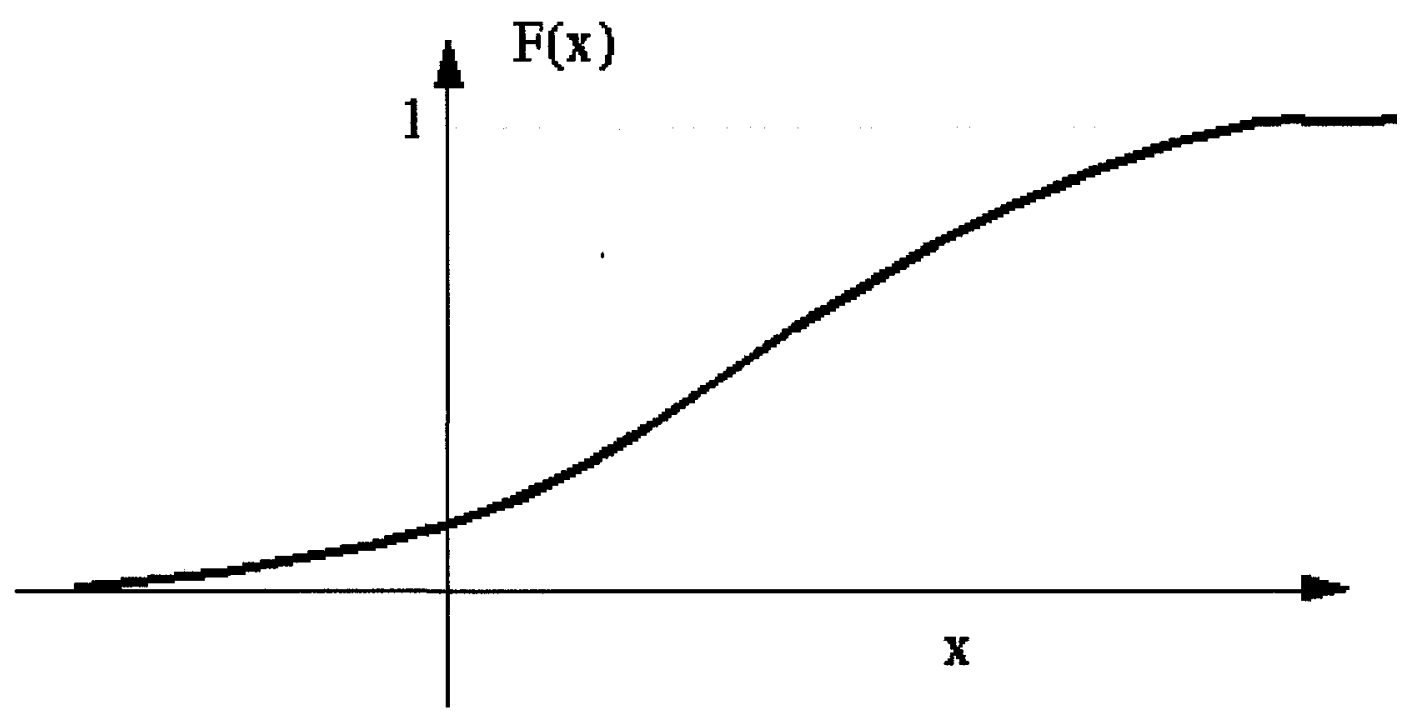

Figure 13 Typical Cumulative Distribution Function (cdf) 


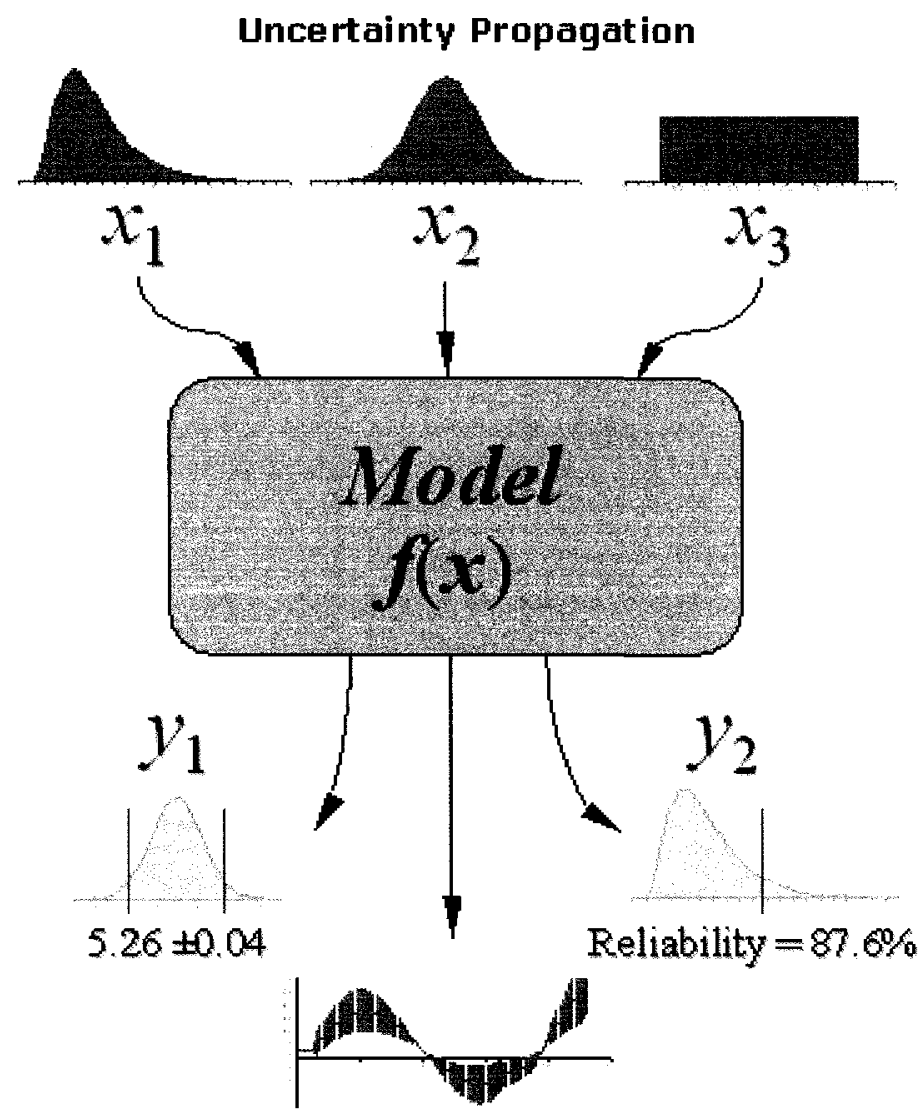

Figure 14 Schematic Principle of Monte Carlo Simulation for Uncertainty Propagation 


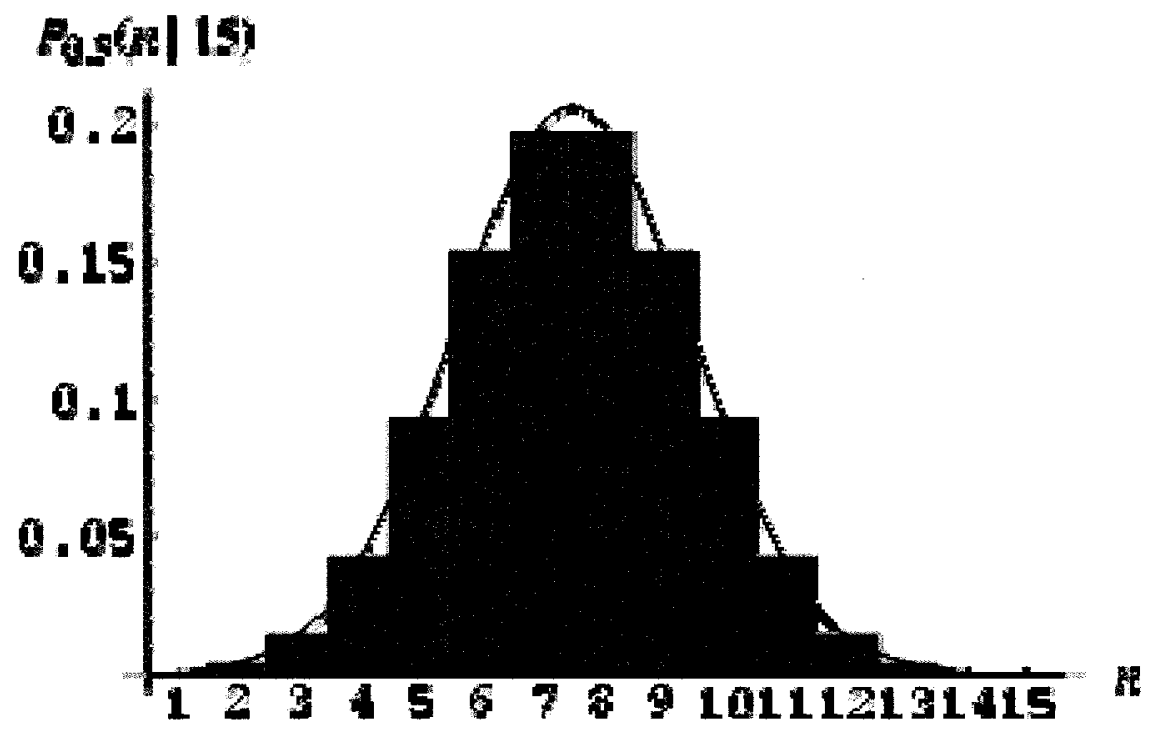

Figure 15 Normal Probability Distribution Function Pattern 


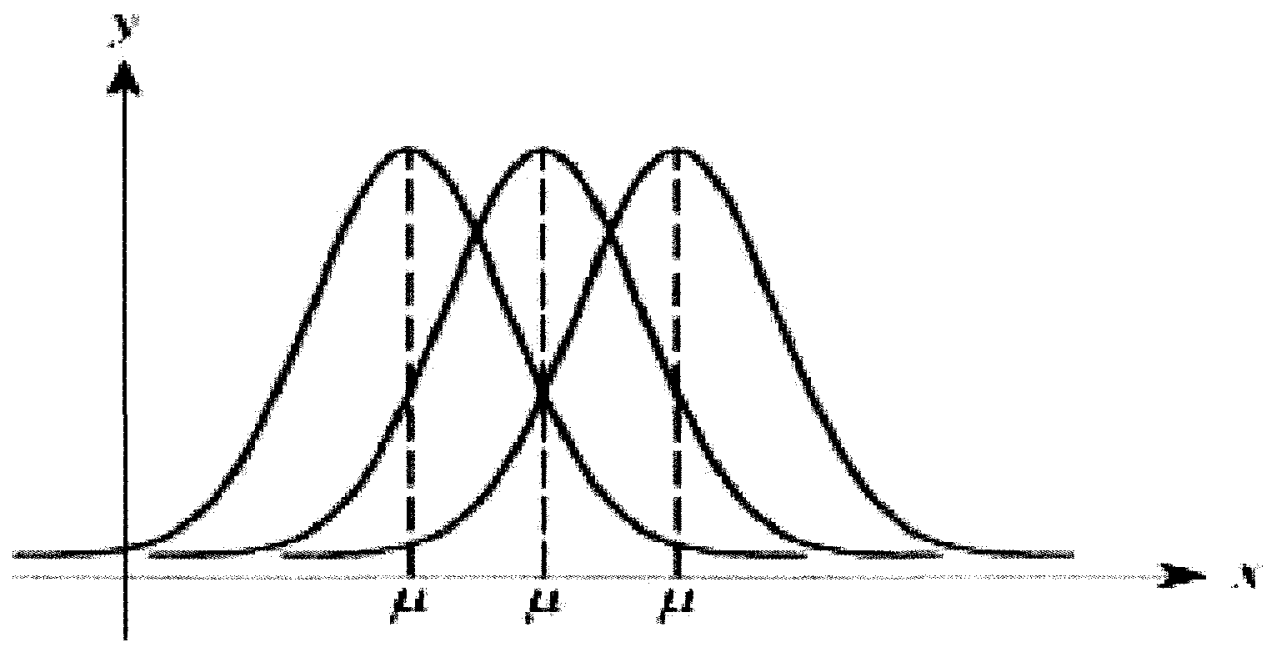

Figure 16 Symmetric Characteristic of Mean in Normal PDF 


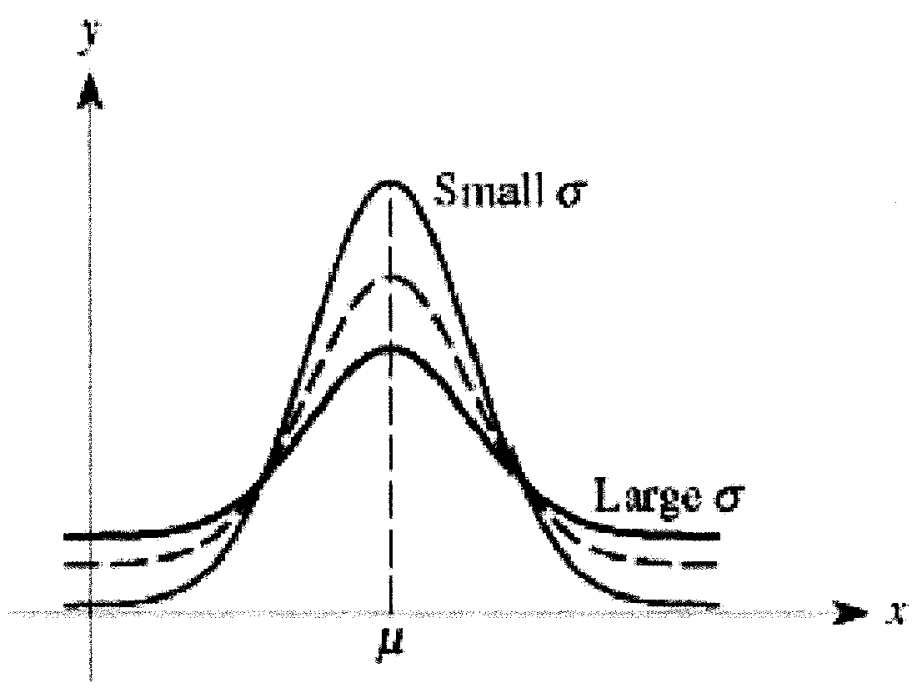

Figure 17 Characteristics of Standard Deviation in Normal PDF 


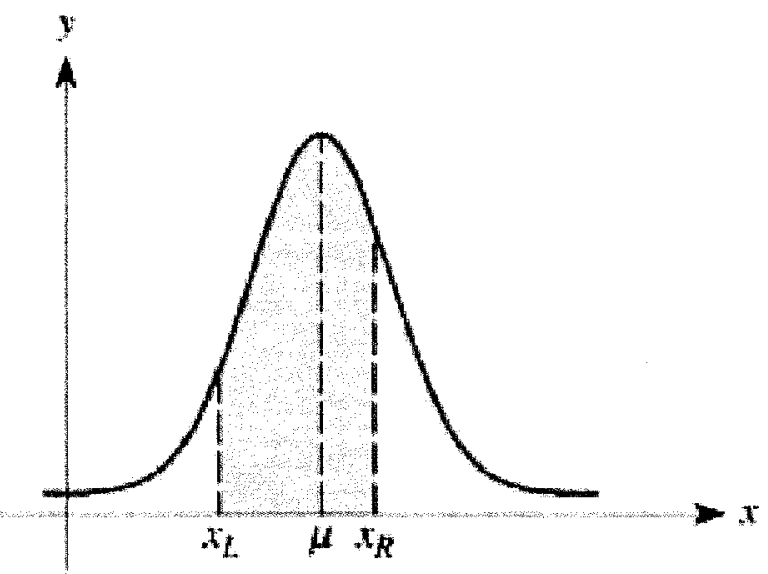

Prohability that a random member of normal population is between $x=x_{L}$ and $x=x_{R}=$ area under the curve

Figure 18 Calculation Principle of Probability for Normal PDF 


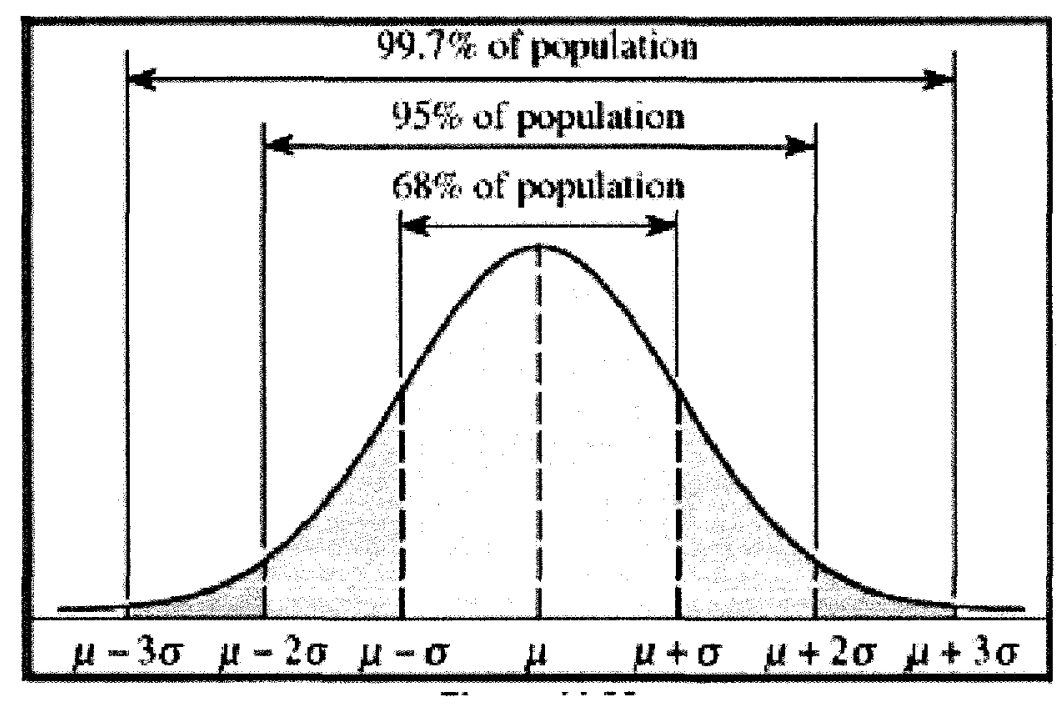

Figure 19 Rules of Thumb for any Normal PDF 

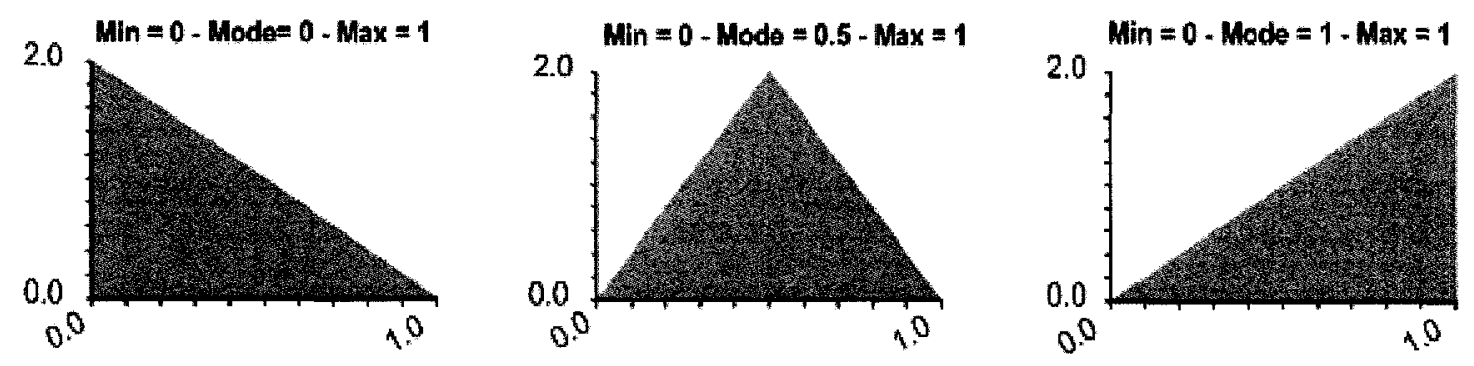

Figure 20 Triangular Probability Distribution Function Pattern 
$\log \operatorname{Normal}(A) \cdot \operatorname{Mean}=1.0$

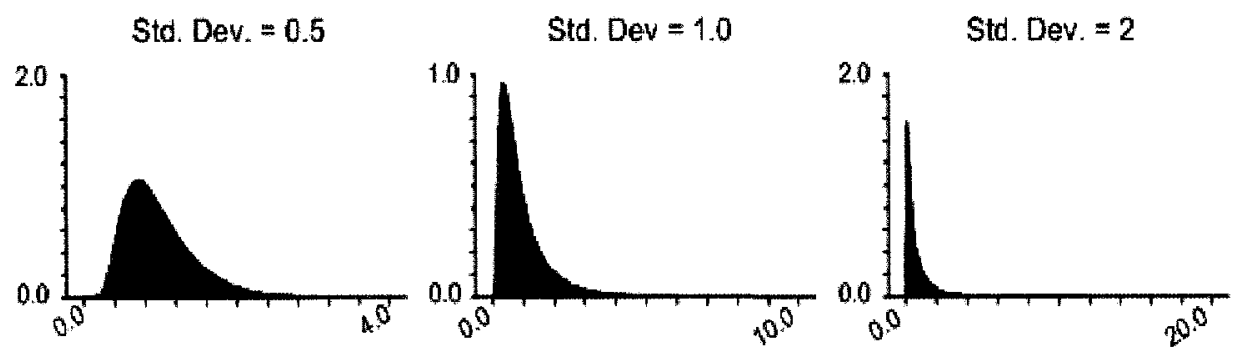

Figure 21 Lognormal Probability Distribution Function Pattern 


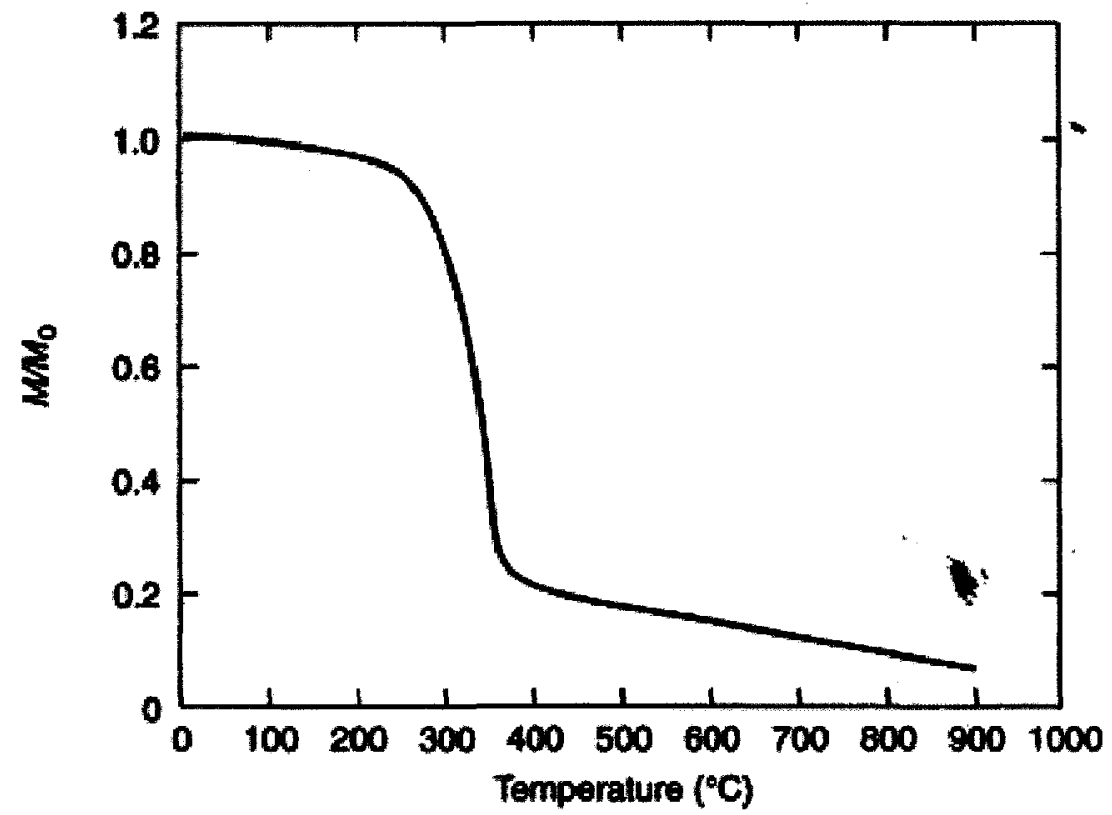

Figure 22 Thermo-Gravimetric Curve for a Pine of $400 \mathrm{~kg} / \mathrm{m}^{3}$ Density [37] 


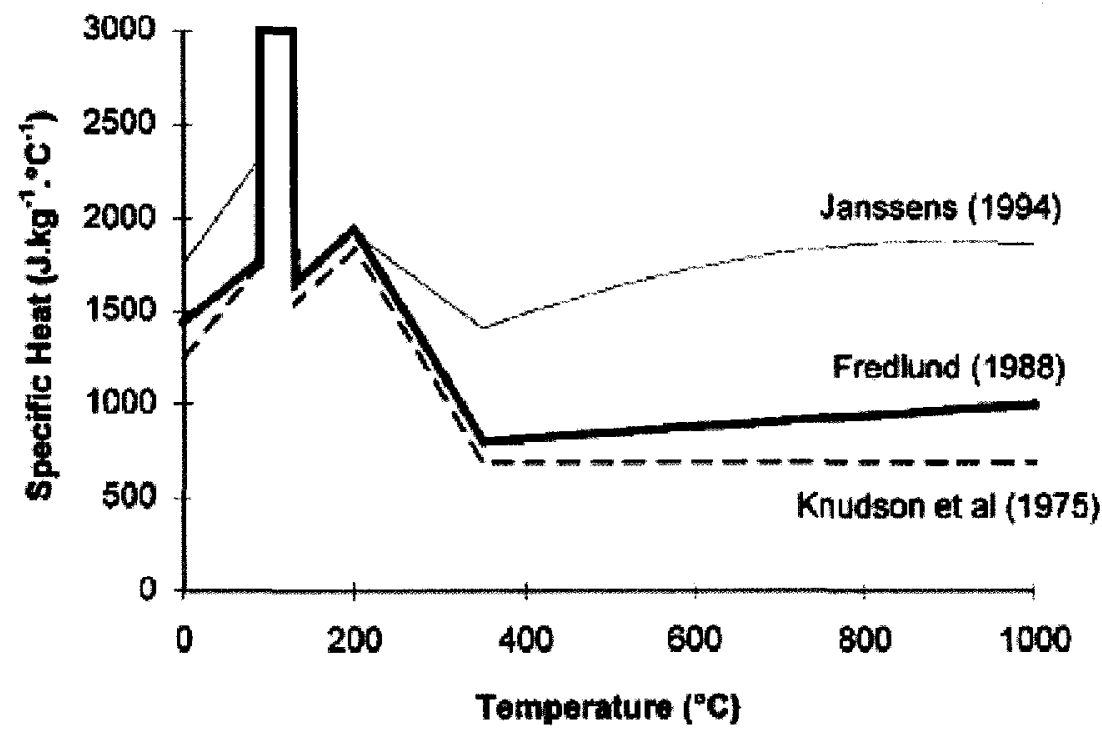

Figure 23 Specific Heat Curves for Wood with 12\% Moisture Content [38, 39] 


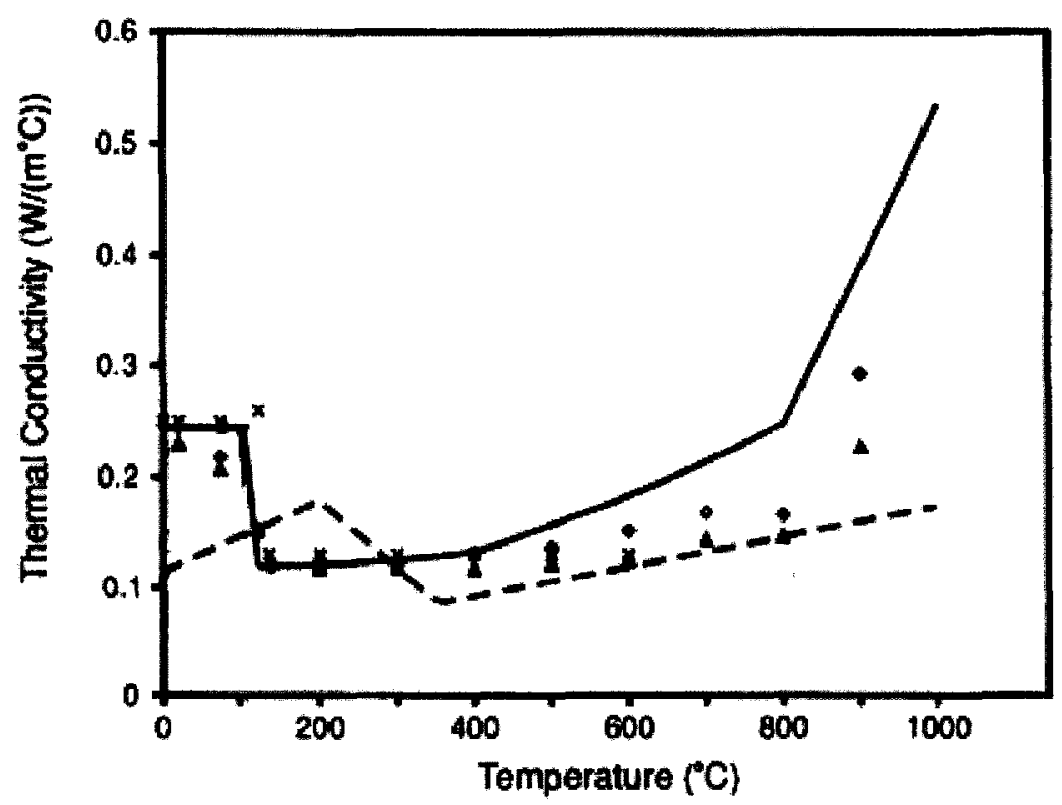

Figure 24 Thermal Conductivity as a Function of Temperature for Gypsum board (solid line) and for Wood (dashed line) Symbols are measured values for gypsum board: diamonds - Type X, triangles - Type $\mathrm{C}$, and crosses - Type $\mathrm{C}$ from other references $[1,2]$. 


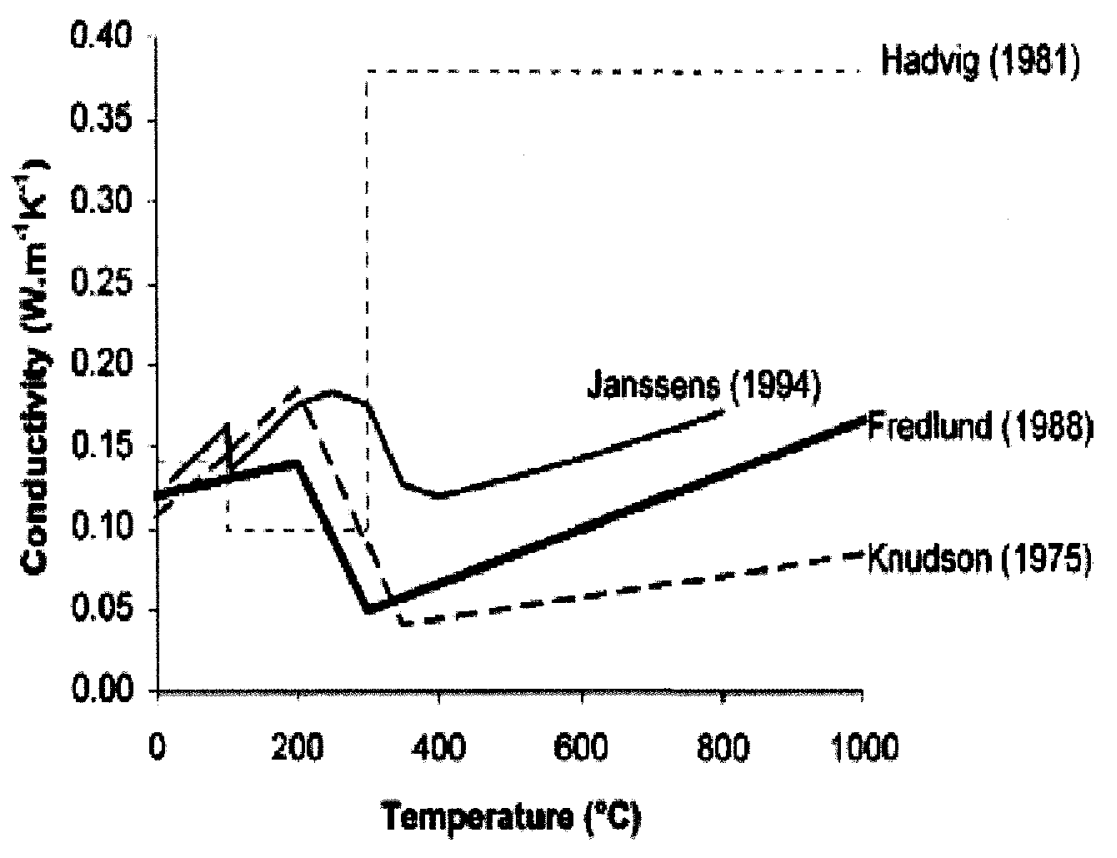

Figure 25 Thermal Conductivity Curves for Wood with a Density of $460 \mathrm{~kg} / \mathrm{m}^{3}$ and Moisture Content of $12 \%$ [38] 


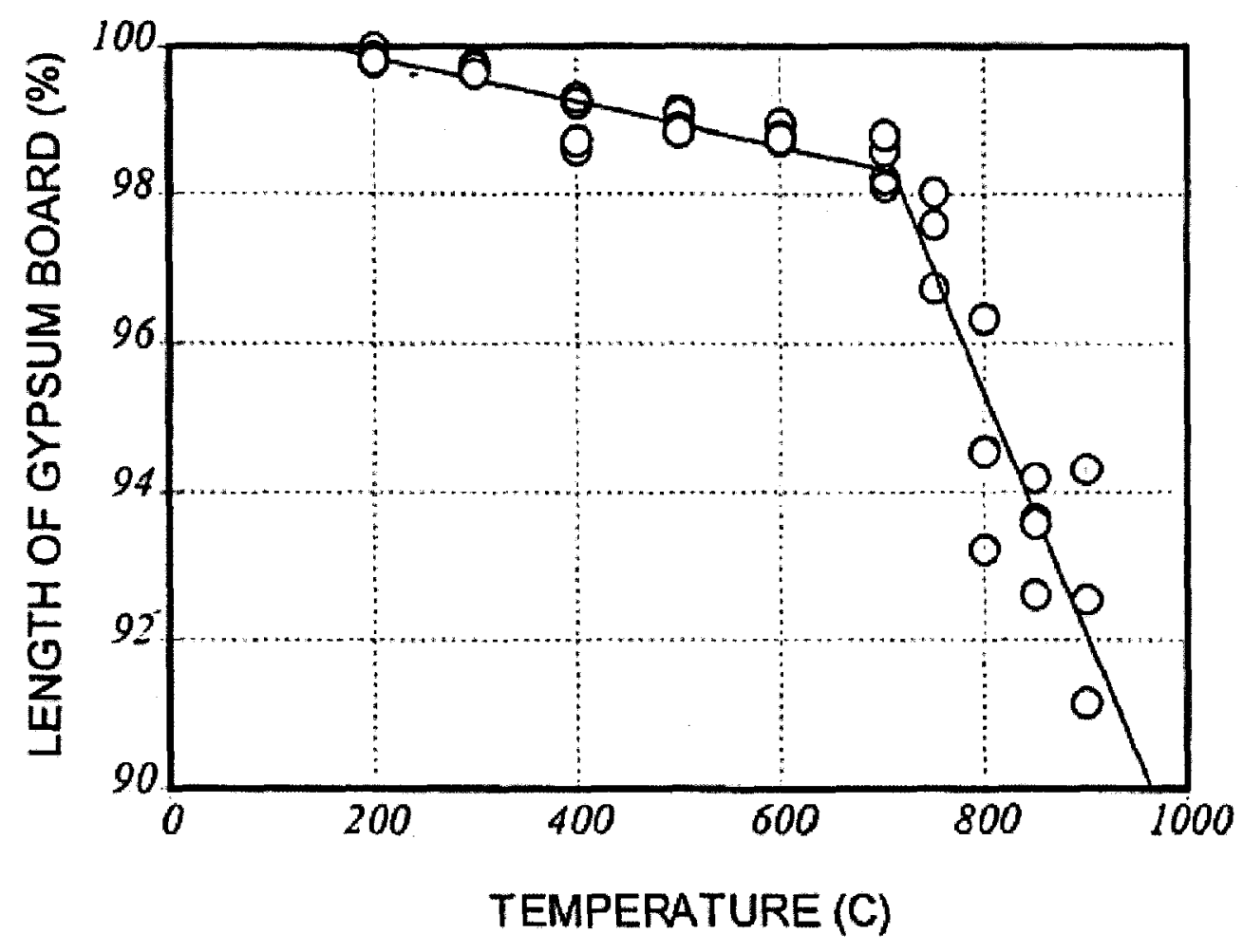

Figure 26 Shrinkage of Gypsum Board as a Function of Temperature [3] 


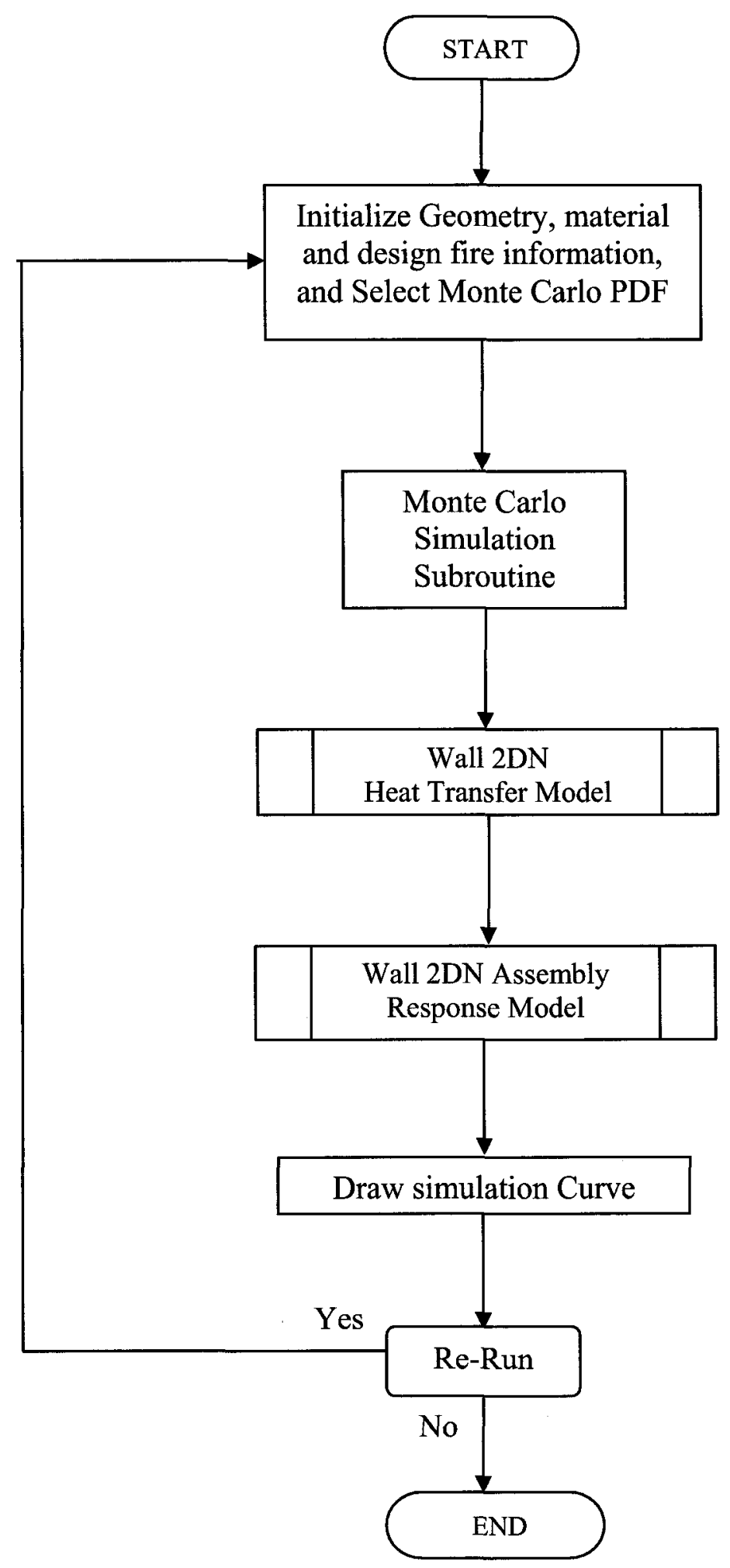

Figure 27 Flow Chart of the WALL2DN-MC Model 


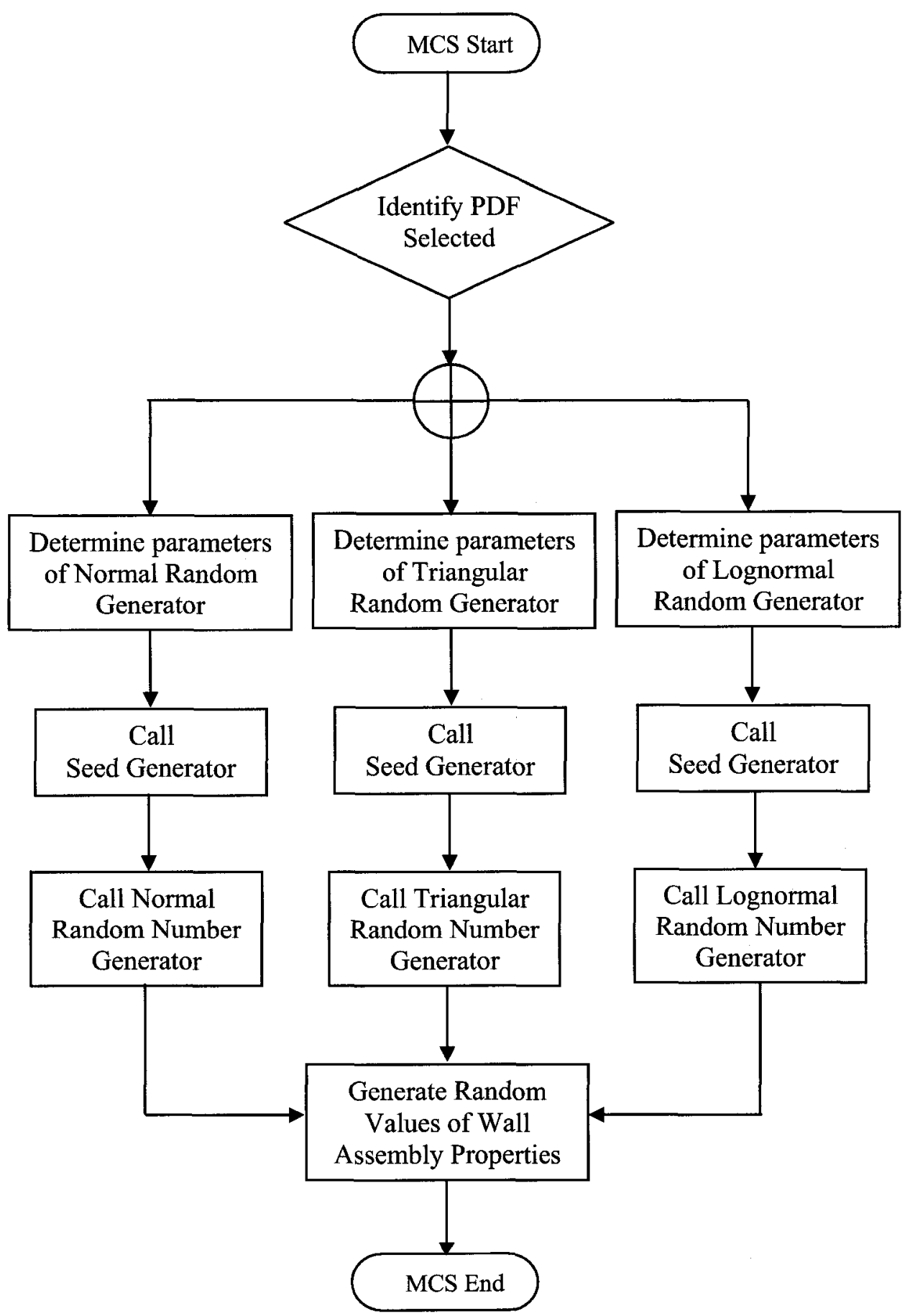

Figure 28 Flow Chart of Subroutine - Monte Carlo Simulation (MCS) 


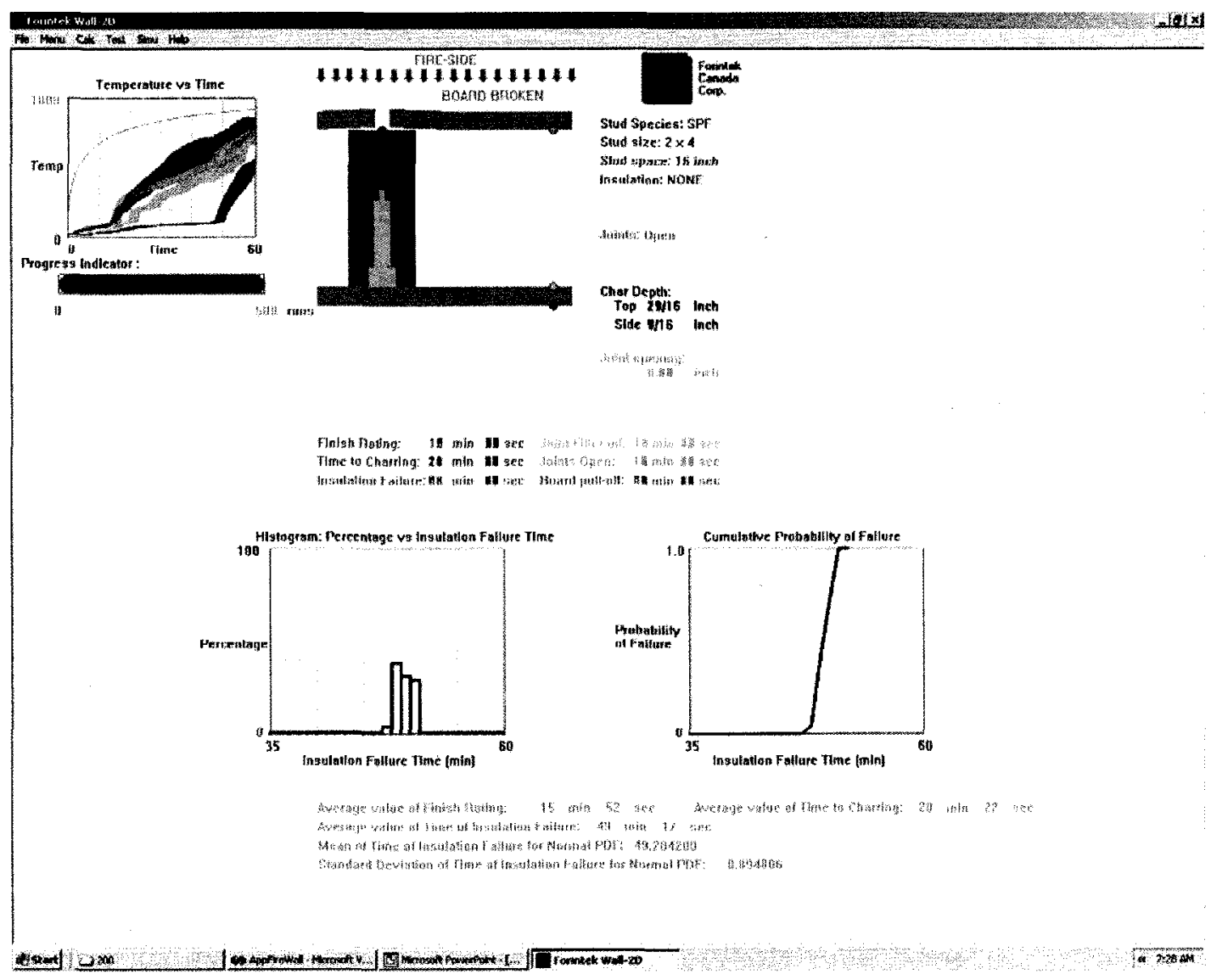

Figure 29 All Five Properties of Wood-Framed Wall simulated on Basis of Normal PDF and Test 5 


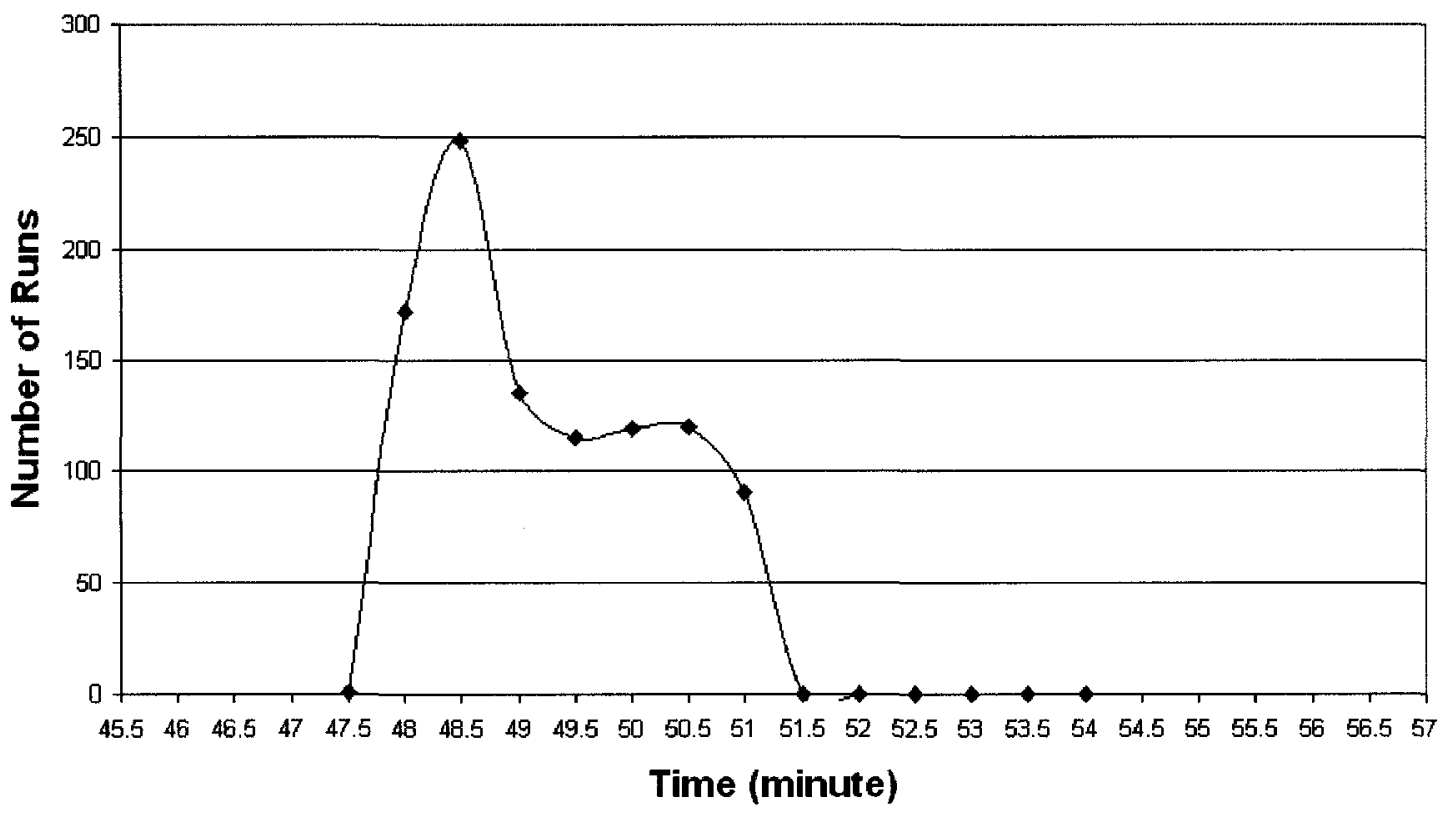

Figure 30 Number of Simulation Runs as a Function of Insulation Failure Time with all Five Properties Selected on Basis of Normal PDF and Test 5 


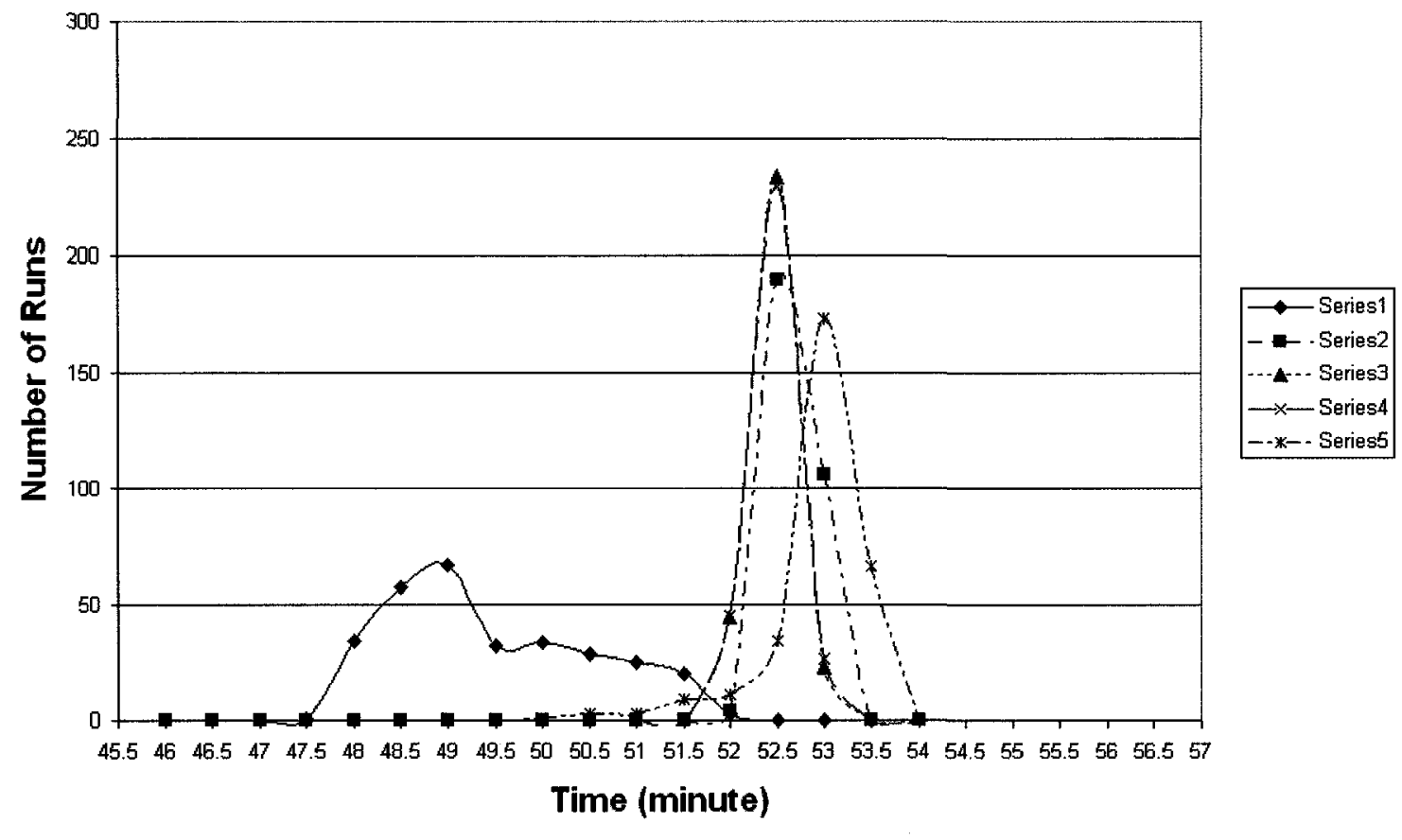

Figure 31 Number of Simulation Runs as a Function of Insulation Failure Time with Each Individual Property on Basis of Normal PDF and Test 5

Series 1: Thermal Conductivity of Gypsum Board only

Series 2: Specific Heat of Gypsum Board only

Series 3: Shrinkage of Gypsum Board only

Series 4: Thermal Conductivity of Wood Stud only

Series 5: Specific Heat of Wood Stud only 


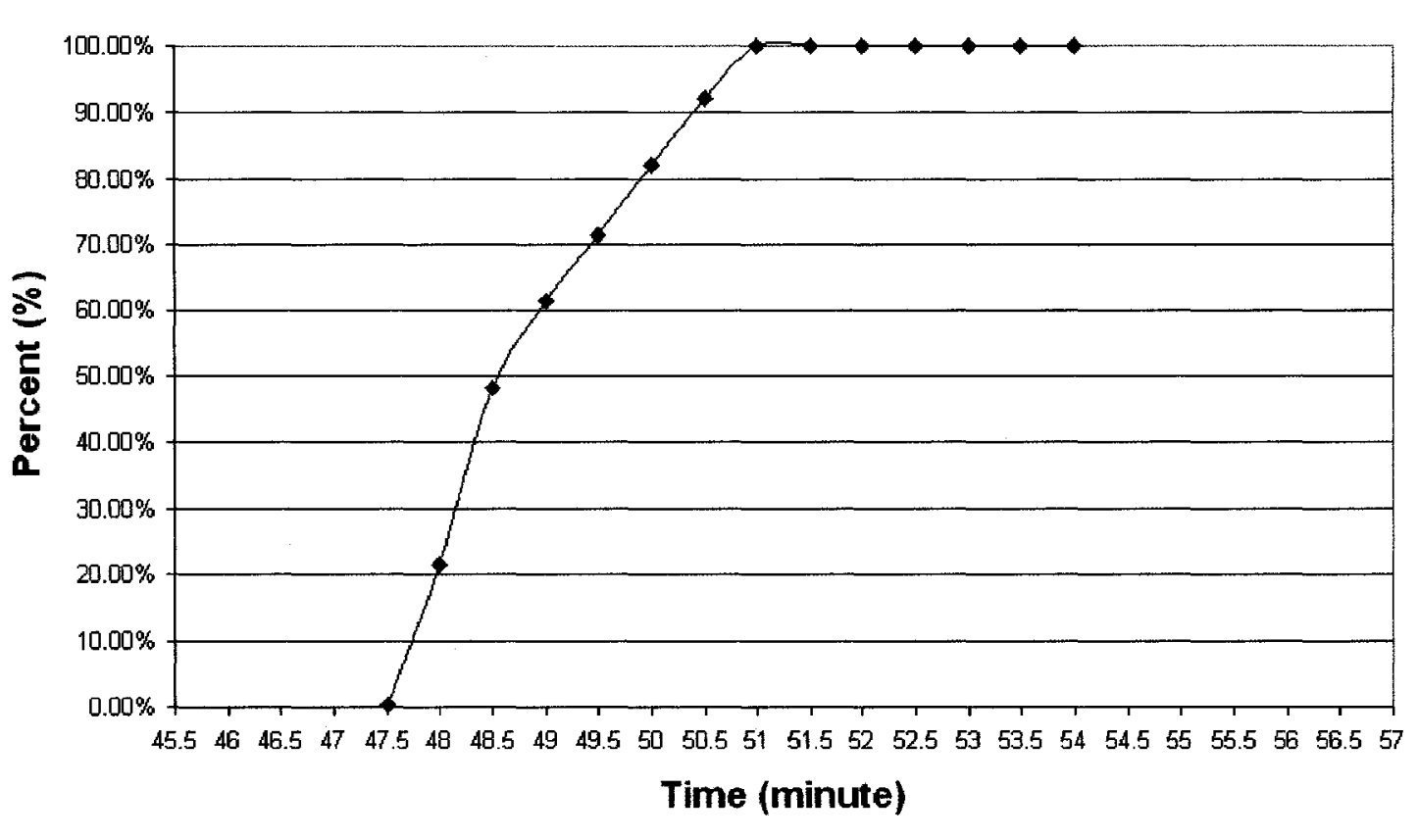

Figure 32 Cumulative Probability as a Function of Insulation Failure Time with all Five Properties Selected on Basis of Normal PDF and Test 5 


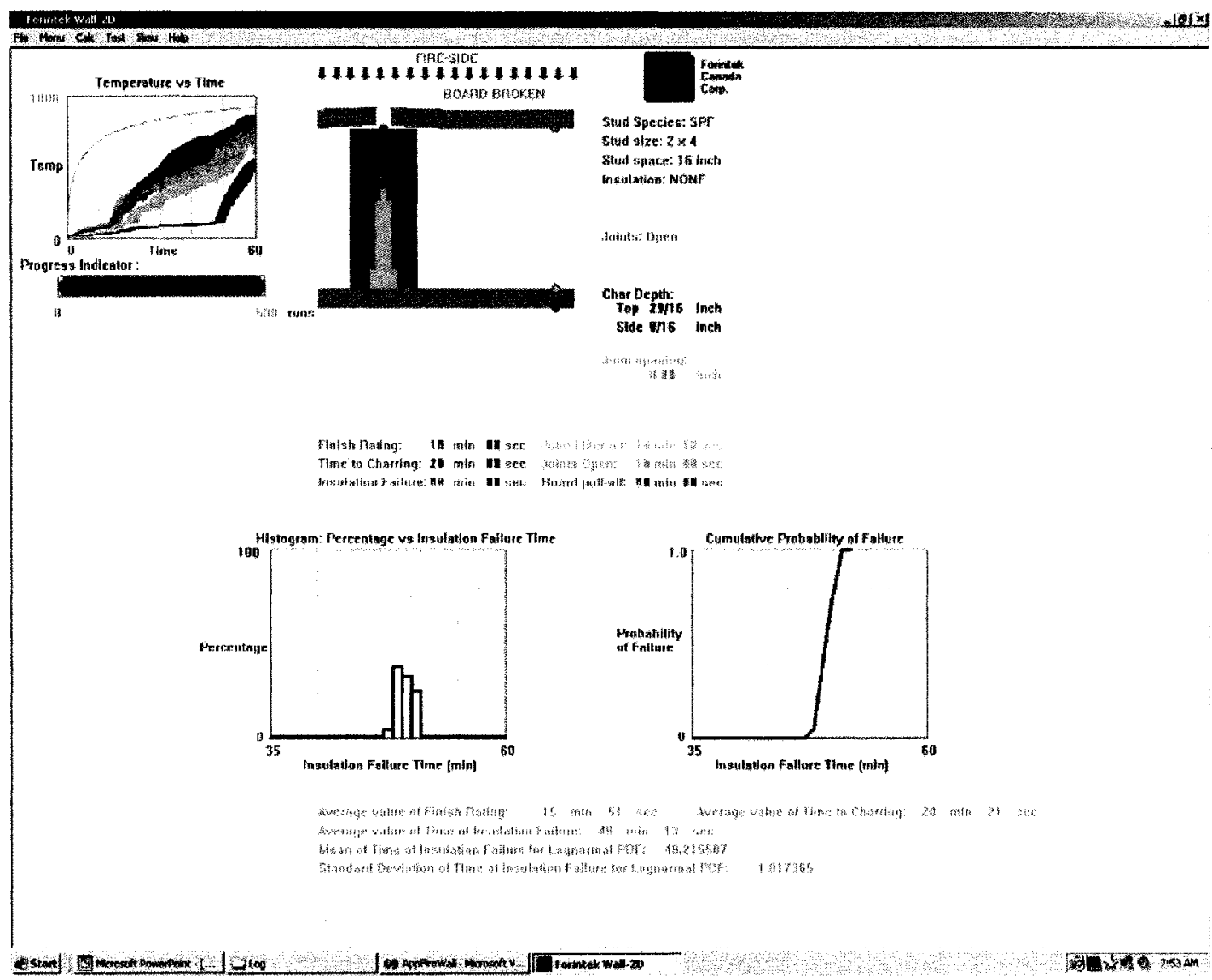

Figure 33 All Five Properties of Wood-Framed Wall simulated on Basis of Lognormal PDF and Test 5 


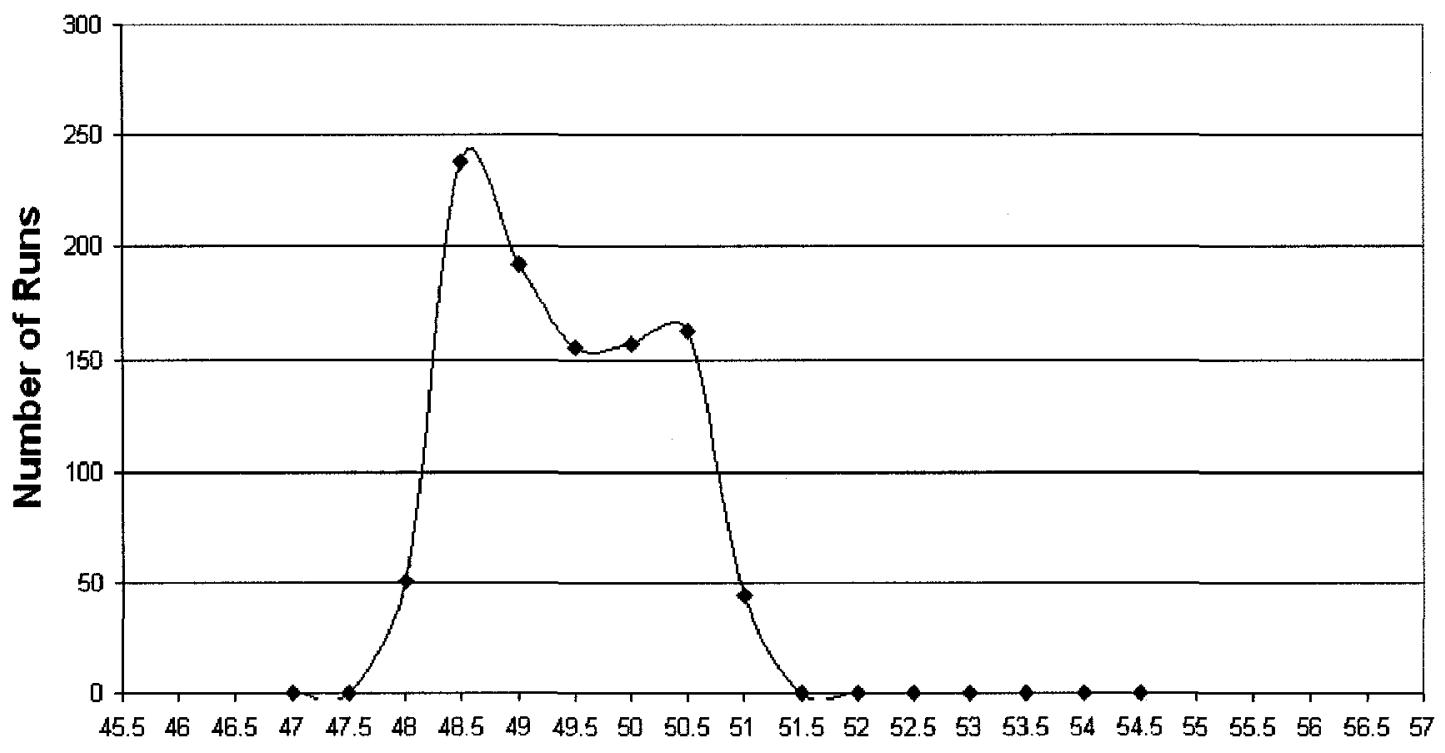

Time (minute)

Figure 34 Number of Simulation Runs as a Function of Insulation Failure Time with all Five Properties Selected on Basis of Lognormal PDF and Test 5 


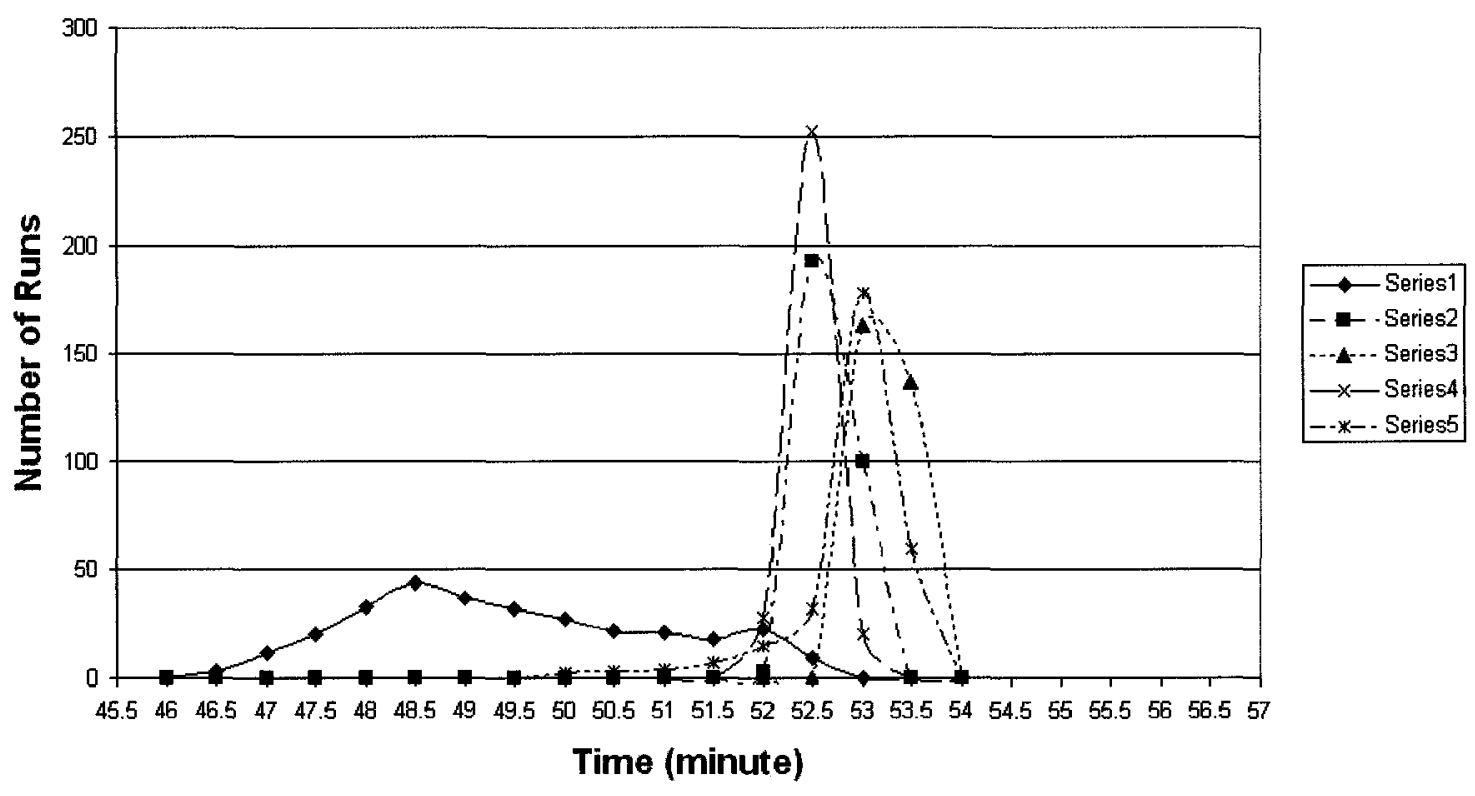

Figure 35 Number of Simulation Runs as a Function of Insulation Failure Time with Each Individual Property on Basis of Lognormal PDF and Test 5

Series 1: Thermal Conductivity of Gypsum Board only

Series 2: Specific Heat of Gypsum Board only

Series 3: Shrinkage of Gypsum Board only

Series 4: Thermal Conductivity of Wood Stud only

Series 5: Specific Heat of Wood Stud only 


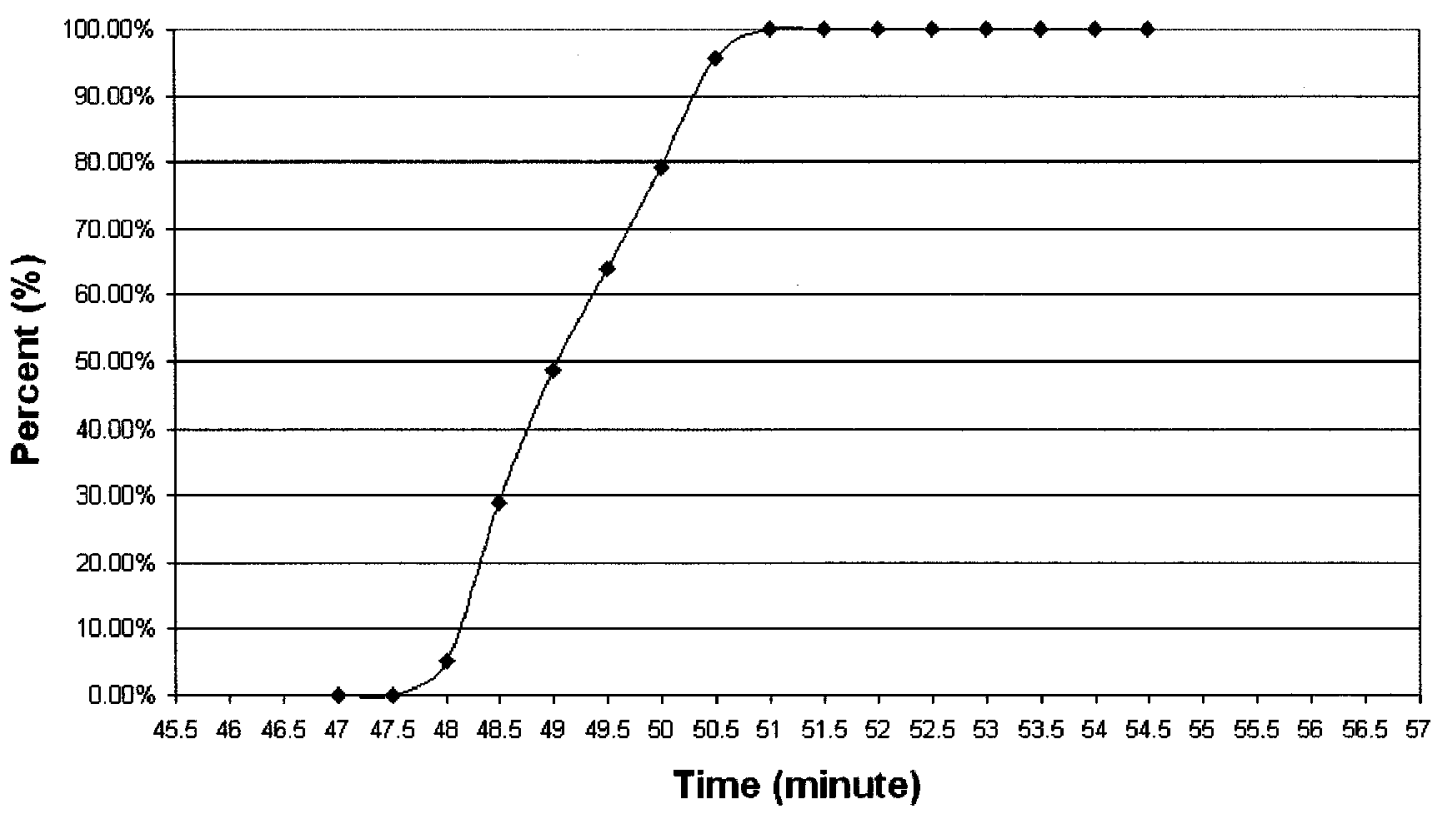

Figure 36 Cumulative Probability as a Function of Insulation Failure Time with all Five Properties Selected on Basis of Lognormal PDF and Test 5 


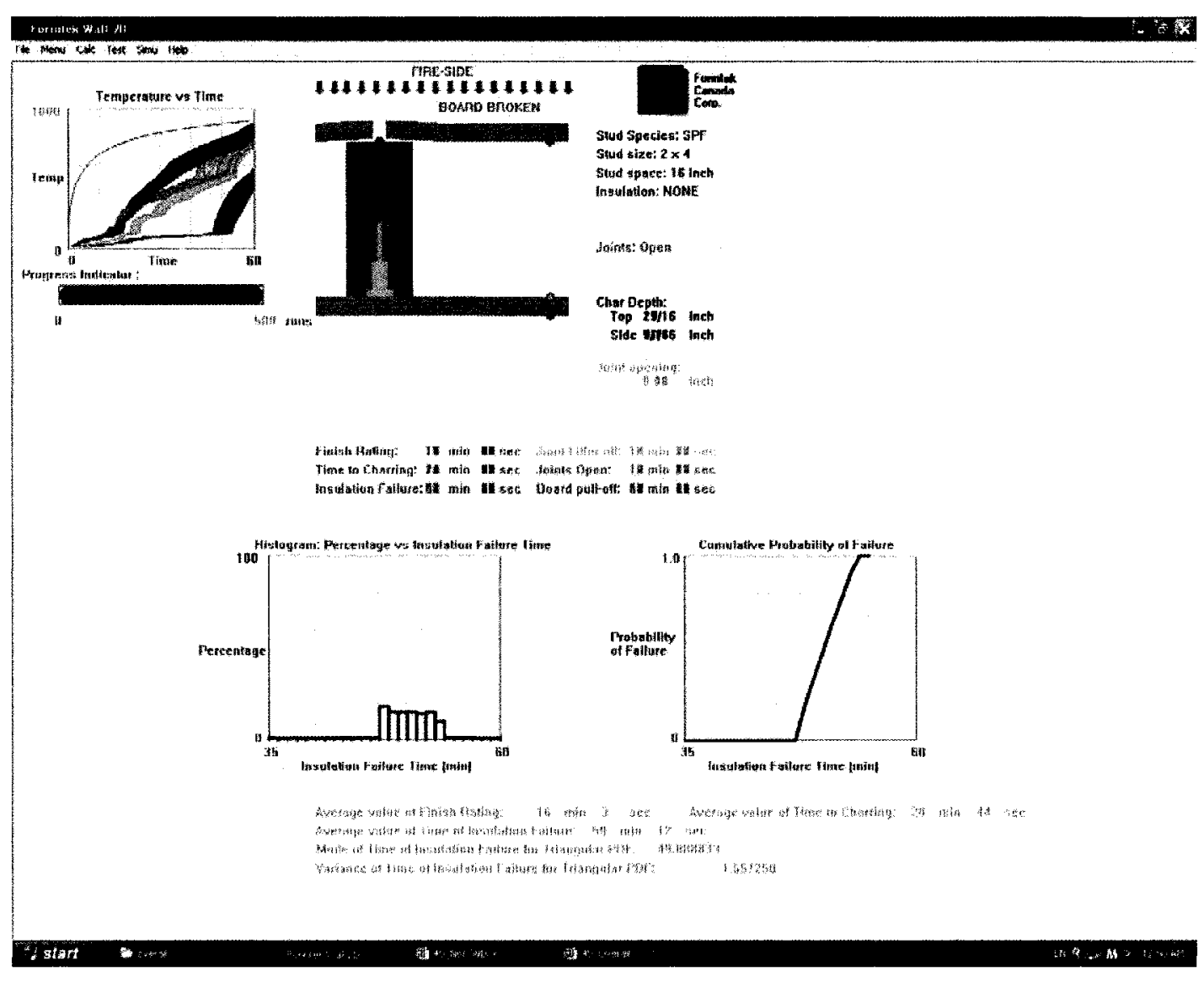

Figure 37 All Five Properties of Wood-Framed Wall Simulated on Basis of Triangular PDF and Test 5 


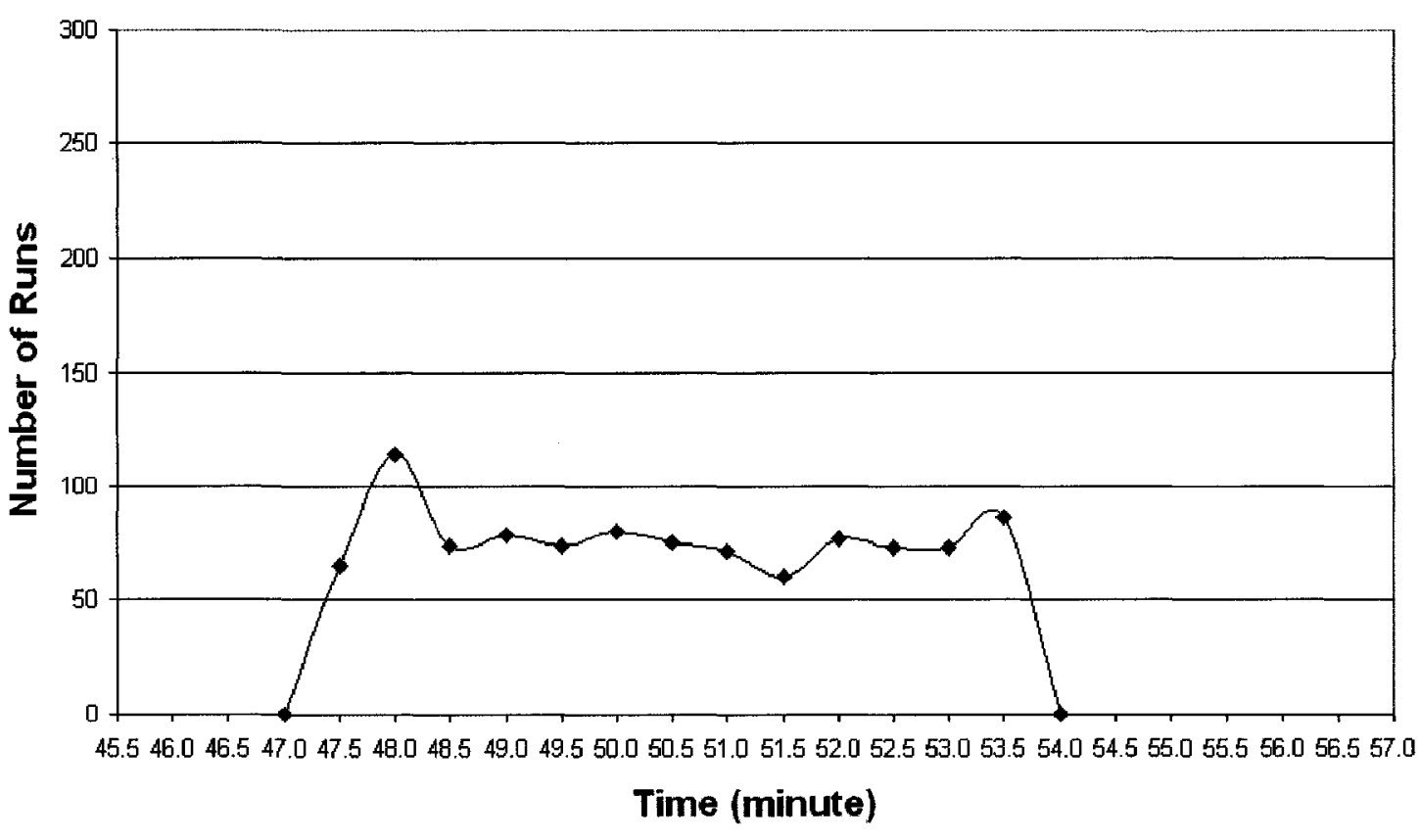

Figure 38 Number of Simulation Runs as a Function of Insulation Failure Time with all Five Properties Selected on Basis of Triangular PDF and Test 5 


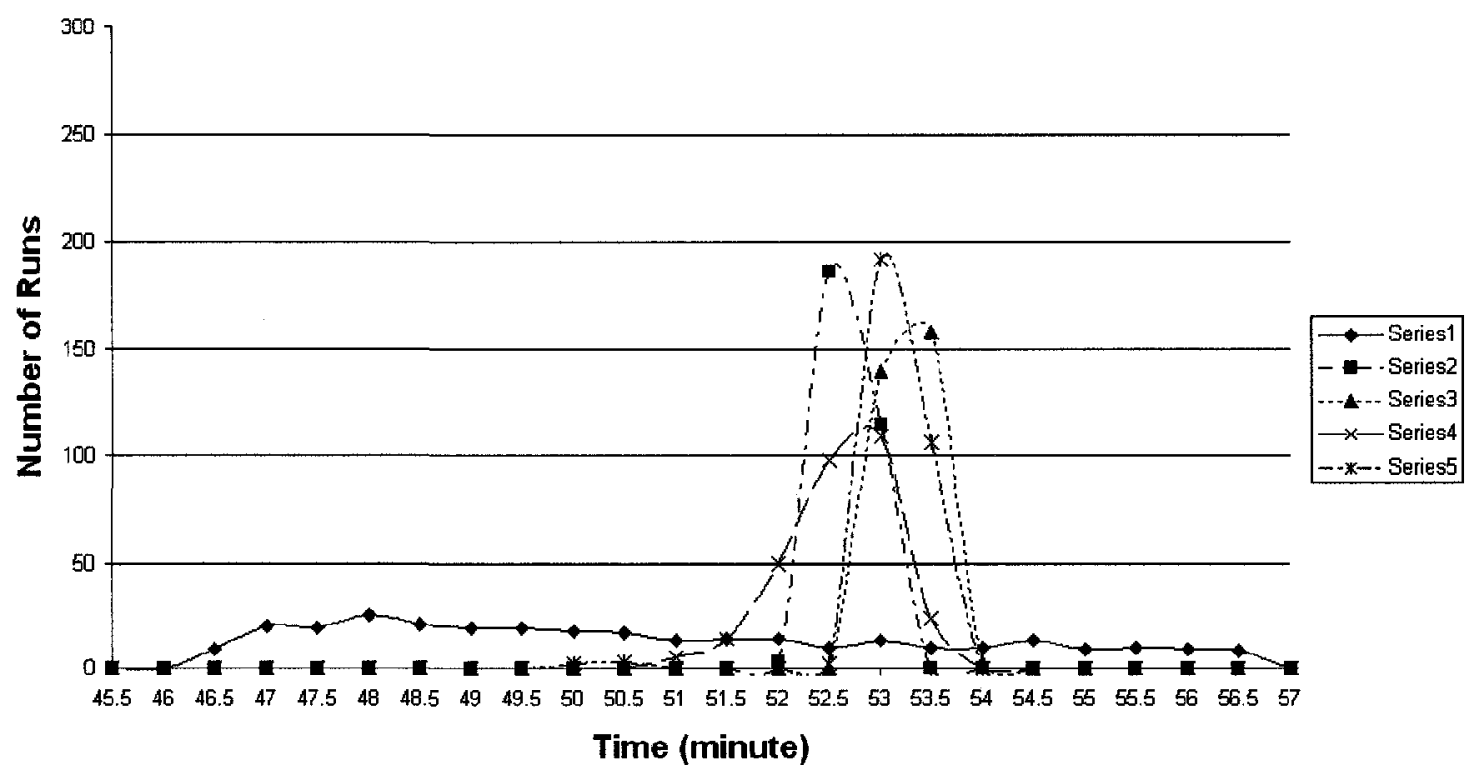

Figure 39 Number of Simulation Runs as a Function of Insulation Failure Time with Each Individual Property on Basis of Triangular PDF and Test 5

Series 1: Thermal Conductivity of Gypsum Board only

Series 2: Specific Heat of Gypsum Board only

Series 3: Shrinkage of Gypsum Board only

Series 4: Thermal Conductivity of Wood Stud only

Series 5: Specific Heat of Wood Stud only 


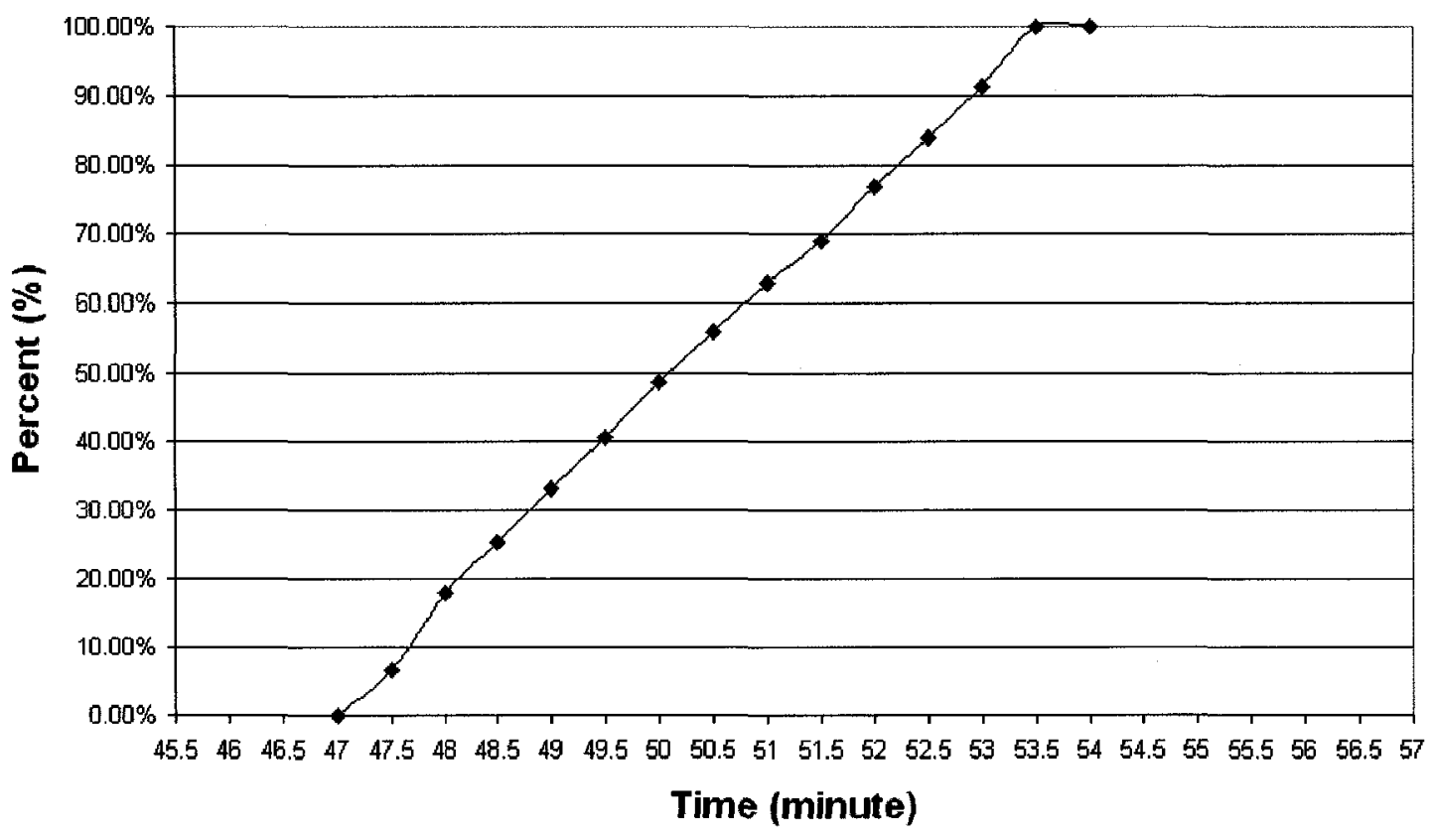

Figure 40 Cumulative Probability as a Function of Insulation Failure Time with all Five Properties Selected on Basis of Triangular PDF and Test 5 


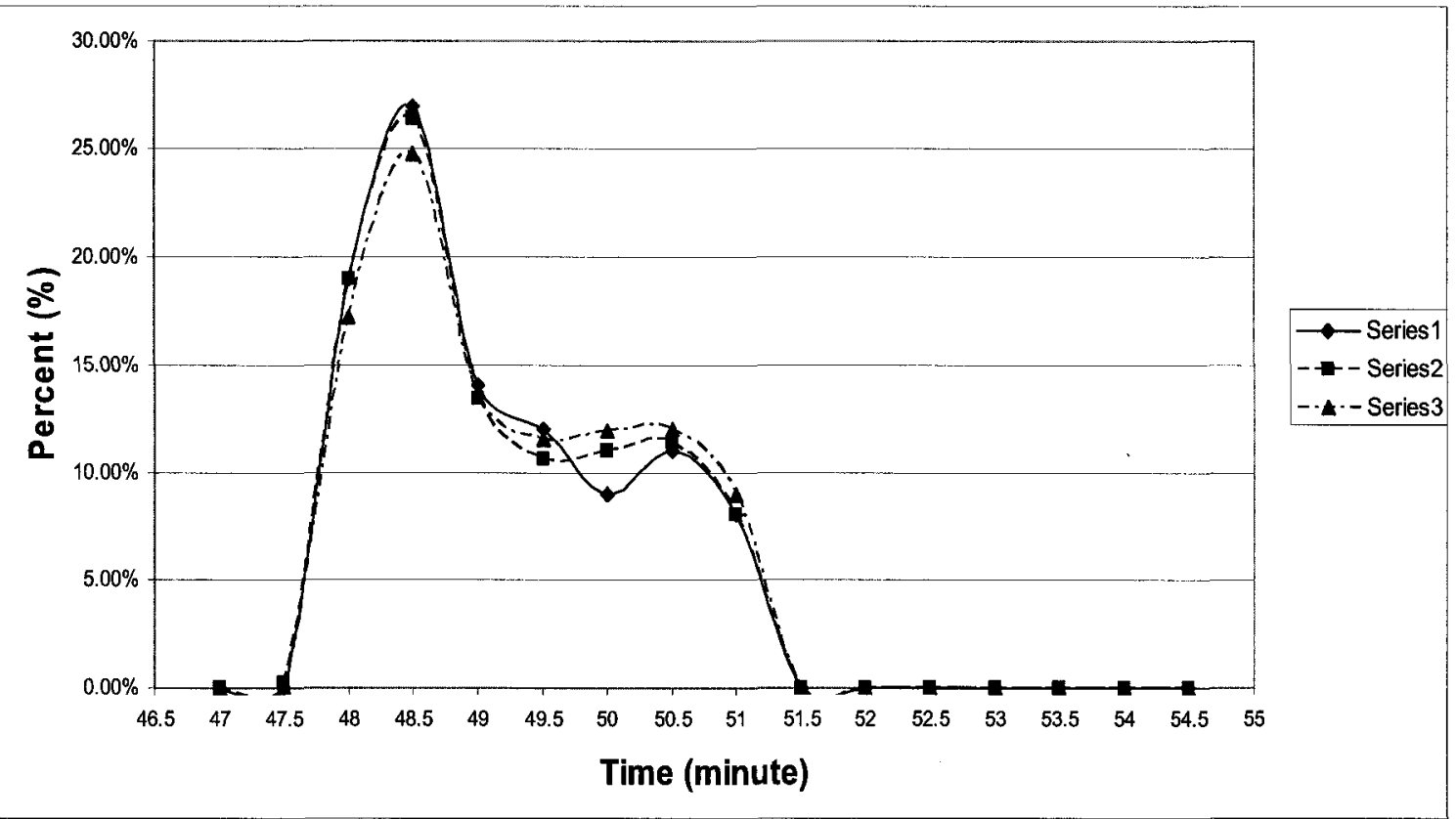

Figure 41 Histogram Curves of 100, 500 and 1,000 Runs as a Function of Insulation Failure Time with all Five Properties Selected on Basis of Normal PDF and Test 5

Series 1: 100 runs (solid line)

Series 2: 500 runs (dash line)

Series 3: 1,000 runs (dash dot line) 


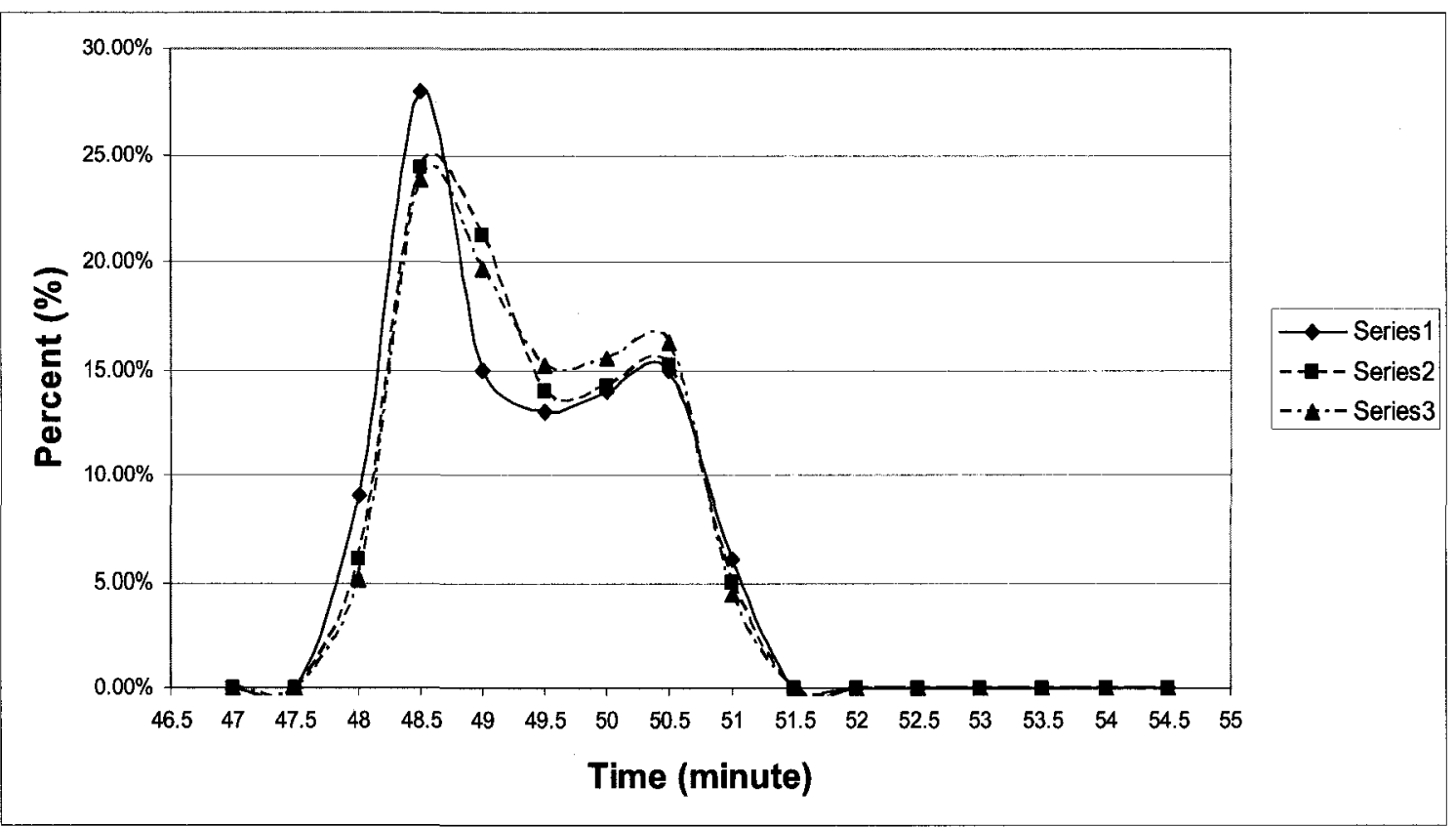

Figure 42 Histogram Curves of 100, 500 and 1,000 Runs as a Function of Insulation Failure Time with all Five Properties Selected on Basis of Lognormal PDF and Test 5 Series 1: 100 runs (solid line) Series 2: 500 runs (dash line) Series 3: 1,000 runs (dash dot line) 


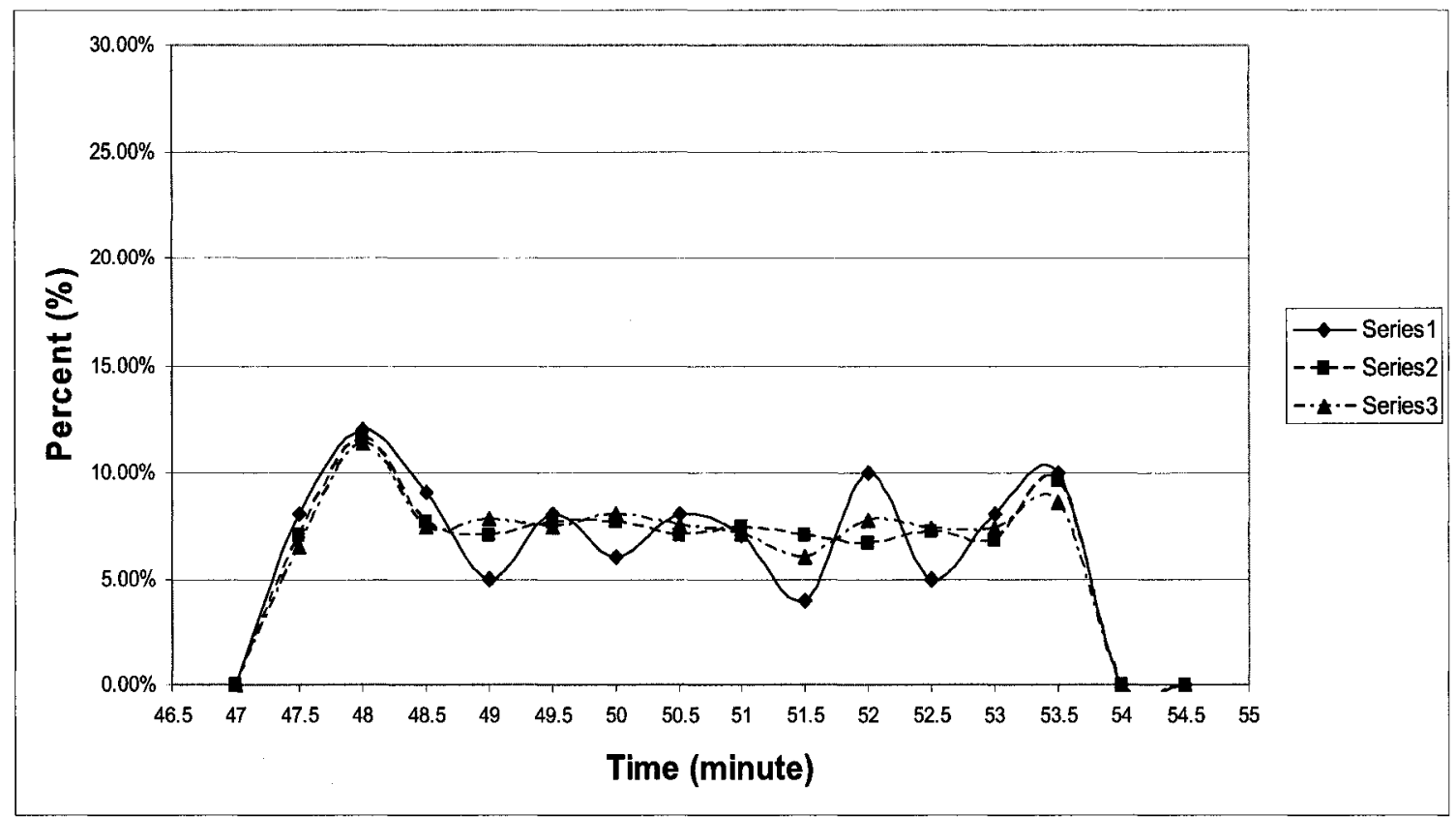

Figure 43 Histogram Curves of 100, 500 and 1,000 Runs as a Function of Insulation Failure Time with all Five Properties Selected on Basis of Triangular PDF and Test 5

Series 1: 100 runs (solid line)

Series 2: 500 runs (dash line)

Series 3: 1,000 runs (dash dot line) 


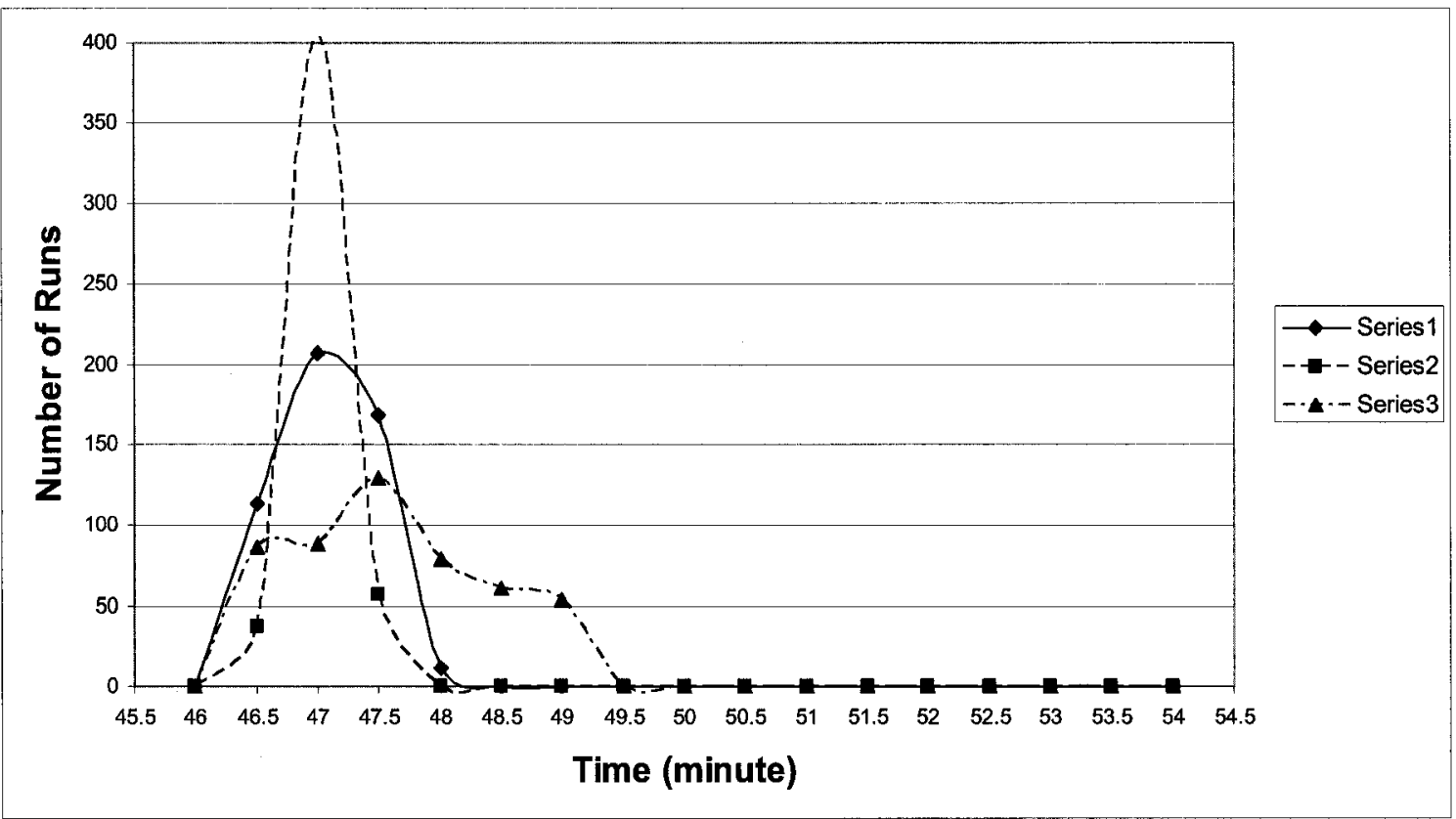

Figure 44 Number of Simulation Runs as a Function of Insulation Failure Time Showing Probability of Insulation Failure for Test G1

Series 1: Normal pdf (solid line)

Series 2: Lognormal pdf (dash line)

Series 3: Triangular pdf (dash dot line) 


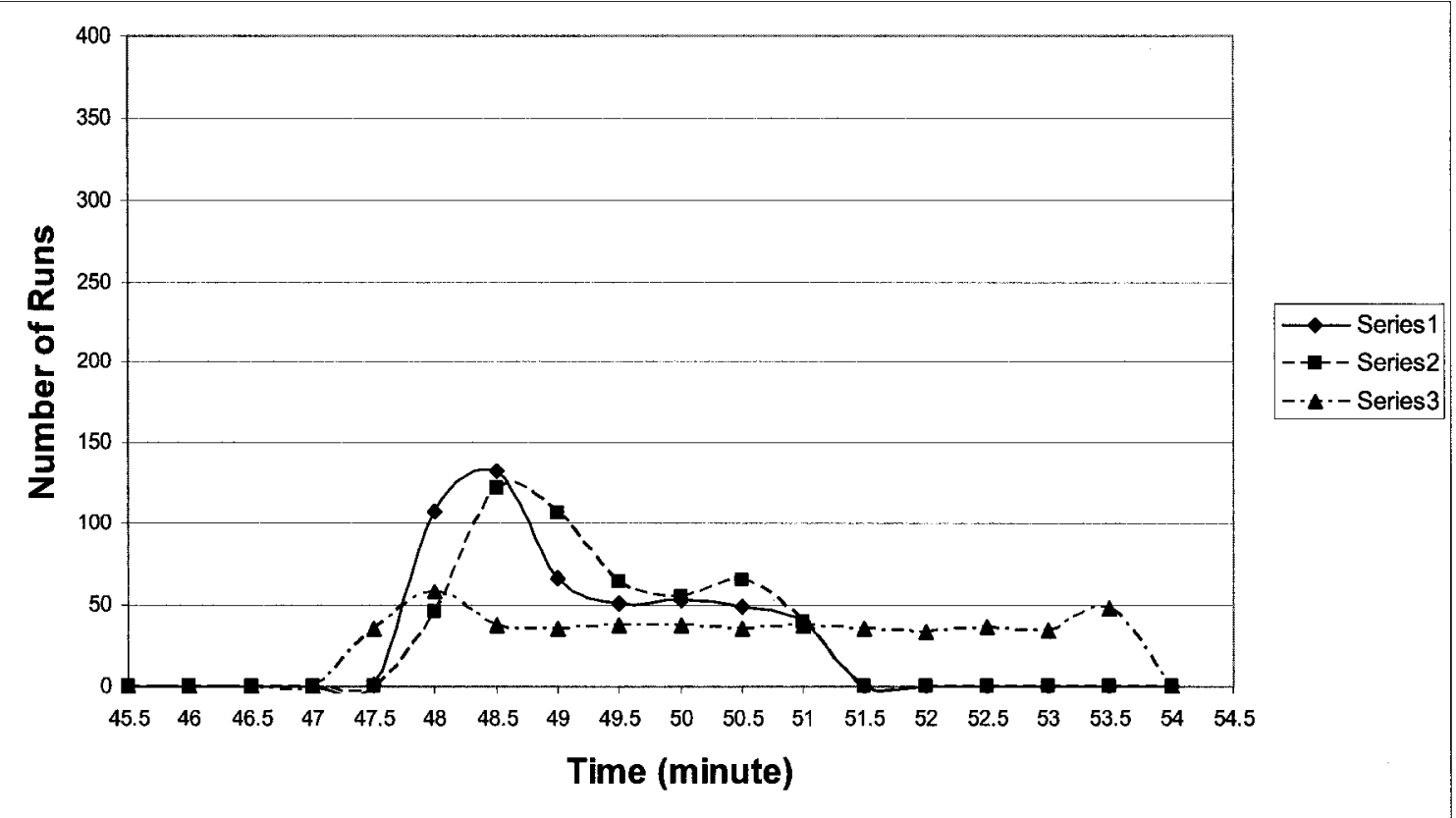

Figure 45 Number of Simulation Runs as a Function of Insulation Failure Time Showing Probability of Insulation Failure for Test 5

Series 1: Normal pdf (solid line)

Series 2: Lognormal pdf (dash line)

Series 3: Triangular pdf (dash dot line) 


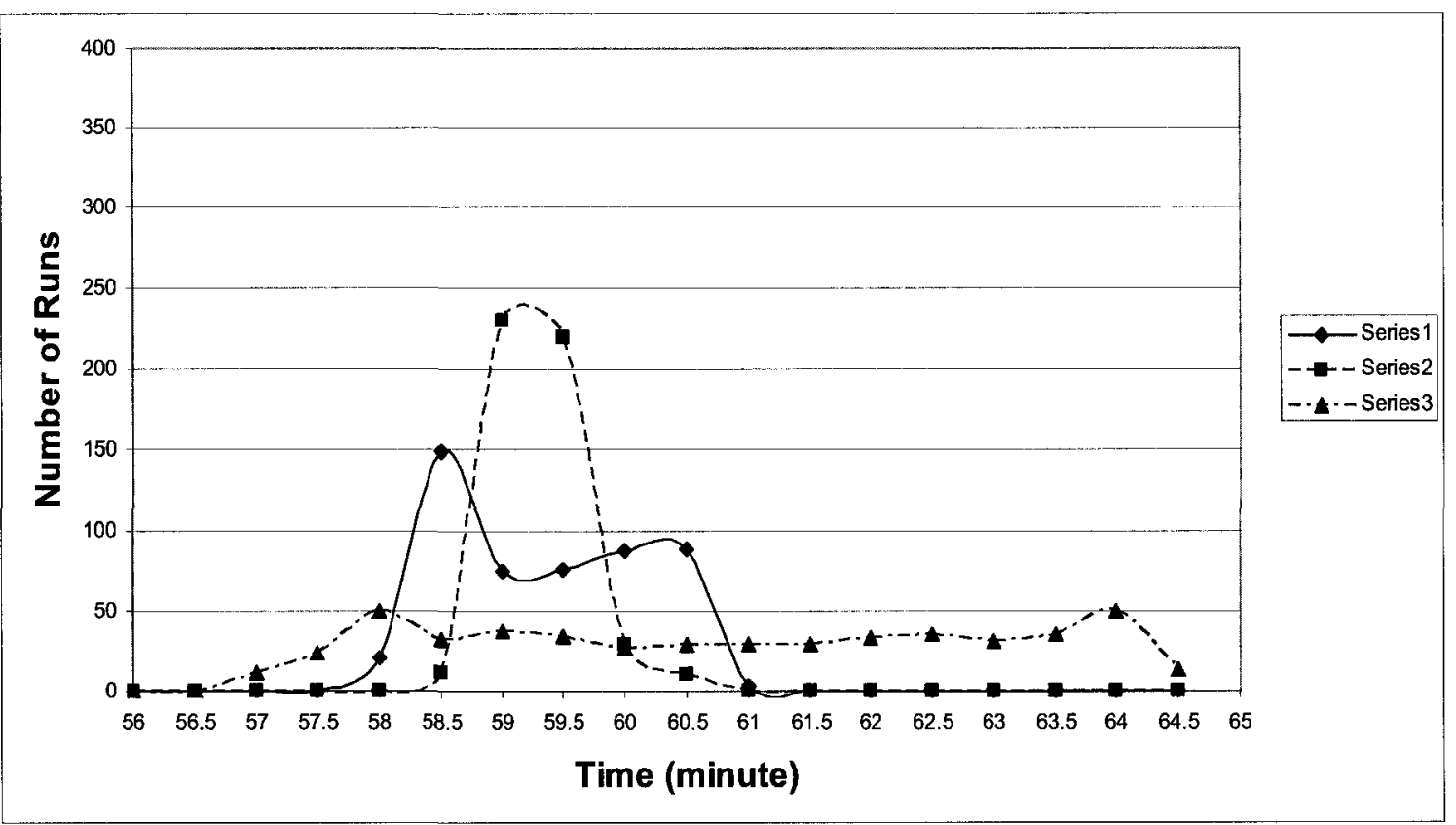

Figure 46 Number of Simulation Runs as a Function of Insulation Failure Time Showing Probability of Insulation Failure for Test 6

Series 1: Normal pdf (solid line)

Series 2: Lognormal pdf (dash line)

Series 3: Triangular pdf (dash dot line) 


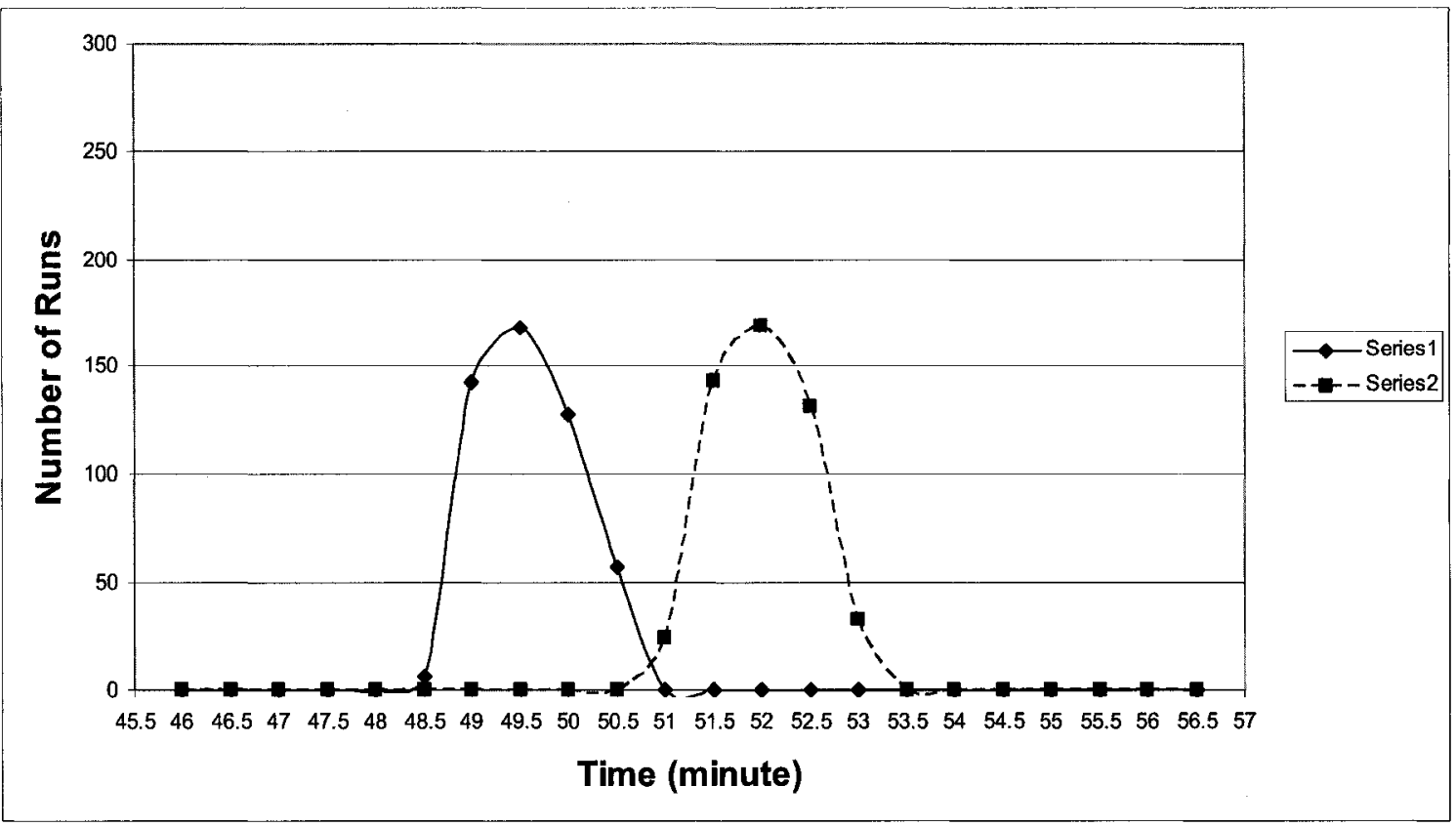

Figure 47 Number of Simulation Runs as a Function of Insulation Failure Time on Basis of Normal PDF and Test 5

Series 1: All three gypsum board properties selected (solid line)

Series 2: All two wood stud properties selected (dash line) 


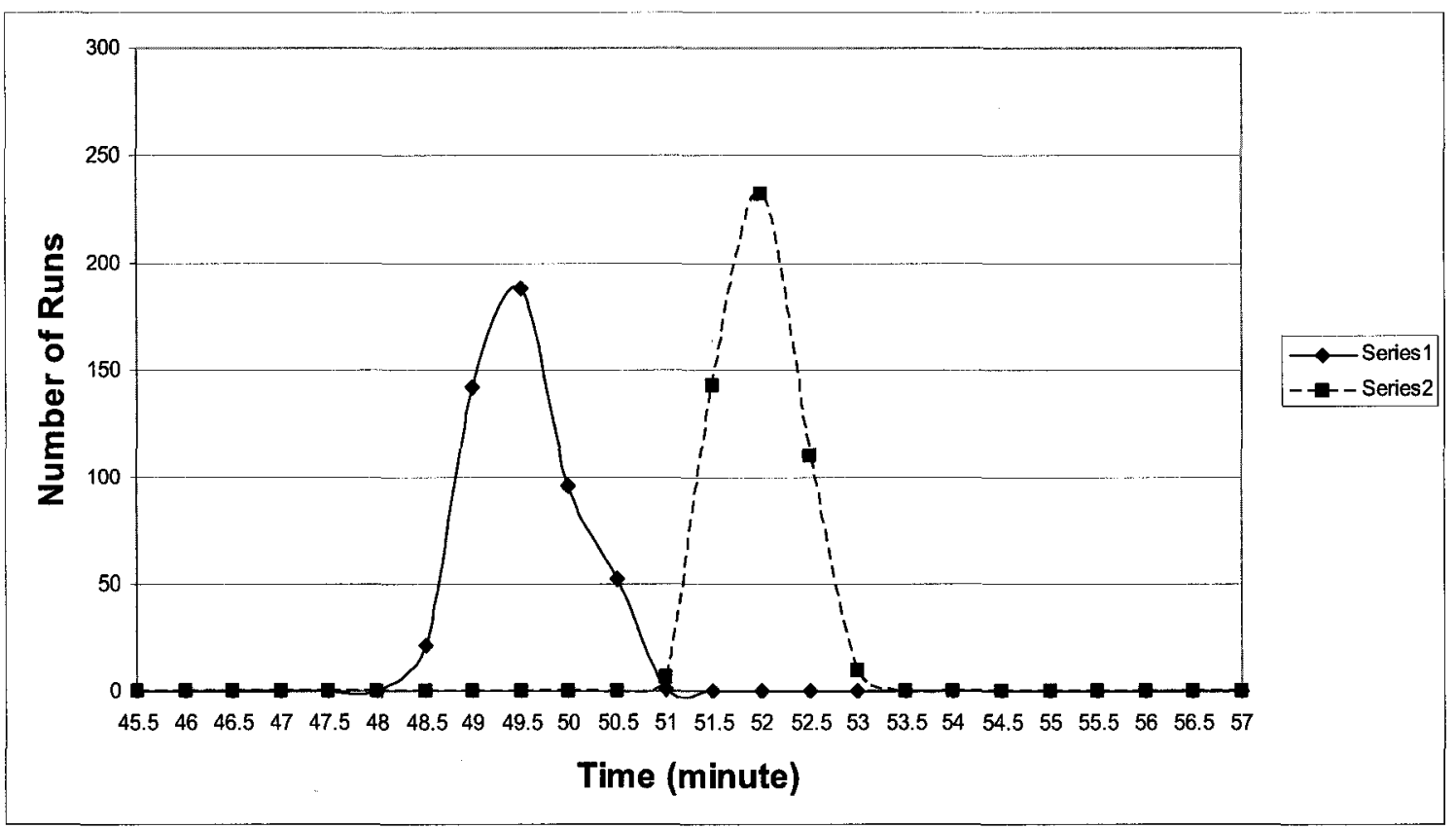

Figure 48 Number of Simulation Runs as a Function of Insulation Failure Time on Basis of Lognormal PDF and Test 5

Series 1: All three gypsum board properties selected (solid line)

Series 2: All two wood stud properties selected (dash line) 


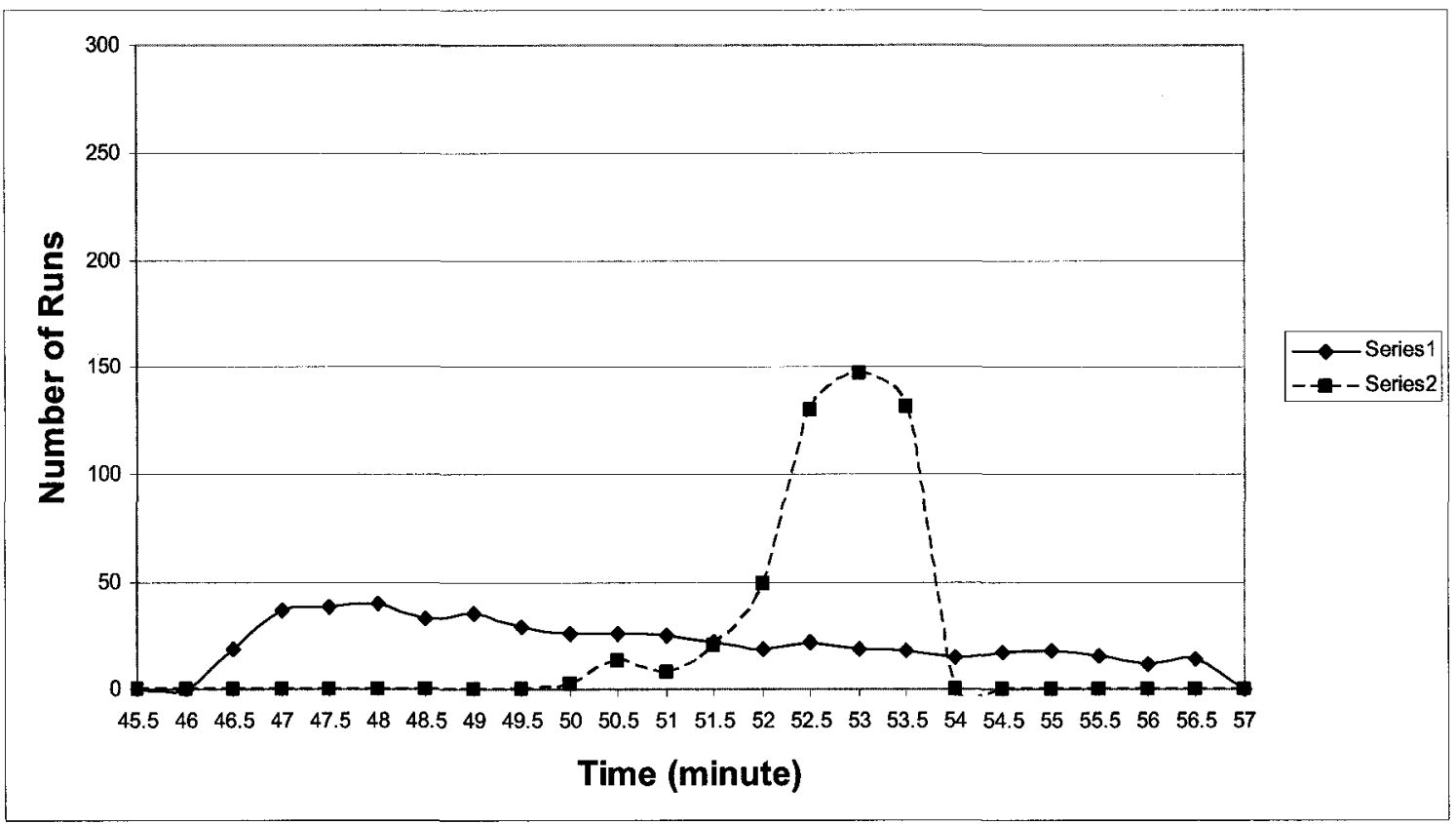

Figure 49 Number of Simulation Runs as a Function of Insulation Failure Time on Basis of Triangular PDF and Test 5

Series 1: All three gypsum board properties selected (solid line) Series 2: All two wood stud properties selected (dash line) 


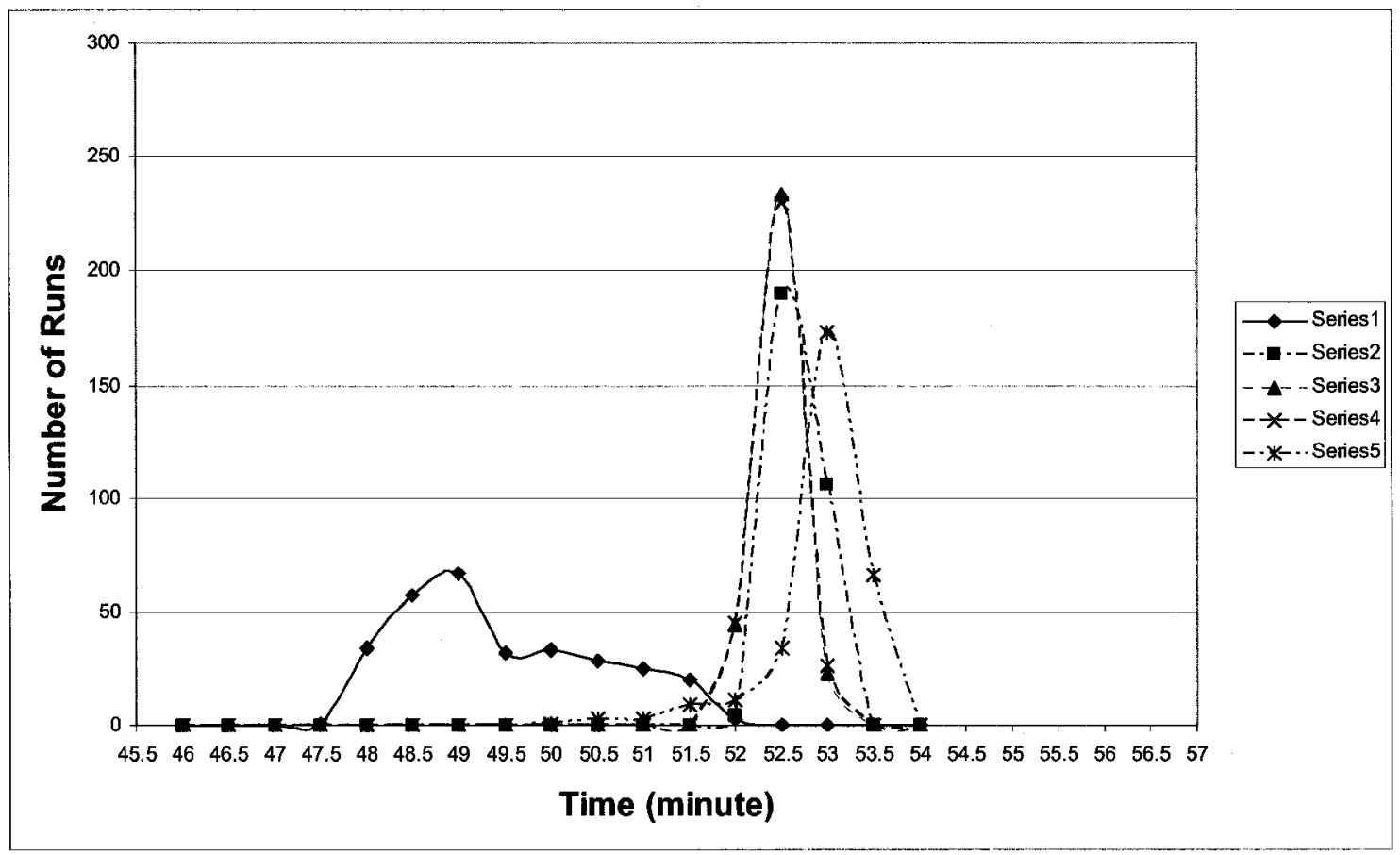

Figure 50 Number of Simulation Runs as a Function of Insulation Failure Time with each individual property on Basis of Normal PDF and Test 5 Series 1: Thermal Conductivity of Gypsum Board only (solid line) Series 2: Specific Heat of Gypsum Board only (dash dot line) Series 3: Shrinkage of Gypsum Board only (short dash line) Series 4: Thermal Conductivity of Wood Stud only (long dash line) Series 5: Specific Heat of Wood Stud only (dash double dot line) 


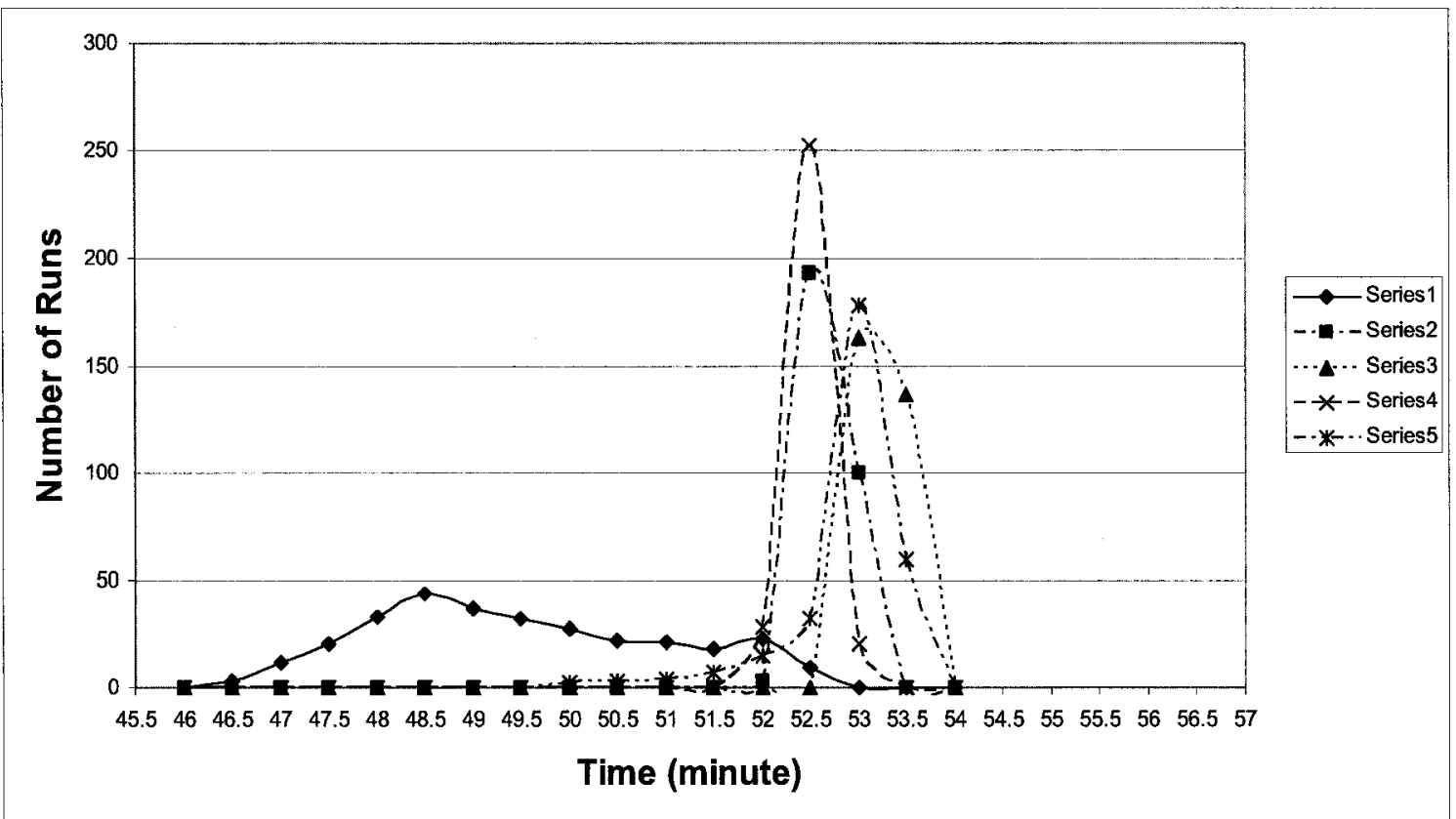

Figure 51 Number of Simulation Runs as a Function of Insulation Failure Time with Each Individual Property on Basis of Lognormal PDF and Test 5

Series 1: Thermal Conductivity of Gypsum Board only (solid line) Series 2: Specific Heat of Gypsum Board only (dash dot line) Series 3: Shrinkage of Gypsum Board only (short dash line) Series 4: Thermal Conductivity of Wood Stud only (long dash line) Series 5: Specific Heat of Wood Stud only (dash double dot line) 


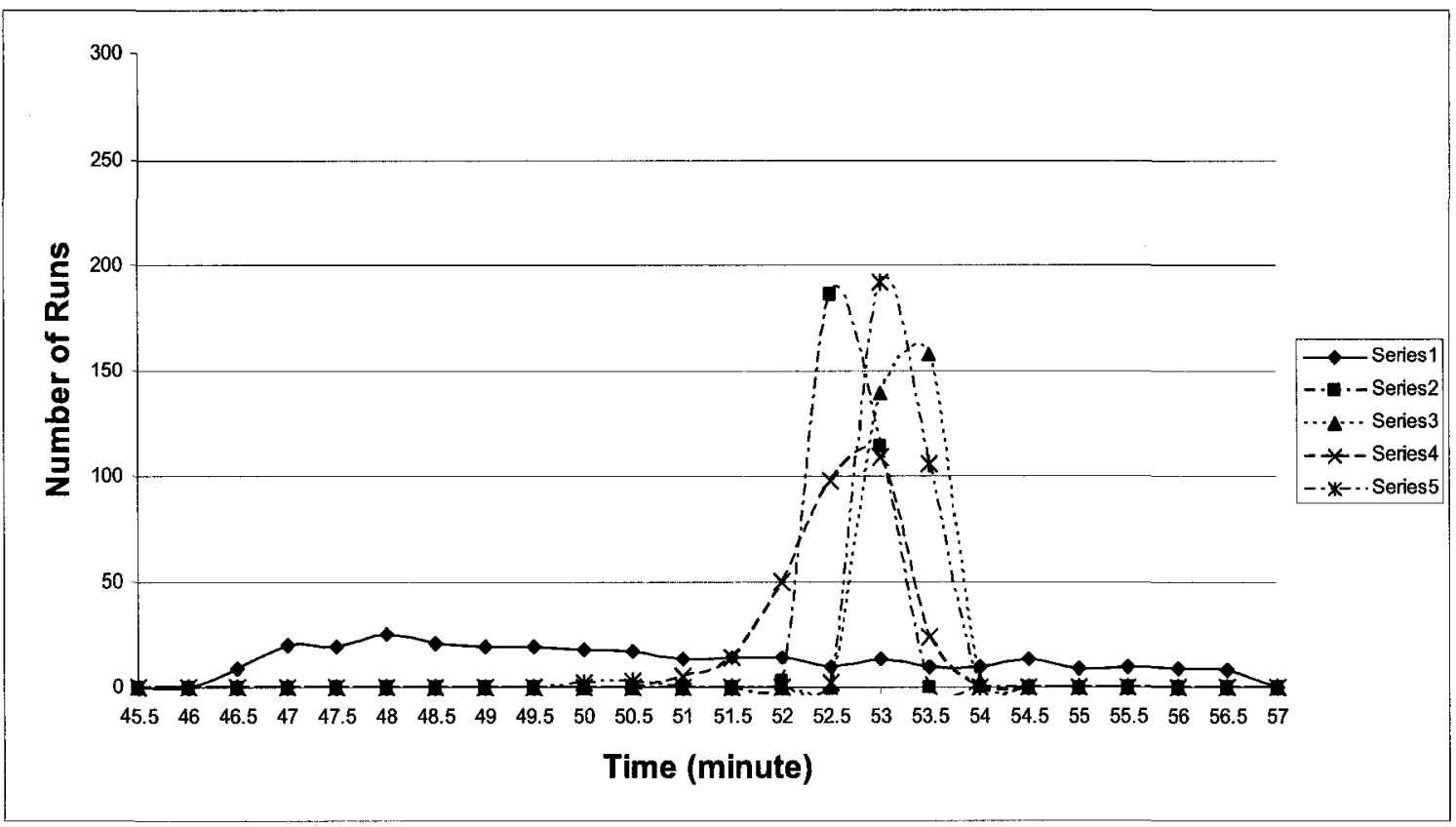

Figure 52 Number of Simulation Runs as a Function of Insulation Failure Time with Each Individual Property on Basis of Triangular PDF and Test 5

Series 1: Thermal Conductivity of Gypsum Board only (solid line)

Series 2: Specific Heat of Gypsum Board only (dash dot line)

Series 3: Shrinkage of Gypsum Board only (short dash line)

Series 4: Thermal Conductivity of Wood Stud only (long dash line)

Series 5: Specific Heat of Wood Stud only (dash double dot line) 


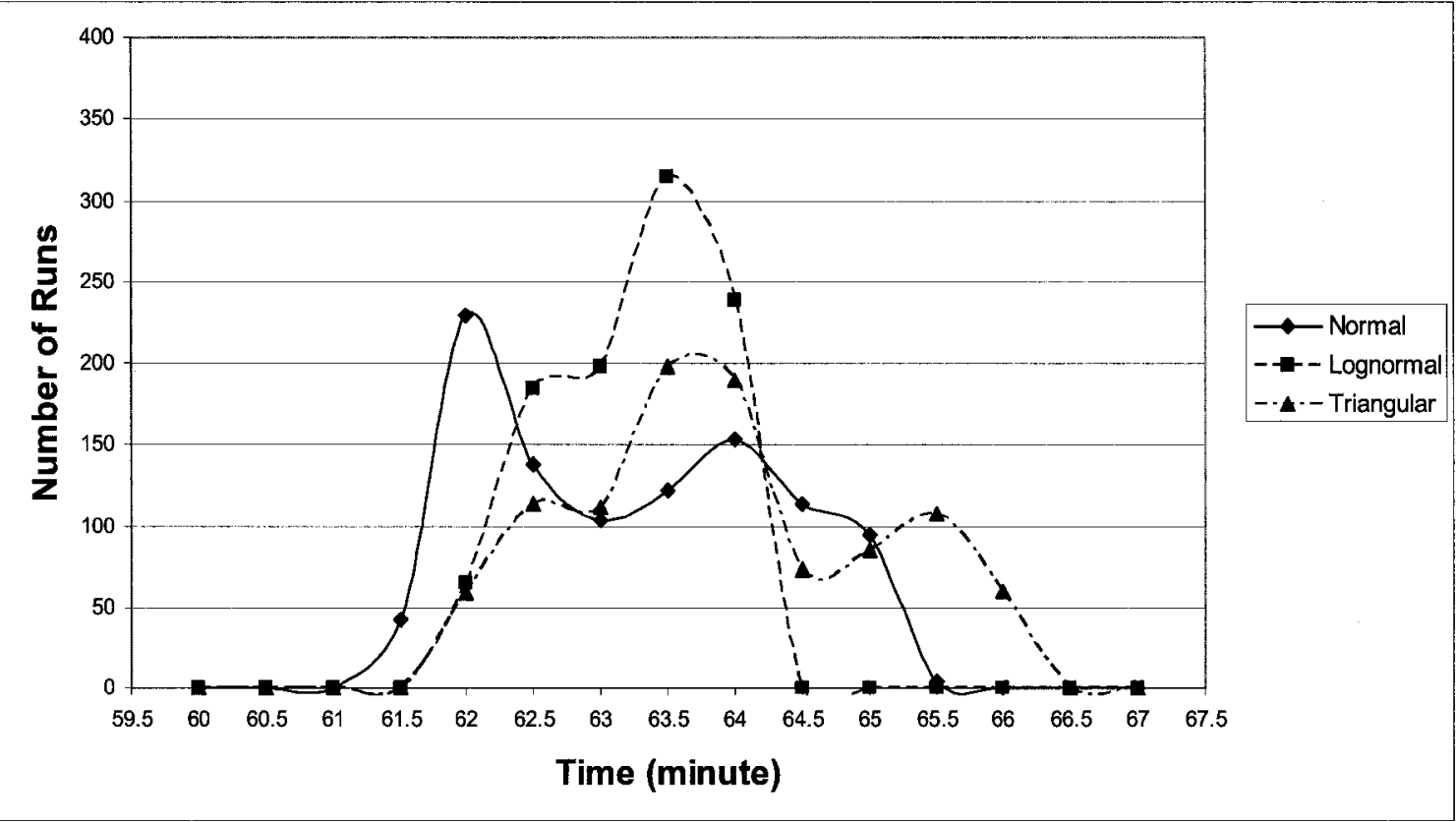

Figure 53 Number of Simulation Runs as Function of Insulation Failure Time Showing Probability of Insulation Failure for an Insulated 60-minute Rating Wall

Series 1: Normal pdf (solid line)

Series 2: Lognormal pdf (dash line)

Series 3: Triangular pdf (dash dot line) 


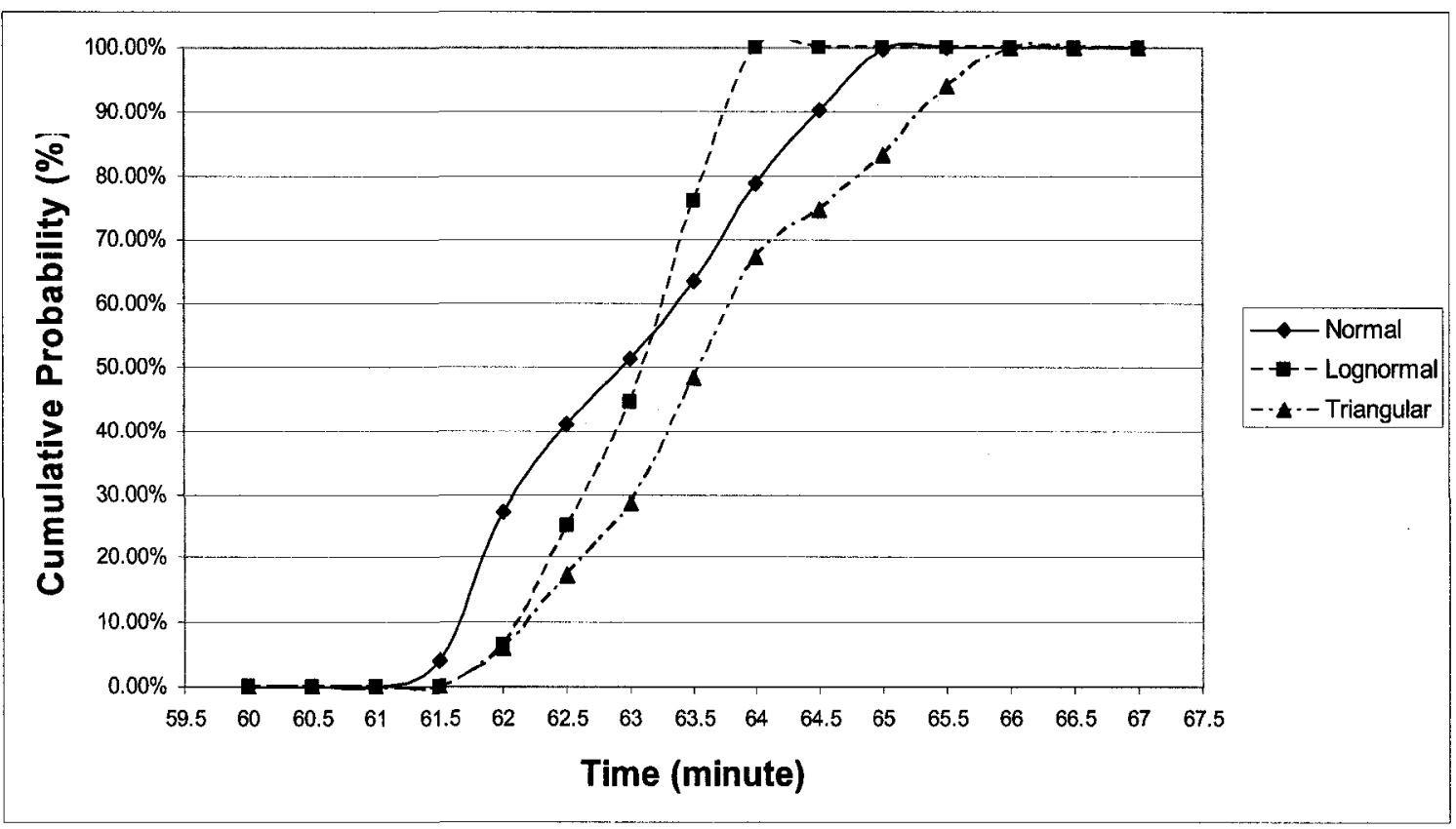

Figure 54 Cumulative Probability as Function of Insulation Failure Time Showing Probability of Insulation Failure for an Insulated 60-minute Rating Wall

Series 1: Normal pdf (solid line)

Series 2: Lognormal pdf (dash line)

Series 3: Triangular pdf (dash dot line) 


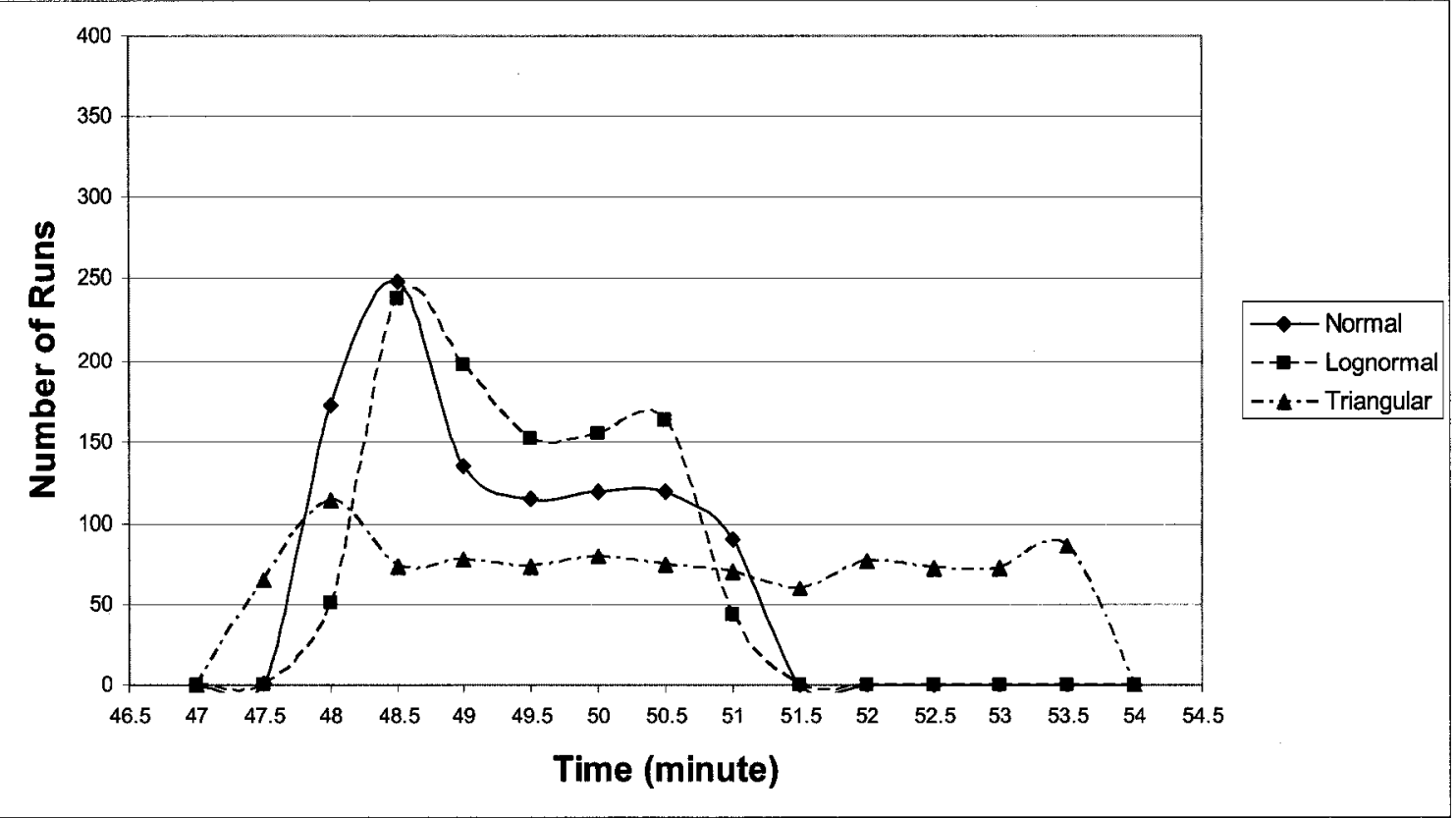

Figure 55 Number of Simulation Runs as Function of Insulation Failure Time Showing Probability of Insulation Failure for a Non-Insulated 45-minute Rating Wall Series 1: Normal pdf (solid line)

Series 2: Lognormal pdf (dash line)

Series 3: Triangular pdf (dash dot line) 


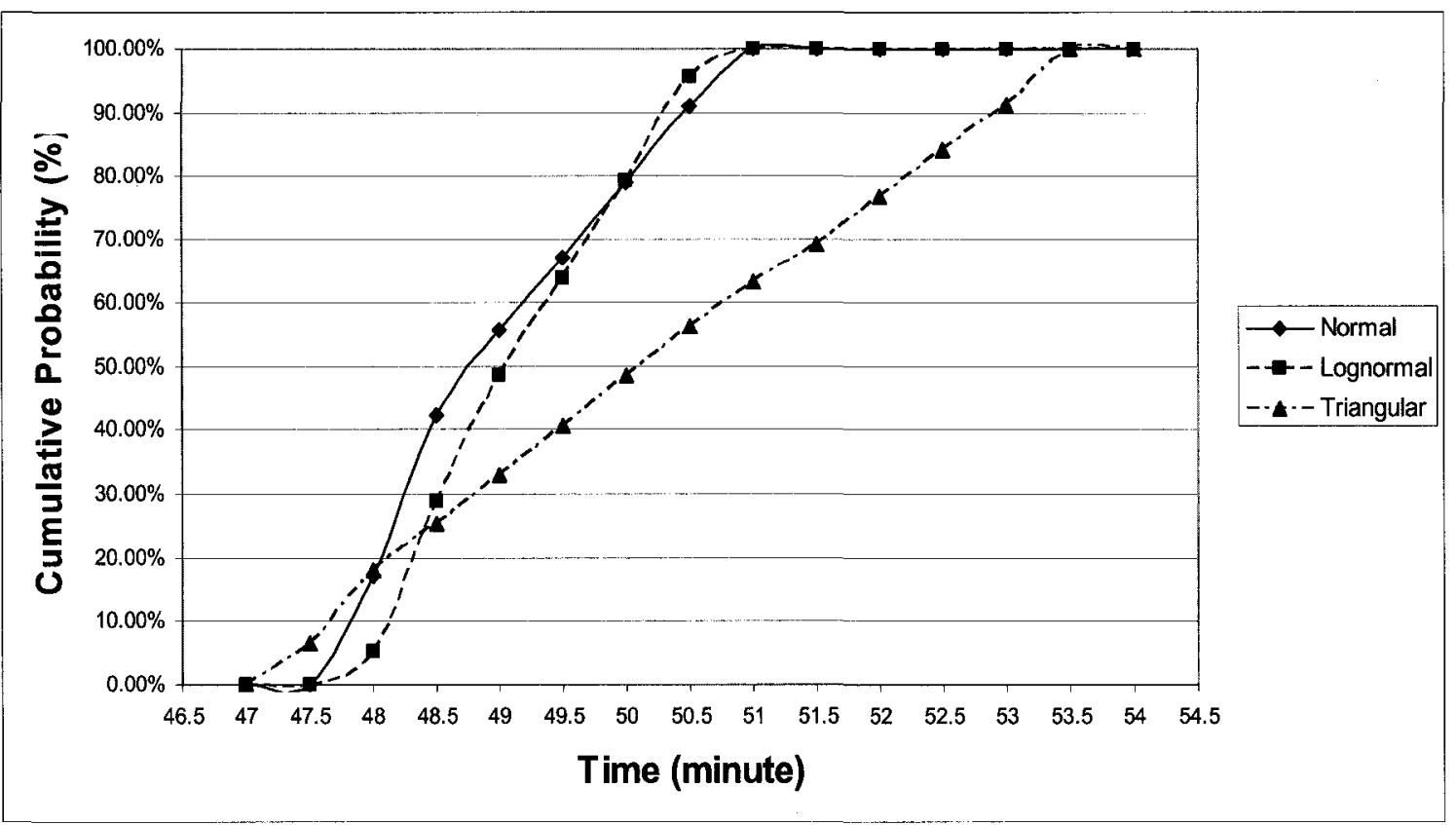

Figure 56 Cumulative Probability as Function of Insulation Failure Time Showing Probability of Insulation Failure for a Non-Insulated 45-minute Rating Wall Series 1: Normal pdf (solid line)

Series 2: Lognormal pdf (dash line)

Series 3: Triangular pdf (dash dot line) 
APPENDIX A

\section{PROGRAM INTRODUCTION}




\section{Introduction}

The program developed herein is for applying Monte Carlo methods to the current WALL2DN model, to predict the heat transfer profile, to determine wood-framed wall fire resistance, and to simulate probability of insulation failure of wood-stud walls. A variety of published test and experimental data of properties of wood framed wall assemblies has been adopted into the model.

The program in the WALL2DN-MC model is designed primarily for generating various property values of wood-framed wall assemblies through three Monte Carlo random number generators, which is based on objectively established relationships between Monte Carlo simulation methods and the temperature-dependent properties of wood-stud walls.

\section{Program Description}

\section{Programming Language}

A computer program to solve these Monte Carlo simulation equations in the WALL2DN-MC model is written as a function form in Visual $\mathrm{C}++$ with the class library included, Microsoft Foundation Class (MFC).

Visual $\mathrm{C}++$ is one of the powerful tools for programming, which has become the industry standard for Windows-based software development in a variety of C++ 
compilers, and has been applied for building 32-bit applications for Windows series and Windows NT.

In this study, the follow-up development of the WALL2DN model will also use Visual $\mathrm{C}++$ as the programming language for uniformity.

\section{Interface Design}

A key point in the follow-up development of the WALL2DN model is to make it as convenient and as simple as possible for users without any statistical knowledge.

Initializing Interface

Only one command bar is added to the original WALL2DN interface, which allows users to select what kind of Monte Carlo simulation will be applied to the model heat transfer simulation. Refer to the Figure 29 of Figures.

All others, such as seed generation, have been designed as the back platform for the reason of simplicity.

Output Interface

There is no big difference in output interface design in this study in comparison with the WALL2DN model in which output interfaces include the wall-assembly Temperature-vs-Time graphic, char diagram, and insulation-melt graphic. 


\section{Subprograms}

The newly developed subprograms used in the WALL2DN-MC model are described in the following section in alphabetical order.

DNRandom: The normal probability distribution function is sampled with mean and standard deviation. It returns a scaled normally distributed pseudorandom value.

DURandom: The pseudorandom number should be uniformly distributed between Min and Max. It returns a scaled double precision uniform pseudorandom number.

GenerateSeed: It is used to generate seeds that are the most essentially required input parameters for random number generator. In the WALL2DN-MC model, time() method provided by MFC is used to generate seeds.

LogNRandom: The lognormal probability distribution function is sampled with log-mean and log-deviation. It returns a scaled lognormally distributed pseudorandom value.

NRandom: The standard normal probability distribution function has mean 0 and standard deviation 1. It samples the unit normal probability distribution. 
TriRandom: The triangular probability distribution function is sampled with maximum, minimum and mode. It returns a scaled triangularly distributed pseudorandom value.

URandom: It returns a unit double precision uniform pseudorandom number.

\section{Program Application}

In this section, some basic topics about running the program are described, as they will give a better understanding of the program. The general forms of the data initializing and their input format, the computer storage of the variable outputs are the main focuses in the discussion.

\section{$>$ Input Initializing}

There are a number of options for users to create their own customized walls and Monte Carlo simulations. The options for walls are:

1. Type of gypsum board either on fire-exposed side or on ambient side: Type X or Type C,

2. Thickness of gypsum board either on fire-exposed side or on ambient side: $12.7 \mathrm{~mm}$ ( $1 / 2$ inches) or $15.8 \mathrm{~mm}$ (5/8 inches), 
3. One layer or two layers for either fire-side or ambient-side gypsum board,

4. Species of wood stud: SPF (spruce-pine-fir), Douglas fire or Southern yellow pine,

5. Wood stud spacing: $406 \mathrm{~mm}$ (16 inches) or $610 \mathrm{~mm}$ (24 inches),

6. Stud size: $38 \mathrm{~mm} \times 89 \mathrm{~mm}(2$ in. $\mathrm{x} 4$ in.) or $38 \mathrm{~mm} \mathrm{x} 140 \mathrm{~mm}(2 \mathrm{in} . \mathrm{x}$ 6 in.),

7. Insulation in stud cavity: No insulation, Glass-fibre and mineral-wool,

8. Insulation density: $0-50 \mathrm{~kg} / \mathrm{m}^{3}$,

9. Simulation time: users defined (default $=50$ minutes $)$,

10. Joint open: present or not present $($ default $=$ yes $)$,

11. Nail space: users defined (default $=16$ in.),

12. Ambient temperature: users defined (default $=20{ }^{\circ} \mathrm{C}$ ), and

13. Design fire: ASTM E-119 or users defined.

14. The options for Monte Carlo simulations are:
a) Normal distribution function,
b) Lognormal distribution function, and
c) Triangular distribution function.

\section{$>$ Output Storage}

Time-based temperature profile is saved as a database file, which can be used as input for predicting the structural failure of load bearing wood-framed wall assemblies. As for other output variables, such as time to charring, insulation 
failure, and so on, they will be directly shown in the simulation output interface similar to Figure 29.

\section{Flow Charts}

Although Monte Carlo methods can be a valuable aid to decision making, they should not be used without an understanding of the process being modeled. Typically, in any activity, there are a few crucial inputs, and it is these inputs, rather than some other minor factors, should be treated as the major variables in the analysis. So a Monte Carlo analysis should be preceded by a sensitivity analysis to determine what the important parameters are.

There are many ways of approaching a Monte Carlo analysis, but a good starting point is a flow chart of the processing being modeled. Diagrams Fig. A1 and A2 are the flowcharts applied to the development of the WALL2DN-MC model in this study. 


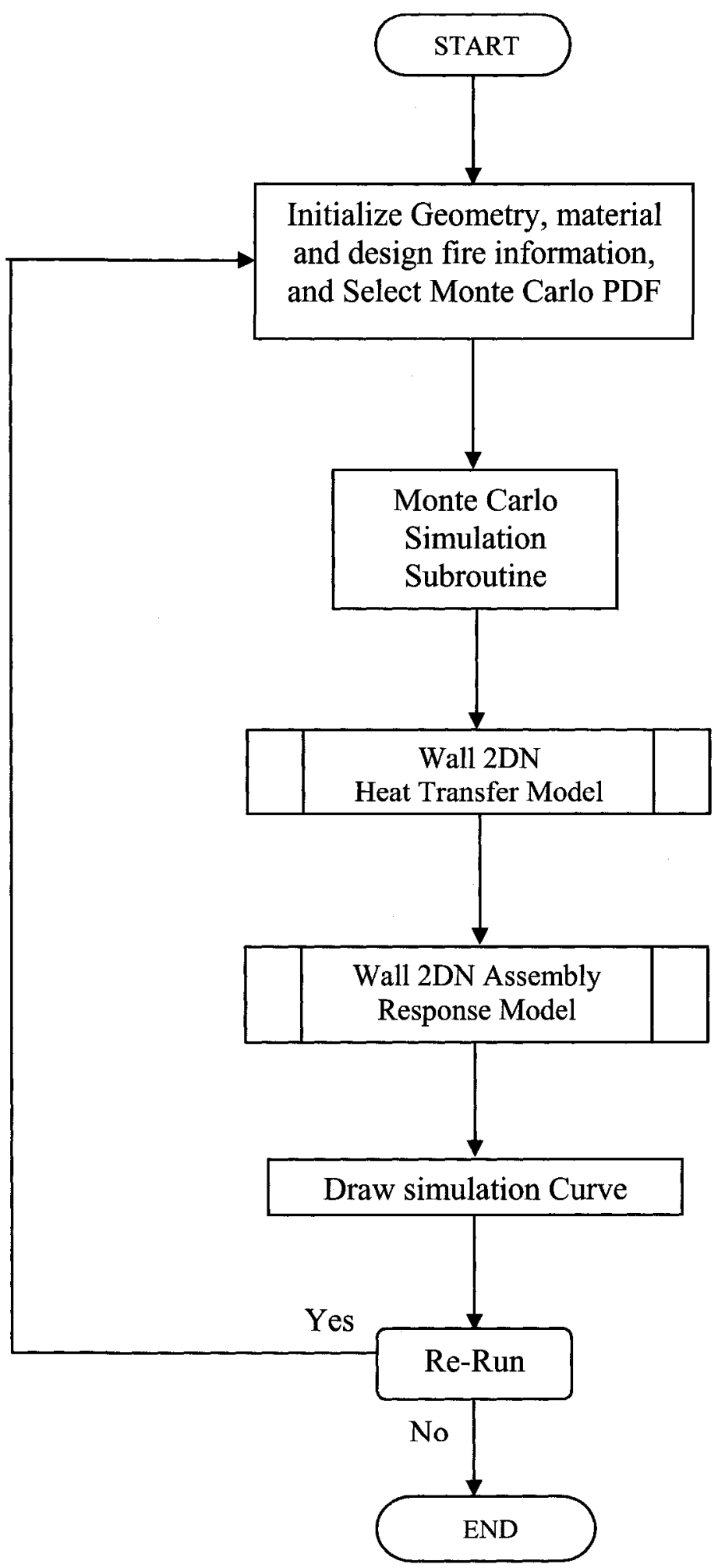

Figure A1. Flow Chart of the WALL2DN-MC Model 


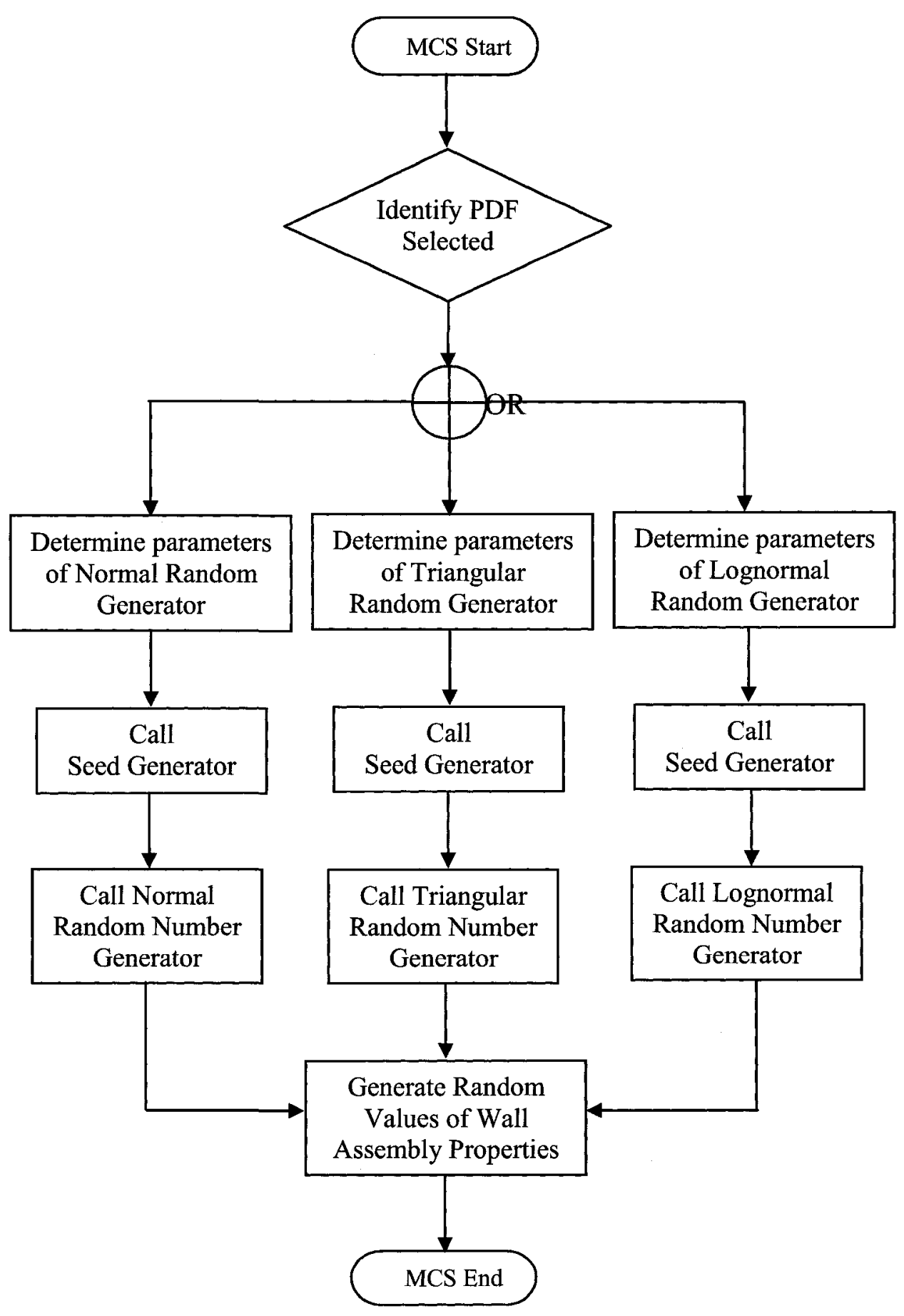

Figure A2. Flow Chart of Subroutine - Monte Carlo Simulation (MCS) 